Portland State University

PDXScholar

Summer 8-4-2014

\title{
Automatic Calibration of Water Quality and Hydrodynamic Model (CE-QUAL-W2)
}

\author{
Nasim Shojaei \\ Portland State University
}

Follow this and additional works at: https://pdxscholar.library.pdx.edu/open_access_etds

Part of the Hydrology Commons

Let us know how access to this document benefits you.

\section{Recommended Citation}

Shojaei, Nasim, "Automatic Calibration of Water Quality and Hydrodynamic Model (CE-QUAL-W2)" (2014). Dissertations and Theses. Paper 1942.

https://doi.org/10.15760/etd.1941

This Thesis is brought to you for free and open access. It has been accepted for inclusion in Dissertations and Theses by an authorized administrator of PDXScholar. Please contact us if we can make this document more accessible: pdxscholar@pdx.edu. 
Automatic Calibration of Water Quality and Hydrodynamic Model (CE-QUAL-W2)

by

Nasim Shojaei

A thesis submitted in partial fulfillment of the requirements for the degree of

Master of Science

in

Civil and Environmental Engineering

Thesis Committee:

Scott Wells, Chair

Chris Berger

Stefan Talke

Portland State University

2014 


\begin{abstract}
One of the most important purposes of surface water resource management is to develop predictive models to assist in identifying and evaluating operational and structural measures for improving water quality. To better understand the effects of external and internal nutrient and organic loading and the effects of reservoir operation, a model is often developed, calibrated, and used for sensitivity and management simulations. The importance of modeling and simulation in the scientific community has drawn interest towards methods for automated calibration. This study addresses using an automatic technique to calibrate the water quality model CEQUAL-W2 (Cole and Wells, 2013). CEQUAL-W2 is a two-dimensional (2D) longitudinal/vertical hydrodynamic and water quality model for surface water bodies, modeling eutrophication processes such as temperature-nutrient-algae-dissolved oxygen-organic matter and sediment relationships. The numerical method used for calibration in this study is the particle swarm optimization method developed by Kennedy and Eberhart (1995) and inspired by the paradigm of birds flocking. The objective of this calibration procedure is to choose model parameters and coefficients affecting temperature, chlorophyll a, dissolved oxygen, and nutrients (such as $\mathrm{NH}_{4}, \mathrm{NO}_{3}$, and $\mathrm{PO}_{4}$ ). A case study is presented for the Karkheh Reservoir in Iran with a capacity of more than 5 billion cubic meters that is the largest dam in Iran with both agricultural and drinking water usages. This algorithm is shown to perform very well for determining model parameters for the reservoir water quality and hydrodynamic model. Implications of the use of this procedure for other water quality models are also shown.
\end{abstract}




\section{Table of Contents}

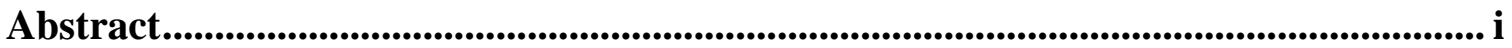

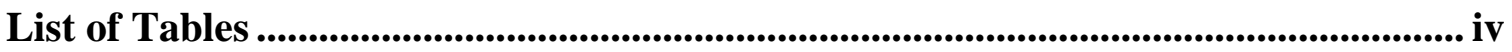

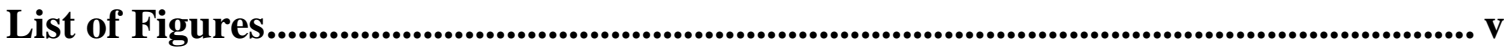

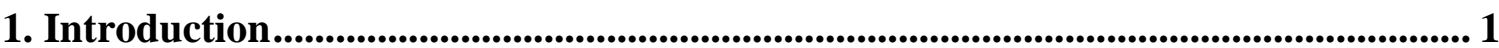

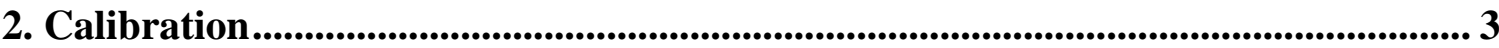

3. Particle Swarm Optimization ............................................................................................... 8

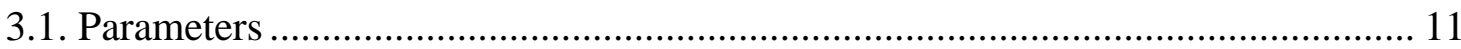

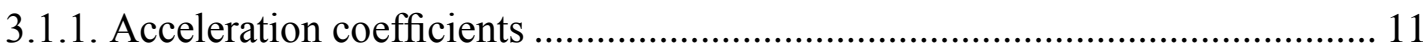

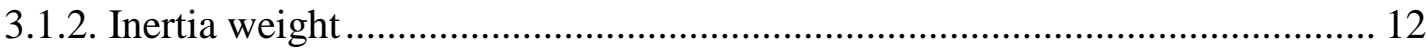

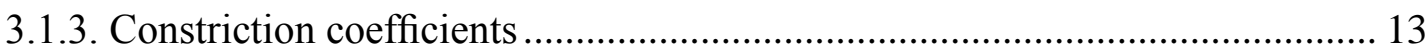

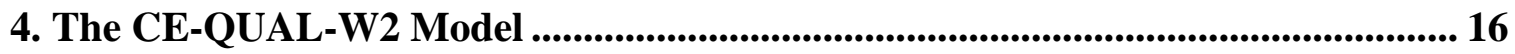

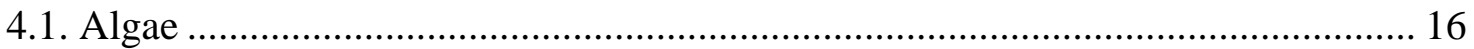

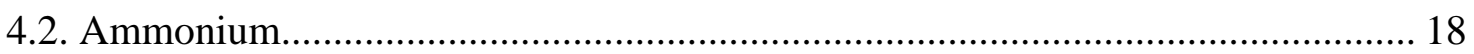

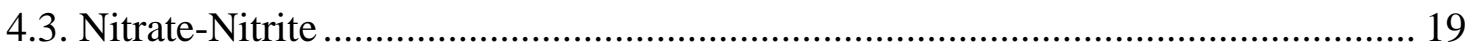

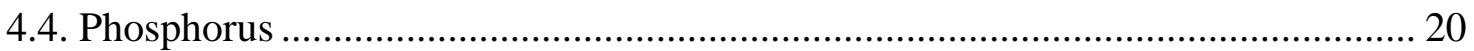

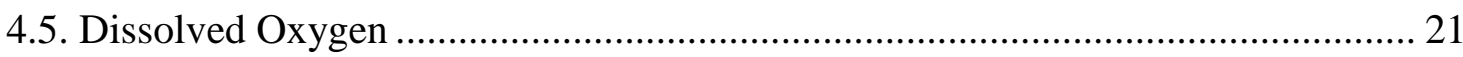

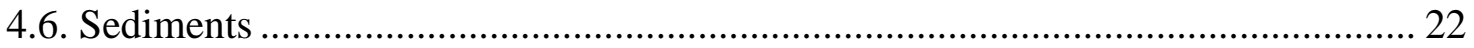

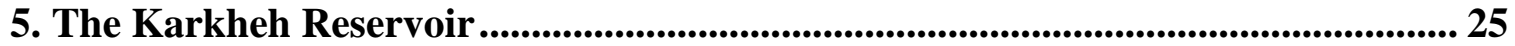

6. The Karkheh CE-QUAL-W2 Model............................................................................ 28

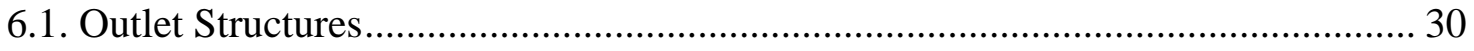

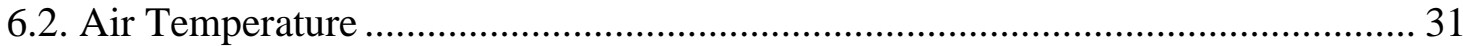

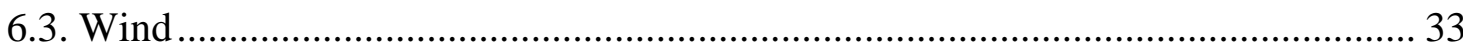

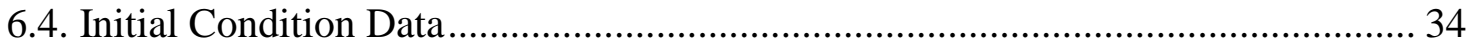

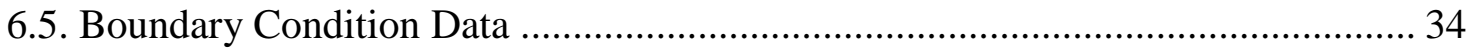

7. Automatic Calibration and Objective Function ................................................. 38

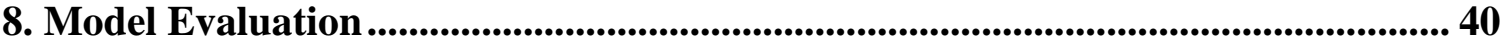

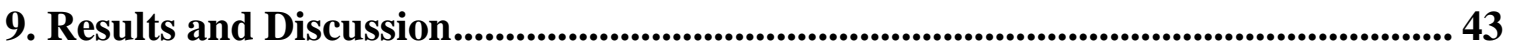

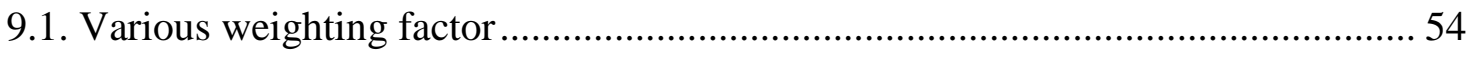

10. Summary and Conclusions ................................................................................................... 57 
11. References ........................................................................................................................6 60

Appendix A Control File of CE-QUAL-W2 model of Karkheh Reservoir ............... 66

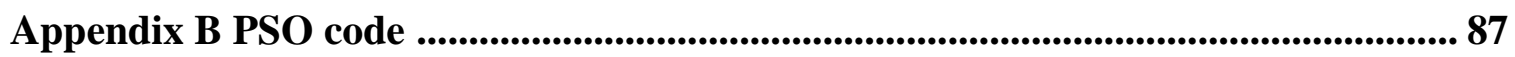




\section{List of TABELS}

TABLE 1.THE KARKHEH RESERVOIR CE-QUAL-W2 MODEL CHARACTERISTICS ............... 27

TABLE 2.RESULTED OBJECTIVE FUNCTIONS OF FIVE STATE VARIABLES ........................... 44

TABLE 3. CALIBRATED VALUE OF PARAMETERS AND THEIR RANGE ............................... 45

TABLE 4. THE OBJECTIVE FUNCTION AND CORRESPONDED WEIGHTING FACTORS .............. 54 


\section{LIST OF FIGURES}

FIGURE 1. INTERNAL FLUX BETWEEN ALGAE AND OTHER COMPARTMENTS, (COLE AND

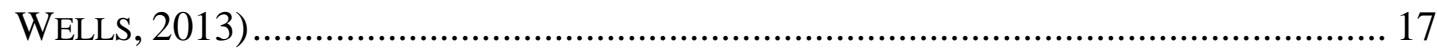

FIGURE 2. INTERNAL FLUX BETWEEN AMMONIUM AND OTHER COMPARTMENTS, (COLE AND

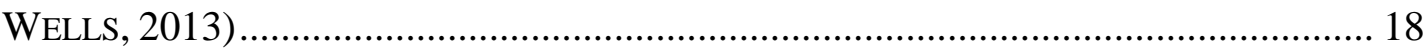

FIGURE 3. INTERNAL FLUX BETWEEN NITRATE + NITRITE AND OTHER COMPARTMENTS

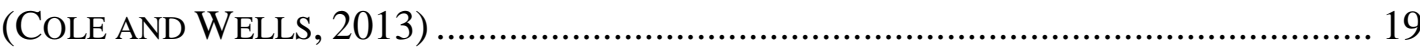

FIGURE 4. INTERNAL FLUX BETWEEN PHOSPHORUS AND OTHER COMPARTMENTS, (COLE

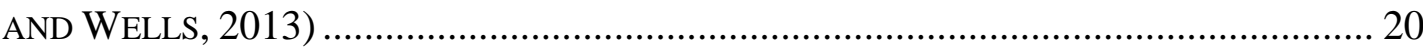

FIGURE 5. INTERNAL FLUX BETWEEN DISSOLVED OXYGEN AND OTHER COMPARTMENTS,

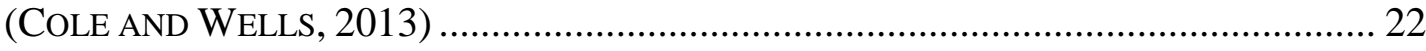

FIGURE 6. INTERNAL FLUX BETWEEN 0-ORDER SEDIMENT COMPARTMENT AND OTHER

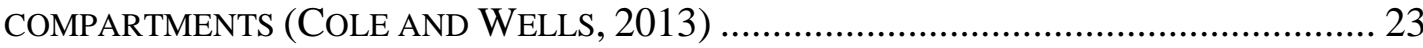

FIGURE 7. INTERNAL FLUX BETWEEN 1ST-ORDER SEDIMENT COMPARTMENT AND OTHER

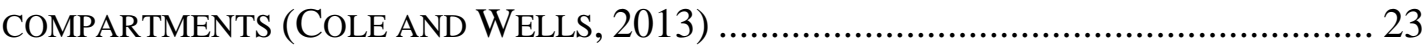

FIGURE 8. KARKHEH RESERVOIR MAP FROM GOOGLE EARTH ........................................ 25

FIGURE 9.KARKHEH RIVER WATERSHED, DAM AND SAMPLING STATION ........................... 26

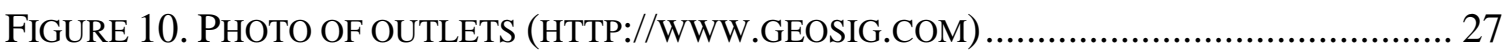

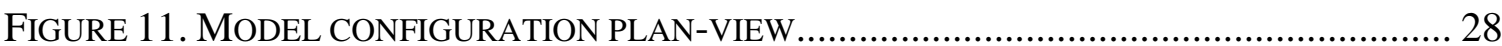

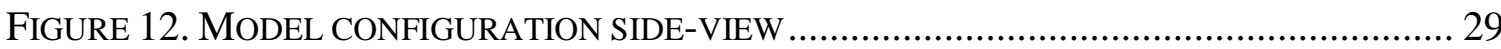

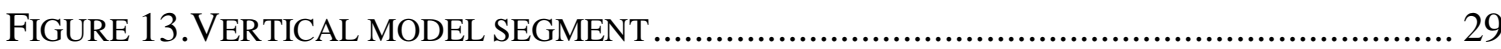

FigURE 14.THE LAYOUT OF SPILLWAYS SET AS A DOWNSTREAM (COLE AND WELLS, 2013)

FIGURE 15. KARKHEH RESERVOIR AIR TEMPERATURE (IRAN WATER AND POWER

COMPANY) 32

Figure 16. KARKHEH RESERVOIR DEW POINT TEMPERATURE (IRAN WATER AND POWER COMPANY)

FIGURE 17.KARKHEH RESERVOIR WIND VELOCITY (IRAN WATER AND POWER COMPANY)

FIGURE 18.KARKHEH RIVER INFLOW TO KARKHEH RESERVOIR (IRAN WATER AND POWER COMPANY) 35

FigURE 19.KARKHEH RIVER FLOW TEMPERATURE (IRAN WATER AND POWER COMPANY)36

FIGURE 20. KARKHEH RESERVOIR OUTFLOW (IRAN WATER AND POWER COMPANY) ....... 36

FIGURE 21.WATER SURFACE ELEVATION PREDICTIONS COMPARED TO OBSERVED

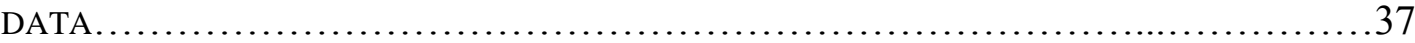

FIGURE 22.FLOWCHART OF AUTOMATIC CALIBRATION $\ldots \ldots \ldots \ldots \ldots \ldots \ldots \ldots \ldots \ldots \ldots \ldots . . . \ldots 1$

FIGURE 23. IMPROVEMENT TREND OF OBJECTIVE FUNCTION VS. INCREASING OF

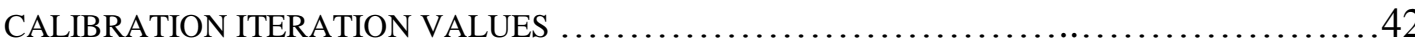


FIGURE 24. DIFFERENCE OF WATER SURFACE ELEVATION PREDICTIONS AFTER CALIBRATION COMPARED TO BEFORE CALIBRATION

FIGURE 25 A. TEMPERATURE PROFILES COMPARED TO MODEL PREDICTIONS NEAR THE RESERVOIR DAM (BEFORE CALIBRATION) ........................................................ 46

FIGURE 25 B.TEMPERATURE PROFILES COMPARED TO MODEL PREDICTIONS NEAR THE

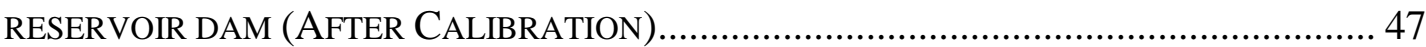

FiguRE 26A. COMPARING CHLR A SIMULATION WITH OBSERVED DATA BEFORE CALIBRATION 48

FIGURE 26 B. COMPARING CHLR A SIMULATION WITH OBSERVED DATA AFTER CALIBRATION 48

FIGURE 27 A. COMPARING DO SIMULATION WITH OBSERVED DATA BEFORE CALIBRATION49 FIGURE 27 B. COMPARING DO SIMULATION WITH OBSERVED DATA AFTER CALIBRATION . 50 FIGURE 28 A. COMPARING NH4 SIMULATION WITH OBSERVED DATA BEFORE CALIBRATION

FIGURE 28 B. COMPARING NH4 SIMULATION WITH OBSERVED DATA AFTER CALIBRATION 51 FIGURE 29 A. COMPARING PO4 SIMULATION WITH OBSERVED DATA BEFORE CALIBRATION

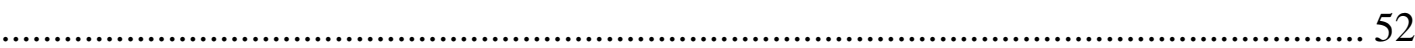

FIGURE 29 B. COMPARING PO4 SIMULATION WITH OBSERVED DATA AFTER CALIBRATION 52 FIGURE 30 A. COMPARING NO3-NO2 SIMULATION WITH OBSERVED DATA BEFORE CALIBRATION 53

FIGURE 30 B.COMPARING NO3-NO2 SIMULATION WITH OBSERVED DATA AFTER CALIBRATION 54

FIGURE 31. COMPARING ALL STATE VARIABLES PROFILE OF MODEL 1 AND 2. 56 


\section{Introduction}

Water quality models are increasingly developed to achieve water quality goals and to evaluate the impacts of climate, land use, and land on the quantity and quality of water resources. Calibration of these models is a critical step in the overall model development before using them in research and/or real-world applications.

During the last 2 decades, the incorporation of monitoring programs and water quality modeling has provided useful tools for water quality management in impounding reservoirs (Hay et al.,1998; Isazadeh et al., 2005; Sullivan and Round, 2005; Afshar and Saadatpour, 2008; Diogo et al., 2008). Most water quality models are characterized by complex functional relationships and large number of parameters to achieve a system that closely resembles the actual system being represented by the model. Manual trial and error calibration is time consuming and depends on the modeler's experience, skill, and knowledge of the model's processes and dynamics. While overcoming the shortcomings of manual trial and error calibration, automatic calibration of complex hydrosystem models requires a tremendous amount of computation (Mahinthakumar G. and Sayeed M. 2005; Chung S.W., and Oh J.K. 2006; Kuo J.T., Wang Y.Y. and Lung W.S. 2006). In fact, both hydrodynamic and water quality behavior of a water body simulated with a representative model may be affected by a set of calibration parameters which are not necessarily independent of each other. This makes automatic calibration of such models more challenging. Calibration of complex river -reservoir water quality models is an excellent example where the model must be calibrated for both hydrodynamic and water 
quality behavior. In such cases, one may define multiple calibration objectives to account for both hydrodynamic and water quality behavior of the model. In such cases multiple objective optimizations may improve model calibration but further increase the computational requirements and cost. One of the most common multi-objective optimization methods involve transforming multiple objectives into a single function, by the weighted sum principle where the objectives are multiplied with user-defined weights and added together to form a single function (Deb K. 2001). In recent years different versions of evolutionary and/or metaheuristic algorithms have been successfully used for various hydrosystems. (Genetic Algorithm (GA), Chang et al., 2005; ant colony optimization algorithm (ACO), Jalali et al., 2007; honey bees mating optimization (HBMO), Bozorg Haddad et al., 2006; particle swarm optimization (PSO), FallahMehdipour et al., 2011).

In spite of broad investigations about automatic calibration of CE-QUAL-W2 model, still finding an automatic optimization approach to calibrate model parameters with reasonable performance is a real challenge (Baker and Dycus, 2004; Nielsen, 2005; Kuo et al., 2006; Chaves and Kojiri, 2007; Gelda and Effler, 2007; Liu et al., 2008; Shourian et al., 2008; Karamouz et al., 2009; Etemad shahidi et al., 2009; and Afshar et al., 2011). The aim of the present study is to show the result of coupling of the particle swarm optimization (PSO) method to the CE-QUAL-W2 model for automatic calibration of temperature, chlorophyll a, dissolved oxygen, and nutrients of a water body. 


\section{Calibration}

It is important to consider the possible reactions of the water body before taking any action and making any management decisions. Surface waters are the complex environmental systems and understanding and predicting their behavior is difficult. During decades, scientists have tried to develop mathematical models to predict the response of water bodies to pollution loads originating from human activities. These models are able to quantitatively describe the physical, chemical and biological behavior of the water bodies and include a collection of mathematical relationships that contain many parameters (e.g., reaction rate coefficients, biological and chemical constants) that are specific to the system modeled. The modeler should decide about the value of these parameters through the calibration phase giving the near optimum model parameters possible for a successful modeling practice. Water quality and hydraulics models generally require a relatively large number of parameters to define, and since prior information on parameter values is limited, these are commonly defined by fitting the model to observed data.

Water quality variables are often highly correlated (Van Griensven et al., 2002). Many model parameters affect more than a single state variable and when this is the case, it is more appropriate to estimate the parameter for all affected state variables simultaneously (Little and Williams, 1992). For example, BOD decay rate affects both BOD and DO values within the system. If parameter estimation is conducted using both DO and BOD data, the estimates will be more accurate than the estimates based only on the DO data (Mulligan and Brown, 1998). Moreover, when all the output variables are used 
simultaneously during the calibration process, all the available information will be used. In addition, the risk of error accumulation at the end step will be reduced (Van Griensven et al., 2002). However, incorporating all the output variables simultaneously to the calibration process will increase the computational complexity substantially. For such intricate systems, exercising typical nonlinear techniques for the solution may be problematic. Moreover, in these multi-dimensional complex systems, the setback of converging to local optima is prominent.

Calibration methods include two major categories:

- Manual calibration

- Automatic calibration

In the manual method, the modeler adjusts the model parameters by running the model for different parameter values several times until achieving a reasonable fitness between the observations and the predictions. This can be time consuming work. The method is subjective since the success of a manual calibration essentially depends on the experience of the modelers and their knowledge of the basic approaches and interactions in the model. The modelers are left unsure whether the calibration result is the best that can be achieved or not. Different methods of automatic calibration were developed to increase the probability of improvement of these weaknesses. 
Automatic calibration methods which are computer-aided optimization techniques increases the efficiency of the modeling process by using objective, statistically valid methods and increase the reliability of the calibration outcome. By this way, the bias introduced by judgment of the modeler is minimized. Moreover, the time allocated for the process can be considerably decreased.

Bowles and Grenney (1978) applied sequential extended Kalman filters as a technique for calibration and water quality modeling of a river. They used the method for a real river system. In their study, they clearly showed the calibration ability of the filter procedure. Coefficients in the model were estimated at the same time as the state variables.

The sum-of-least-squares approach as an objective function was employed in the most of the model calibration studies using optimization (Yih and Davidson, 1975; Wood et al., 1990; Little and Williams, 1992; Mulligan and Brown, 1998; Van Griensven and Bauwens, 2001). Minimizing the error between the observed and simulated state variables is the general objective in all of these studies, although they applied different methods to find the best solution for the objective function such as Kalman filters, Nelder mead algorithm, etc.

Wood et al. (1990) developed a system to use in the calibration process and a streamquality simulation model. The author linked a biochemical oxygen demand (BOD) - 
dissolved oxygen model, graphics software, and a code to perform the model calibration to an expert system shell. The objective function was an average absolute-value deviation of the calculated values from the measured ones in the calibration process. The pattern search technique was applied in calibration to determine the search direction that would cause a lower error. He has calibrated four parameters for river model in his research. The calibration process was applied on each reaches separately and sequentially instead of consideration of whole system to simplify the procedure.

Today, water quality models are developed in a highly advanced and complex way. They can simulate a high variety of water quality constituents, and require a high number of input parameters. For the calibration of these models, using new, global optimization techniques may give better results compared to the traditional methods. These new techniques are more robust to messy problems such as discontinuities and difficult-toevaluate or nonexistent derivatives (Little and Williams, 1992). Most of them use statistical, probabilistic or heuristic algorithms that rarely trapped at the local optima (Cooper et al., 1997; Goldberg, 1989).

For example, Mulligan and Brown (1998) used genetic algorithms to calibrate the steadystate Streeter-Phelps model. They compared genetic algorithms performance with a more traditional optimization technique, the Marquardt algorithm, and found GA results is superior. Although there exist quite a number of studies for implementing objective 
methods in water quality model calibration, application of such methods in practice has gained importance recently. Recent developments in the global search techniques and advancements in the computer technology will promote their application. 


\section{Particle Swarm Optimization}

One of the population-based evolutionary algorithms that has shown great potential in various optimization problems of water resources management (Izquierdo, J., 2008) is Particle Swarm Optimization. The PSO algorithm was introduced by Kennedy and Eberhart (1995) and is based on the simulation of the social behavior of migrating birds trying to reach a destination. Since PSO requires low memory and CPU speed, it is computed inexpensively and is implemented easily.

The computer simulations of various interpretations of the movement of organisms in a bird flock or fish school have been created by a number of scientists. Firstly, Reynolds C. W. (1987) and Heppner and Grenander (1990) presented simulations of bird flocking. Reynolds was interested in the aesthetics of bird flocking choreography, and Heppner, a zoologist, has worked in discovering the primary principal that showed how a large

numbers of birds can flock synchronously, can change direction suddenly, can separate and reform a group. Both of these scientists had understood that local processes, such as those modeled by cellular automata, are basically the unpredictable group dynamics of bird social behavior. Both models were based on modification of distance between birds flying together. The flocking behavior of birds was considered as a function of birds' efforts to maintain an optimum distance between themselves and their neighbors. (Kennedy and Eberhart, 1995)

Wilson (1975), a sociobiologist, has written, in reference to fish schooling, In theory at least, individual members of the school can profit from the discoveries and previous 
experience of all other members of the school during the search for food. This advantage can become decisive, outweighing the disadvantages of competition for food items, whenever the resource is unpredictably distributed in patches. This idea was behind the particle swarm optimization.

In PSO, each bird is a potential solution and is called a particle. Second, there is socialpsychological tendency among individuals with communication and information exchange in the population to emulate the success of other individuals. The position of each particle is changed based on individual intelligence and the intelligence of its neighbors to coordinate their movement towards the best position. At the first swarm, the position and velocity of particles have been determined randomly and then an objective function of each particle is then evaluated to find the optimal solution by iteration.

Particle swarm optimization and the genetic algorithm are similar in that the system is initialized with a population of random solutions. They are not the same because in PSO for each potential solution is also assigned a randomized velocity, and the potential solutions, called particles, are then "flown" through hyperspace. In PSO, velocity is in the unit of $[\mathrm{L}]$ not $[\mathrm{L} / \mathrm{T}]$. So, velocity, in this case, is just a direction that defines the direction of movement to each particle in search space. This term helps increase the time efficiency of procedure by preventing of particles to move toward positions that are far from optimum solution. Each particle memorizes track of its coordinates in hyperspace which are known as the best solution (fitness) it has achieved so far. (The value of that fitness is also stored.) This value is called pbest. Another "best" value is also tracked. Each particle also keeps 
the overall best value, and its location obtained thus far by any particle in the population; this is called gbest. Particles in the case of water quality are the vector of all calibrated parameters. PSO tries to find the best particle which is the near optimum solution and defines optimum parameters to CE-QUAL-W2 model.

Algorithm below explains all steps of original PSO which used in this study. (Poli et. al. 2007)

"1: Initialize a population array of particles with random positions and velocities on D dimensions in the search space.

2: loop

3: For each particle, evaluate the desired optimization fitness function in D variables.

4: Compare particle's fitness evaluation with its pbesti. If current value is better than pbest $t_{\mathrm{i}}$,then set pbest $t_{\mathrm{i}}$ equal to the current value, and $\vec{p}_{i}$ equal to the current location $\vec{x}_{i}$ in D-dimensional space.

5: Identify the particle in the neighborhood with the best success so far, and assign its index to the variable $\mathrm{g}$.

6: Change the velocity and position of the particle according to the following equation

$$
\begin{gathered}
\vec{v}_{i} \leftarrow \vec{v}_{i}+\vec{U}\left(0, \varphi_{1}\right) \otimes\left(\vec{p}_{i}-\vec{x}_{i}\right)+\vec{U}\left(0, \varphi_{2}\right) \otimes\left(\vec{p}_{g}-\vec{x}_{i}\right) \\
\vec{x}_{i} \leftarrow \vec{x}_{i}+\vec{v}_{i}
\end{gathered}
$$

7: If a criterion is met (usually a sufficiently good fitness or a maximum number of iterations), exit loop.

8: end loop

Where: 
$-\vec{U}\left(0, \varphi_{\mathrm{i}}\right)$ represents a vector of random numbers uniformly distributed in $\left[0, \varphi_{\mathrm{i}}\right]$ which is randomly generated at each iteration and for each particle.

$-\otimes$ is component-wise multiplication.

- In the original version of PSO, each component of $\vec{v}_{i}$ is kept within the range [-Vmax, $+\mathrm{Vmax}] "$

\subsection{Parameters}

There are a small number of parameters that need to be fixed in the PSO algorithm. The size of the population is one parameter that should be set. The size of the population is dependent on the basis of the dimensionality and perceived difficulty of a problem. The common values are in the range $20-50$. There are other parameters including acceleration coefficients, inertia weight, and constriction coefficients which I will discuss below.

\subsubsection{Acceleration coefficients}

The other parameters $\varphi_{1}$ and $\varphi_{2}$ in equation (1) which are often called acceleration coefficients shows the magnitude of the random forces in the direction of personal best $\vec{p}_{i}$ and global best $\vec{p}_{g}$. The behavior of a PSO changes radically with the value of $\varphi_{1}$ and $\varphi_{2}$.

Poli et. al. (2007) interpreted the components $\vec{U}\left(0, \varphi_{1}\right) \otimes\left(\vec{p}_{i}-\vec{x}_{i}\right)$ and $\vec{U}\left(0, \varphi_{2}\right) \otimes\left(\vec{p}_{g}\right.$ $-\vec{x}_{i}$ ). In (1) as attractive forces produced by springs of random stiffness and they interpreted the motion of a particle as the integration of Newton's second law. In this interpretation, $\varphi_{1} / 2$ and $\varphi_{2} / 2$ represent the mean stiffness of the springs pulling a particle. When $\varphi_{1}$ and $\varphi_{2}$ are modified, the PSO get more or less "responsive" and unstable if particle speeds are increased without control. The common value of $\varphi_{1}$ and $\varphi_{2}$ is 2.0. But it is better to control their values to protect search from harmful bias and to balance system between 
exploration and exploitation. The idea behind these parameters was to bound velocities and to keep $\vec{v}_{i}$ within the range $[-\mathrm{Vmax},+\mathrm{Vmax}]$. If acceleration coefficients set the largescale steps in the system, exploratory search is represented.

\subsubsection{Inertia weight}

Shi and Eberhart (1998b) presented inertia weight parameter to better control the scope of the search, reduce the importance of Vmax, and to eliminate it altogether. So updated equations were proposed:

$\vec{v}_{i} \leftarrow w \vec{v}_{i}+\vec{U}\left(0, \varphi_{1}\right) \otimes\left(\vec{p}_{i}-\vec{x}_{i}\right)+\vec{U}\left(0, \varphi_{2}\right) \otimes\left(\vec{p}_{g}-\vec{x}_{i}\right)$,

$\vec{x}_{i} \leftarrow \vec{x}_{i}+\vec{v}_{i}$

Where, $\omega$ is the inertia weight. Poli et al. (2007) mentioned if $\vec{U}\left(0, \varphi_{1}\right) \otimes\left(\vec{p}_{i}-\vec{x}_{i}\right)+\vec{U}$ $\left(0, \varphi_{2}\right) \otimes\left(\vec{p}_{g}-\vec{x}_{i}\right)$ is interpreted as the external force, $\vec{f}_{i}$, acting on a particle, then the change in a particle's velocity (i.e., the particle's acceleration) can be written as $\Delta \vec{v}_{i}=\vec{f}_{i}-$ $(1-\omega) \vec{v}_{i}$. The constant $1-\omega$ uses as a friction coefficient, and so $\omega$ might be considered as the fluidity of the medium in which a particle moves. Because of this effect, researchers set $\omega$ to some relatively high value (e.g., 0.9$)$ which corresponds to a system where particles move in a low viscosity medium and perform extensive exploration, and gradually reducing $\omega$ to a much lower value (e.g., 0.4 ), where the system would be more dissipative and exploitative and would be better at homing into local optima. (Poli et al. 2007)

Eberhart and Shi (2000) used other methods to adjust the inertia weight. They applied a fuzzy system which improved significantly PSO performance. Moreover, Eberhart and Shi (2001) used an inertia weight with a random component, rather than time-decreasing. 
Zheng et al. (2003) also reported that with increasing inertia weight, better results were obtained. Finally, appropriate choice of $\omega$ and of the acceleration coefficients, $\varphi_{1}$ and $\varphi_{2}$, make PSO more stable.

\subsubsection{Constriction coefficients}

It is realized that using some forms of damping is required (e.g., Vmax) to help algorithm stay stable within running. Clerc and Kennedy (2002) noted a strategy for the placement of "constriction coefficients" which controlled the convergence of the particle to prevent explosion, ensure convergence, and eliminate the arbitrary Vmax parameter. One of the simplest methods of incorporating of the constriction coefficient based on Clerc and Kennedy (2002) research is:

$\vec{v}_{i} \leftarrow \chi\left(\vec{v}_{i}+\vec{U}\left(0, \varphi_{1}\right) \otimes\left(\vec{p}_{i}-\vec{x}_{i}\right)+\vec{U}\left(0, \varphi_{2}\right) \otimes\left(\vec{p}_{g}-\vec{x}_{i}\right)\right)$

$\vec{x}_{i} \leftarrow \vec{x}_{i}+\vec{v}_{i}$

Where $\phi_{1}+\phi_{2}=\Phi \geq 4$ and

$$
\chi=\frac{2}{\Phi-2+\sqrt{\Phi^{2}-4 \Phi}}
$$

If Clerc's constriction method is applied, $\varphi_{1}=\varphi_{2}=4.1$, and the constant multiplier $\chi$ is 0.7298. So the previous velocity is multiplied by 0.7298 and each of the two $(\vec{p}-\vec{x})$ terms being multiplied by a random number limited by $0.7298 \times 2.05 \approx 1.49618$.

In this method without using any $\mathrm{V}_{\max }$, the constricted particles will converge. Eberhart and Shi (2000) also noted that it is better to limit $\mathrm{V}_{\max }$ to $\mathrm{X}_{\max }$, the dynamic range of each variable on each dimension, in conjunction with equations (3) and (4) resulting a particle 
swarm optimization algorithm with no problem-specific parameters. In comparison of equation 2 with 3, we can say they are equivalent to a PSO with inertia. They can be transformed into one another via the mapping $\omega \leftrightarrow \chi$ and $\varphi_{\mathrm{i}} \leftrightarrow \chi \varphi_{\mathrm{i}}$. So, the optimal settings suggested by Clerc correspond to $\omega=0.7298$ and $\varphi_{1}=\varphi_{2}=1.49618$ for a PSO with inertia.

In a D-dimensional space, where $\mathrm{D}$ is the number of variables involved in the problem, the $\mathrm{i}^{\text {th }}$ particle is $\mathrm{Xi}=\left(x \mathrm{i}_{1} \ldots \mathrm{xi}\right)$, and the velocity of that particle is $\mathrm{Vi}=\left(v \mathrm{vi}_{1} \ldots v \mathrm{i}_{\mathrm{D}}\right)$. The best position of the $\mathrm{i}$-th particle reached in a previous cycle is $\mathrm{Pi}=\left(\mathrm{pi}_{1} \ldots\right.$ piD $)$, and the best particle in the whole swarm is $\mathrm{Pg}=\left(\mathrm{pg}_{1} \ldots \mathrm{pg}_{\mathrm{D}}\right)$. The velocity and the position of the particle $\mathrm{i}$ in the iteration of $\mathrm{n}+1^{\text {th }}$ are governed by

$$
\begin{gathered}
V_{\mathrm{i}}^{\mathrm{n}+1}=w \cdot V_{\mathrm{i}}^{\mathrm{n}}+\mathrm{c}_{1} \mathrm{r}_{1}^{\mathrm{n}}\left(\mathrm{P}_{\mathrm{i}}^{\mathrm{n}}-\mathrm{X}_{\mathrm{i}}^{\mathrm{n}}\right)+\mathrm{c}_{2} \mathrm{r}_{2}^{\mathrm{n}}\left(\mathrm{P}_{\mathrm{g}}^{\mathrm{n}}-\mathrm{X}_{\mathrm{i}}^{\mathrm{n}}\right) \\
X_{\mathrm{i}}^{\mathrm{n}+1}=X_{\mathrm{i}}^{\mathrm{n}}+V_{\mathrm{i}}^{\mathrm{n}+1}
\end{gathered}
$$

Here, $c_{1}$ and $c_{2}$ are learning factors (usually positive constant numbers); $r$ represents a random number between 0 and $1 ; \mathrm{w}$ is a factor of inertia that is a balance between velocity history and the new velocity. In this study, the optimal settings suggested by Clerc and Kennedy (2002) correspond to $\mathrm{w}=0.7298$ and $\mathrm{c}_{1}=\mathrm{c}_{2}=1.496$. In the first generation PSO randomly creates particles, so $\mathrm{v}$ is zero in the initial loop.

Each particle has a position which includes D component which is 17 in this study and the velocity which is direction of that particle in search space. So, each particle defines 17 
parameters of CE-QUAL-W2 and each particle includes velocity (direction) that helps to find next direction which is led next generation of particles. 


\section{The CE-QUAL-W2 Model}

CE-QUAL-W2 (Cole and Wells, 2013) is a two-dimensional, longitudinal/vertical, hydrodynamic and water quality model for rivers, estuaries, lakes, reservoirs and river basin systems. Some of the model capabilities are hydrodynamic modeling, water quality, long term simulations, head boundary conditions, multiple branches, multiple water bodies, variable grid spacing, coupled water quality with hydrodynamics, auto stepping, restart provision, layer/segment addition and subtraction, multiple inflows and outflows, ice cover calculations, selective withdrawal calculations, and time-varying boundary conditions. The governing equations are laterally averaged which may be inappropriate just for large water bodies exhibiting significant lateral variations in water quality. The CE-QUAL-W2 model uses information such as geometric data, initial conditions, boundary conditions, hydraulic parameters, kinetic parameters, and calibration data and includes a graphical pre- and postprocessor for plotting/ visualization. The required data is hourly meteorological data such as air temperature, dew point temperature (or relative humidity), wind speed and direction, solar radiation and cloud cover, bathymetric x-y-z data of the reservoir, flow rates (Q) and temperatures $(\mathrm{T})$, chlorophyll a, dissolved oxygen, and nutrients (such as $\mathrm{NH}_{4}, \mathrm{NO}_{3}$, and $\mathrm{PO}_{4}$ ) for all inflows, flow rates and locations of outflows from the system, including the dam outlet, irrigation and other water withdrawals, outlet structure details for the power house and spillways, including rating curves for the spillways, and water surface elevation data.

\subsection{Algae}

Algae are a very diverse group of organisms categorized from diatoms to multicellular and can be broken down into greens, and cyanobacteria (blue-greens). CE-QUAL-W2 includes 
the capability to specify the kinetic rate parameters that define the characteristics of each algal group regarding given kinds of algal groups.

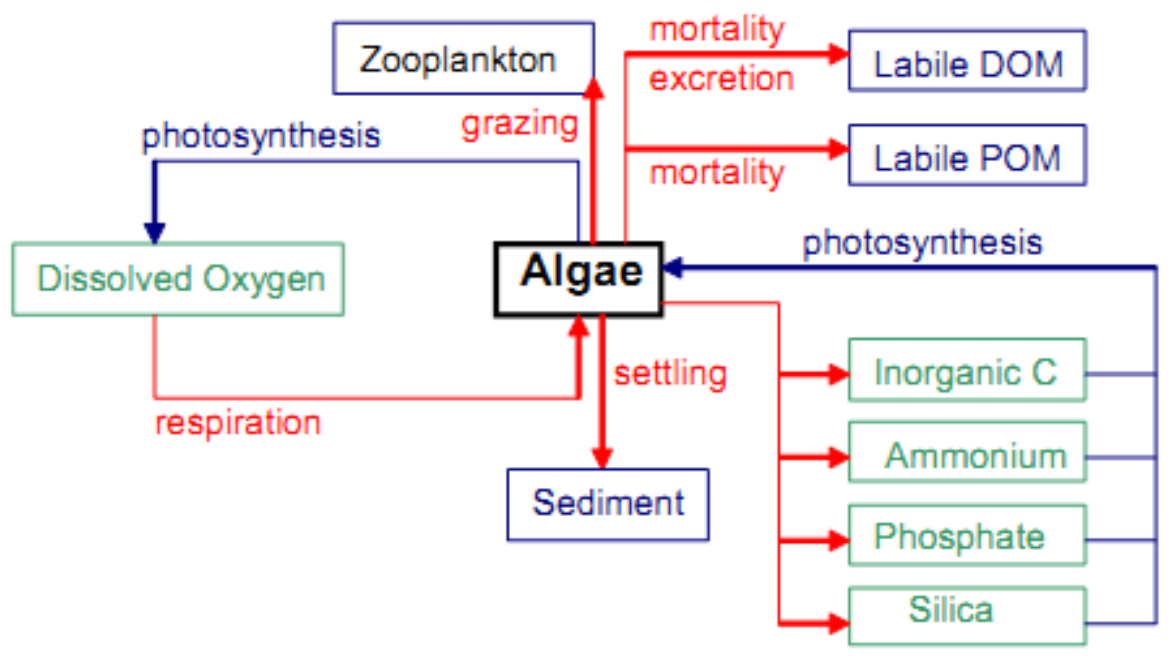

Figure 1. Internal flux between algae and other compartments, (Cole and Wells, 2013)

Algal biomass in the system is affected by Algal growth (AG), mortality (AM), and settling (AS), Algal half-saturation for phosphorus limited growth, (AHSP) $\mathrm{g} \mathrm{m}^{-3}$, Algal halfsaturation for nitrogen limited growth, (AHSN) $\mathrm{g} \mathrm{m}^{-3}$, Light saturation intensity at maximum photosynthetic rate, (ASAT) $\mathrm{W} \mathrm{m}^{-2}$ as fig 1 represented. Moreover maximum growth rate is strongly affected by temperature, light, and nutrient availability. [AG] in the CE-QUAL-W2 is not the net production rates. It is the maximum gross production rate that is not corrected for respiration, mortality, excretion, or sinking.

Chlorophyll a (chl a) is most commonly considered as an index for algal biomass. Multiplying chla by the given algae ratio (as $\mathrm{g} \mathrm{m}-3$ or $\mathrm{mg} / \mathrm{l}$ dry weight $\mathrm{OM}$ )/chl a (as 
$\mu \mathrm{g}$ chlorophyll a/L) convert simply chl a to algal biomass. The ratio between algal biomass and chlorophyll a [ACHLA] is a function of the makeup of the algal population and algal species. [ACHLA] is also changed over time for a given algal species. This value is noted by regressing particulate organic matter with chl a in some previous studies. Based on EPA (1985) reports about percentages of chlorophyll a compared to dry weight algae biomass, it would be concluded that [ACHLA] is ranging from 0.01 to 0.40 for blue-green algae and total phytoplankton.

\subsection{Ammonium}

Ammonium is used by algae during photosynthesis to form proteins. Nitrogen is commonly the limiting nutrient for algal growth with high phosphorus loadings or in estuaries. Internal flux between ammonium and other compartments is presented in Fig 2. by Cole and Wells, 2013.

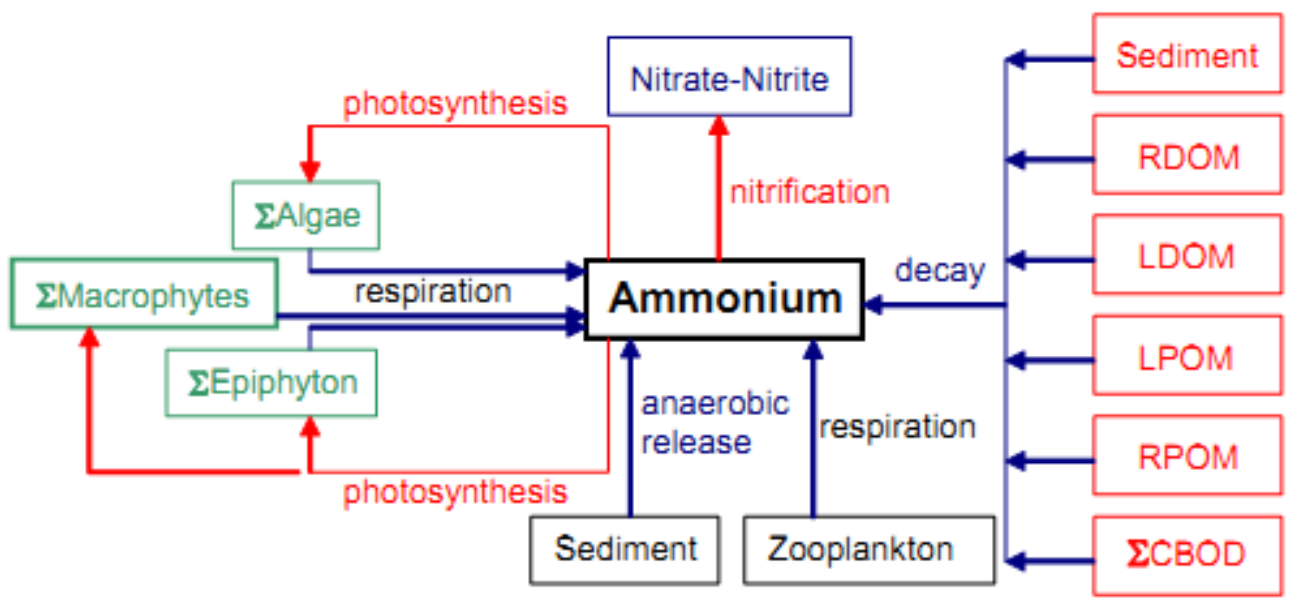

Figure 2. Internal flux between ammonium and other compartments, (Cole and Wells, 2013)

The rate that nitrification occurs in the system represented by NH4DK [day $\left.{ }^{-1}\right]$ that is the rate which ammonium is oxidized to nitrate-nitrite. Cole and Wells, 2013 noted when there 
is anoxia, the rate of ammonia release is approximately the (SOD rate)*(NH4R) in units of $\mathrm{g} \mathrm{NH} 4-\mathrm{N} / \mathrm{m}^{2} /$ day or if divided by the layer height in $\mathrm{m}$ in units of $\mathrm{g} \mathrm{NH} 4-\mathrm{N} / \mathrm{m}^{3} /$ day. These rates are modified by the temperature multiplier for SOD. Beutel (2006) showed that release rates of ammonia- $\mathrm{N}$ ranging from less than 5 to more than $15 \mathrm{mg} \mathrm{NH} 4-$ $\mathrm{N} / \mathrm{m}^{2} /$ day between oligotrophic to hypereutrophic lakes, respectively.

\subsection{Nitrate-Nitrite}

Nitrate and nitrite were considered both together in CE-QUAL-W2. As Fig. 3 has presented, during nitrification, ammonium converts to nitrate and nitrite is an intermediate production of this process. Algae and epiphyton use nitrate as a source of nitrogen during photosynthesis. As mentioned previously, nitrogen may be the limiting nutrient for algae in systems with high phosphorus loadings or in estuaries.

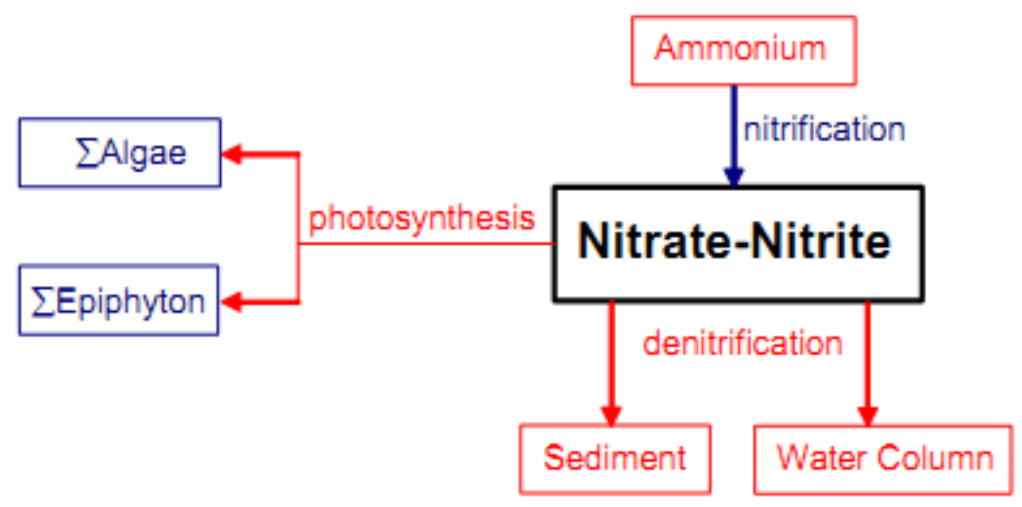

Figure 3. Internal flux between nitrate + nitrite and other compartments (Cole and Wells, 2013)

Denitrification rate in the water column and from the water column to the sediments (NO3S), m day ${ }^{-1}$ is analogous to a settling velocity and represents how fast nitrate is diffused into the sediments where it undergoes denitrification (Fig 3). Nitrate decay rate 
(NO3DK), day ${ }^{-1}$ represents how fast ammonium decays to nitrite and nitrate and have ranged from $0.05-0.15 \mathrm{day}^{-1}$.

\subsection{Phosphorus}

Phosphorus is also an important nutrient for phytoplankton growth. In many fresh water system, phosphorus is the nutrient limiting the production of phytoplankton biomass is phosphorus (Schindler, 1971; Schindler et al., 1973; Vollenweider, 1968, 1976). Macrophytes are also taking P from the sediments or from the water column.

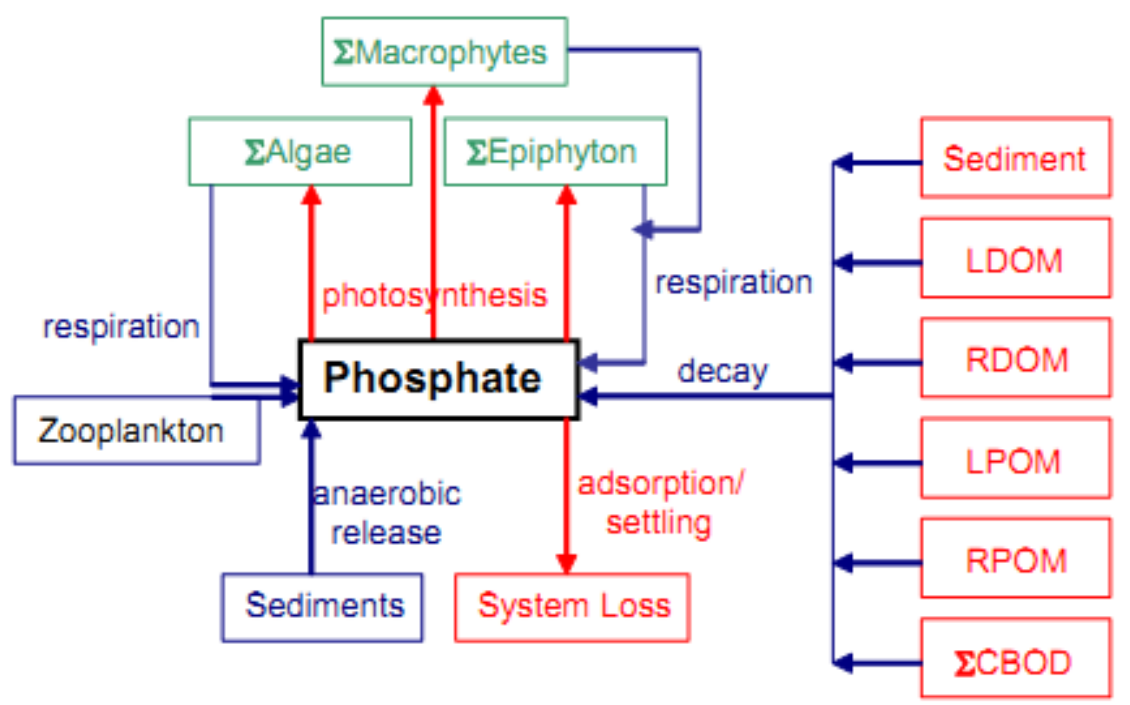

Figure 4. Internal flux between phosphorus and other compartments, (Cole and Wells, 2013)

In CE-QUAL-W2, the sediment release rate of phosphorous under anaerobic conditions (PO4R) is noted as a fraction of the sediment oxygen demand. So, the PO4 release rate under anaerobic conditions is $[\mathrm{PO} 4 \mathrm{R}] \times[\mathrm{SOD}]$ in units of $\mathrm{g} / \mathrm{m}^{2} /$ day modified by the temperature multiplier for SOD. So, PO4R is a function of the SOD rate and site-specific. Cole and Wells, 2013 compared PO4R reported by different researchers. Based on that 
comparison, Sen et al. (2004) determined an average anaerobic P release rate of 0.57 $\mathrm{mg} / \mathrm{m}^{2} /$ day for Beaver Lake, Arkansas. Auer et al. (1993) found rates in a hypereutrophic lake from $9-21 \mathrm{mg} / \mathrm{m}^{2} /$ day (mean $13 \mathrm{mg} / \mathrm{m}^{2} / \mathrm{day}$ ). Kim et al. (2004) found rates in the summer between $20-24{ }^{\circ} \mathrm{C}$ up to $16 \mathrm{mg} / \mathrm{m}^{2} /$ day.

Spears et al. (2007) showed that for a large shallow lake recovering from high

nutrient that the maximum $\mathrm{P}$ release was $12 \mathrm{mg} / \mathrm{m}^{2} /$ day. James et al. (1995) found that $\mathrm{P}$ release rates for Lake Pepin, an impoundment on the upper Mississippi River, were between 3.8 and $15 \mathrm{mg} / \mathrm{m}^{2} /$ day.

\subsection{Dissolved Oxygen}

Oxygen is one of the most important limiting factor in aquatic ecosystems. Dissolved oxygen can provide broad information about the system state. It is essential for aquatic life, controls many chemical reactions through oxidation, and is a surrogate variable indicating the general health of aquatic systems.

CE-QUAL-W2 is capable to model both aerobic and anaerobic processes. The modeling of anaerobic processes is an important step in the water quality modeling of reservoir because simulations of that can be used to identify possibilities for both metalimnetic and hypolimnetic oxygen depletion and its impact on various water control management alternatives. 


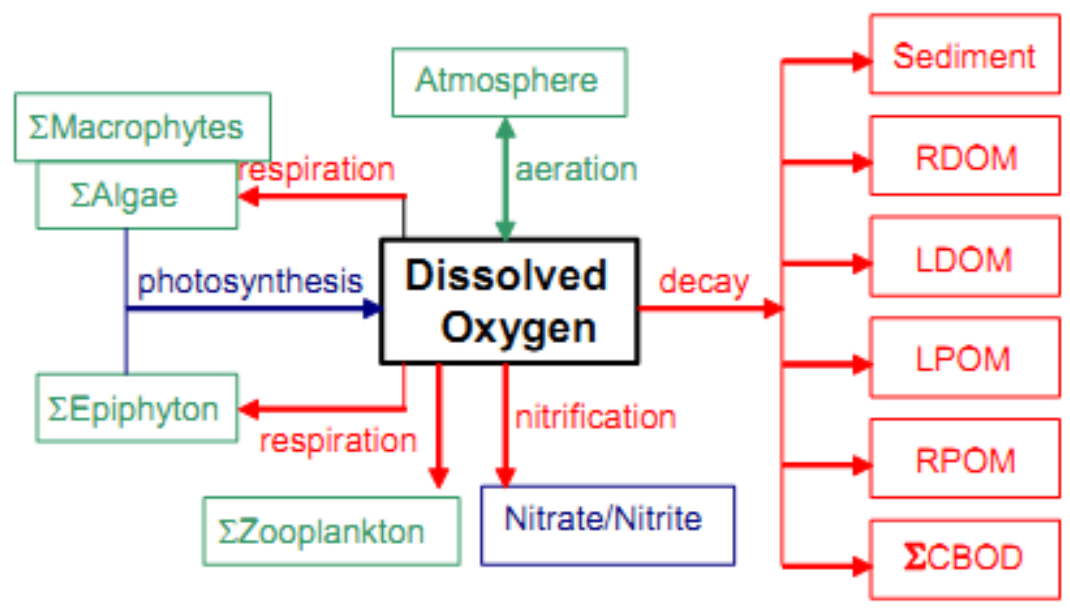

Figure 5. Internal flux between dissolved oxygen and other compartments, (Cole and Wells, 2013)

\subsection{Sediments}

In CE-QUAL-W2 contribution of organic sediment to nutrients and dissolved oxygen demand are simulated using two methods. The first method uses zero-order and constant sediment oxygen demand and anoxic release rates for phosphorus, ammonium, inorganic carbon, and iron (Fig 6). This method is commonly used to model sediment demands and nutrient release rates. This model requires a separate sediment compartment rather than sediment concentrations. The overall formulation is not variable over time but the decay rate is a function of temperature. So, when effects of different nutrient loadings on dissolved oxygen is evaluating in a waterbody, results should be interpreted cautiously. Sediment oxygen demand value is commonly between 0.1 to $1.0 \mathrm{gO} 2 \mathrm{~m}^{-2} \mathrm{day}^{-1}$. According to Cole and Wells (2013), the second method uses a sediment compartment to accumulate organic sediments and allow their decay. So, $1^{\text {st }}$-order decay affects nutrient releases and oxygen demand (Fig 7). Effects of organic sediments upon water 
quality can be simulated by either of these methods, or a combination. SEDK is a parameter that specifies the $1^{\text {st }}$ order sediment decay rate value.

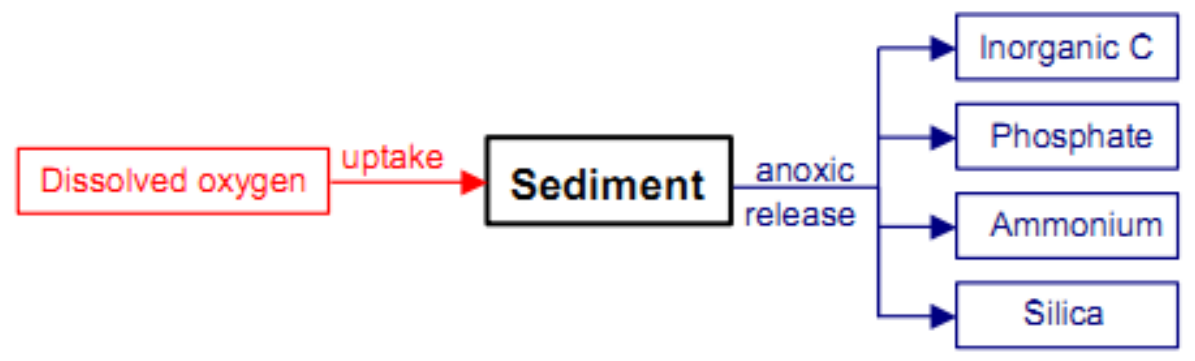

Figure 6. Internal flux between 0-order sediment compartment and other compartments (Cole and Wells, 2013)

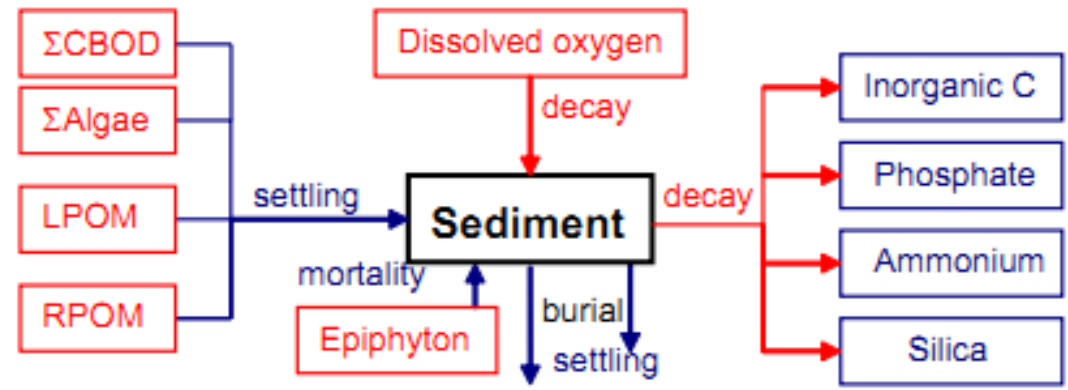

Figure 7. Internal flux between 1st-order sediment compartment and other compartments (Cole and Wells, 2013)

Based on a literature survey and screening process, the most important parameters which significantly affect reservoir's temperature profile were identified and selected as decision variables in the optimization routine. The extinction coefficient for pure water $(\mathrm{EXH} 2 \mathrm{O})$ that is attenuation rate due to water, and the fraction of solar radiation absorbed in the surface layer (BETA) which both control distribution of solar radiation in the water column and also wind sheltering coefficients (WSC) affect thermal stratification on reservoirs. Gas 
exchange is also affected by the wind sheltering coefficient [WSC]. EXH2O and BETA affect directly temperature that affects hydrodynamics but WSC directly affects hydrodynamics that affect heat and constituent transport. Cole and Wells, (2013) mentioned that the wind sheltering coefficient is approximately from 0.5-0.9 for mountainous and/or dense vegetative canopy and 1.0 for open terrain. In a very few cases, the wind-sheltering coefficient (WSC) has been increased above 1.0 to account for funneling effects on systems with steep banks.

Realizing the complex relationships between model parameters (BETA and EXH2O), it is assumed that the model parameters are independent of each others. For implicit and partial consideration of this dependency, the bounds on the model parameters are defined based on measured Secchi Disk Depth in IWPC (Iran Water and Power Company 2006) Karkheh reservoir Monitoring Program and reference values considering water turbidity. There are some other variables that also affect evaporation process (one of the phrases of surface heat exchange). These parameters are $\mathrm{AFW}, \mathrm{BFW}$, and $\mathrm{CFW}$. These last parameters affect water surface elevation (water budget), too. The evaporation formulation via a user defined evaporation wind speed formula is shown in Eq. 7, (Cole TM, Wells SA 2013).

$$
F\left(w_{z}\right)=a f w+b f w \times W_{z}^{c f w}
$$

$F\left(w_{z}\right)$; wind speed function, afw, bfw, cfw are the empirical coefficients, and $W_{z}$ is the wind speed measure at $2 \mathrm{~m}$ above the ground. 


\section{The Karkheh Reservoir}

The Karkheh Reservoir (Fig. 8) is located on the Karkheh River in the southeast region of Iran and has the following characteristics: a maximum of depth of $117 \mathrm{~m}, 162 \mathrm{~km}^{2}$ surface area, $5 \times 10^{9} \mathrm{~m}^{3}$ capacity, and $64 \mathrm{~km}$ length.

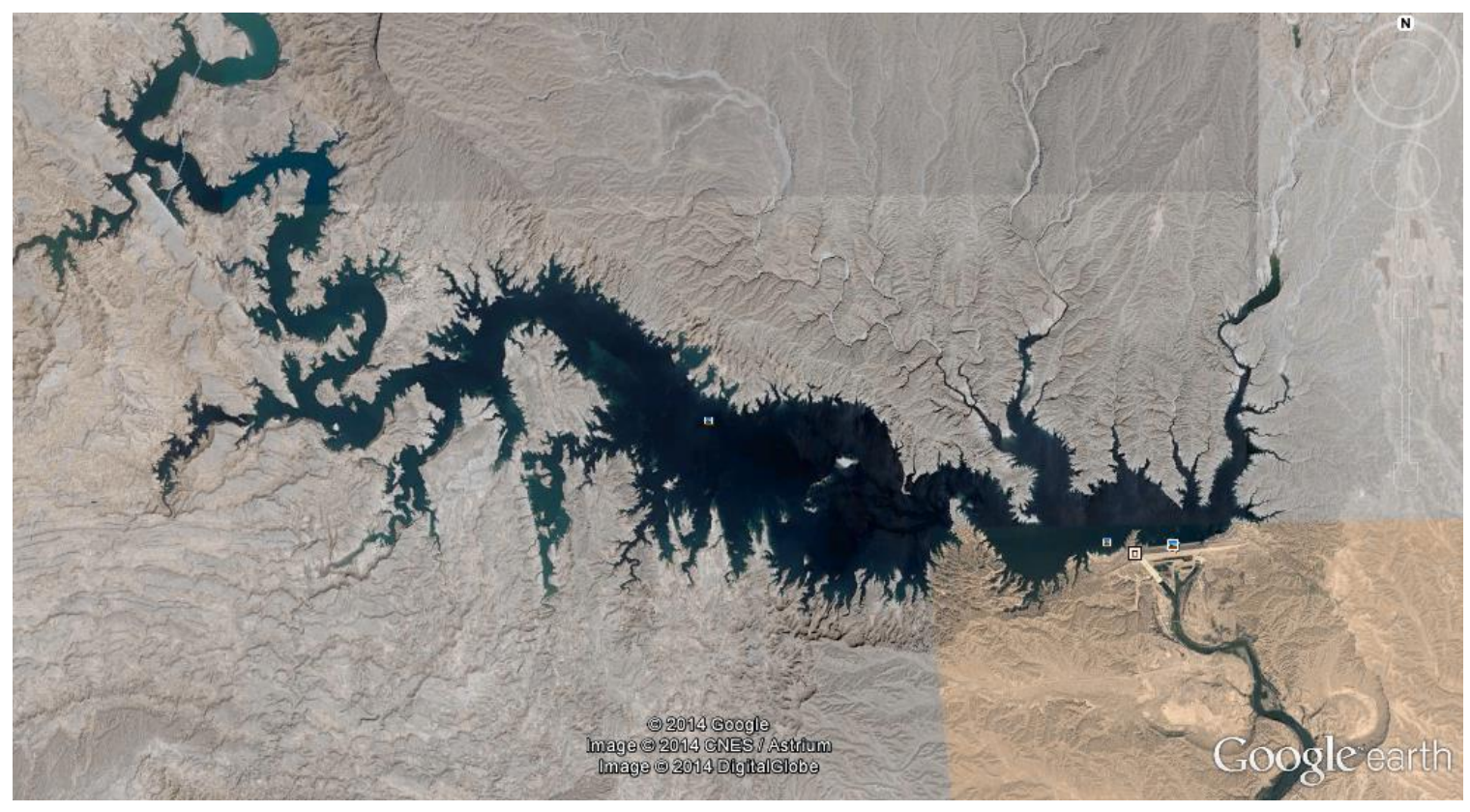

Figure 8. Karkheh Reservoir map from Google Earth

This reservoir supplies municipal drinking water and irrigation water for 350,000 ha of irrigable agriculture. Water in the Karkheh Basin is used for domestic purposes, agricultural production and limited industrial activity. The basin is third basin in surface water use and fourth basin in groundwater use in Iran (Ahmad and Giordano 2010). The Karkheh Basin is noted as the most productive basin in Iran that includes 9\% of Iran's total irrigated area and produce around $11 \%$ of country's total wheat supply. 
The Karkheh Dam on the Karkhe River is a multi-purpose dam in the northwestern Province of Khuzestan in Iran, close to the city of Andimeshk. It is designed to produce $520 \mathrm{MW}$ of hydroelectric power, prevent downstream floods and provide irrigation water to 350,000 ha in the Khuzestan Plains in the lower Karkheh region. The dam has been operated since 2002 and accumulated dam outflow was measured at 2.8 Billion cubic meters in November 2002 and October 2003. The maximum storage capacity of dam is about 4.7 BCM.

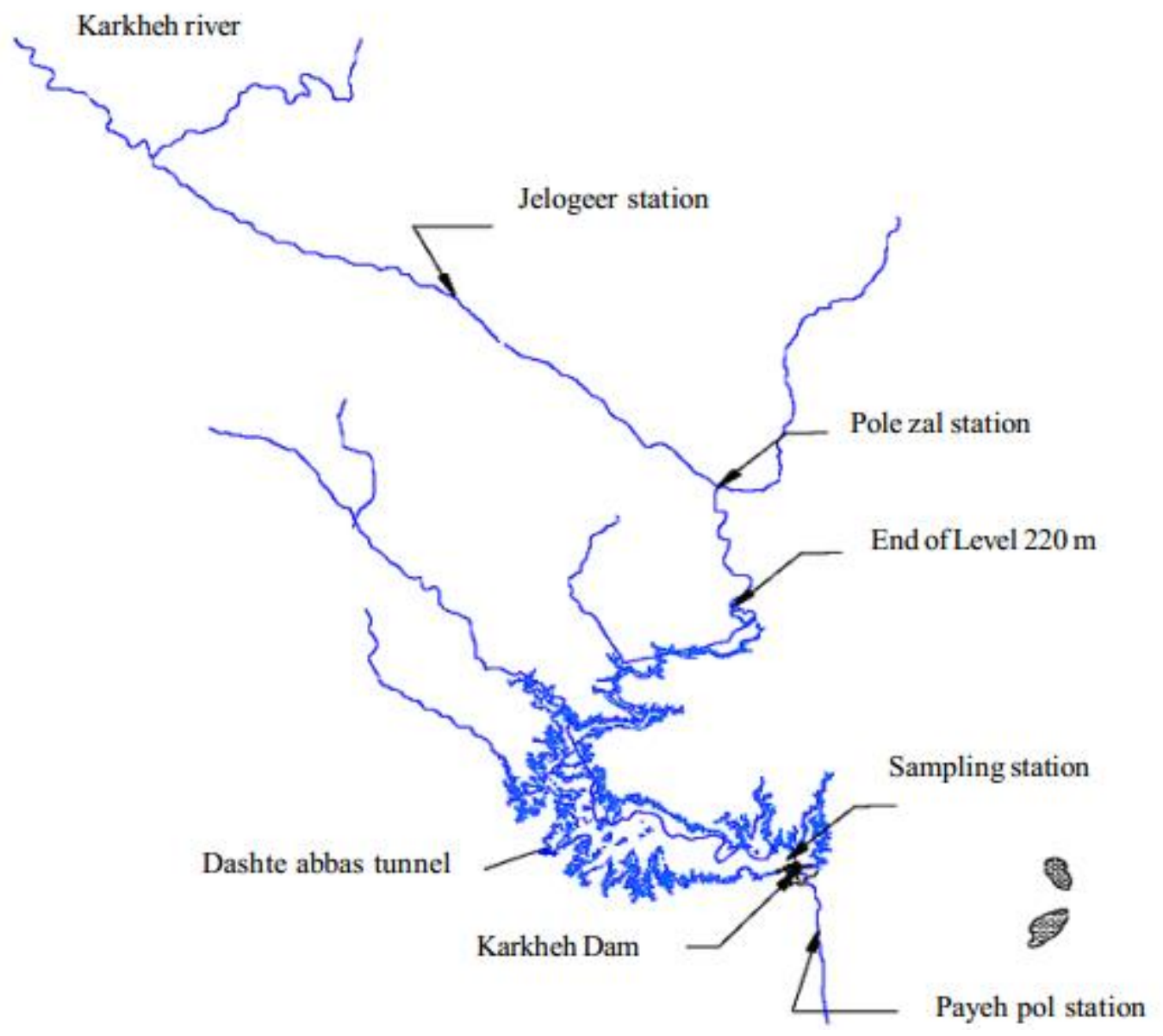

Figure 9.Karkheh River watershed, dam and sampling station 


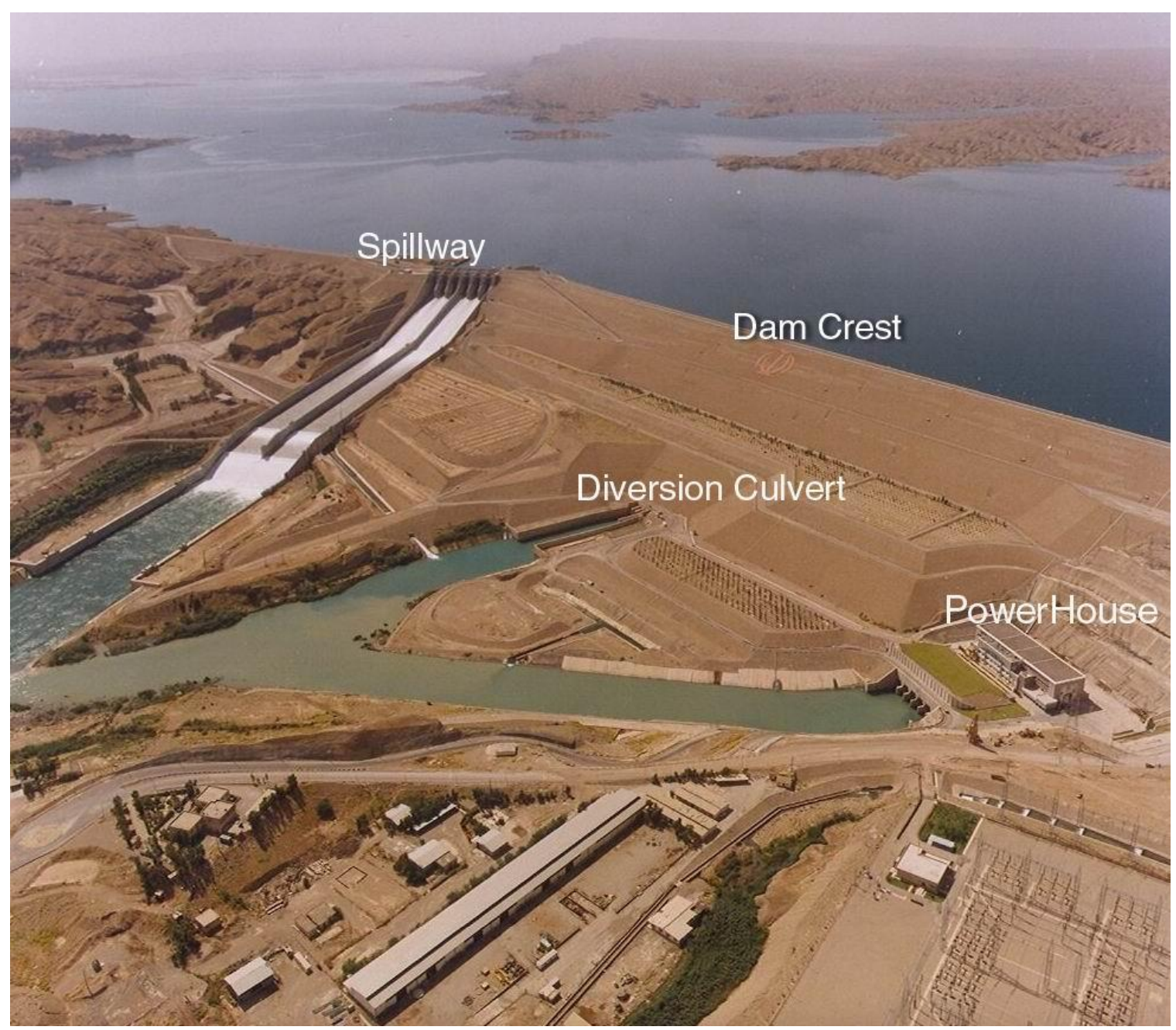

Figure 10. Photo of outlets (http://www.geosig.com)

Table 1.The Karkheh reservoir CE-QUAL-W2 model characteristics

\begin{tabular}{|c|c|c|c|c|c|c|}
\hline Number of & Number of & Number of & Segment & Width of & Number & Layer \\
waterbodies & branches & segments & length & segments & of layers & thickness \\
\hline 1 & 1 & 64 & $1000 \mathrm{~m}$ & $26-2673 \mathrm{~m}$ & 55 & $2 \mathrm{~m}$ \\
\hline
\end{tabular}




\section{The Karkheh CE-QUAL-W2 Model}

The Karkheh reservoir CE-QUAL-W2 model has 64 longitudinal segments and 55 vertical layers as shown in Figure 11, 12, and 13 and table 1. The Karkheh model includes inflows and outflows such as Karkheh River, the spillway, water supply withdrawals (Dashtabbas tunnel), and the dam outlet (hydropower and agricultural outlet) (Fig. 9 and 10). Hourly meteorological data and hydrological data were obtained from the Karkheh Meteorology Station included air temperature, dew point temperature, wind speed and direction and cloud cover. The residence time during the simulation period is 117 days which shows the simulation is highly dependent on initial condition. Therefore, accurate inflow temperatures and constituent concentrations were crucial for accurate simulations of temperature and water quality in Karkheh Reservoir.

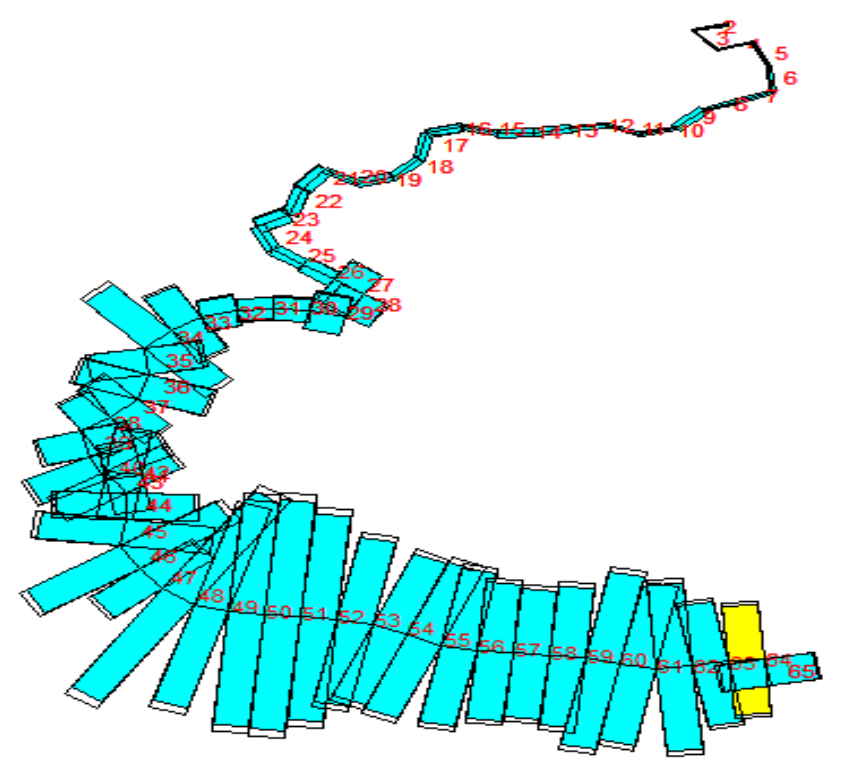

Figure 11. Model configuration plan-view 


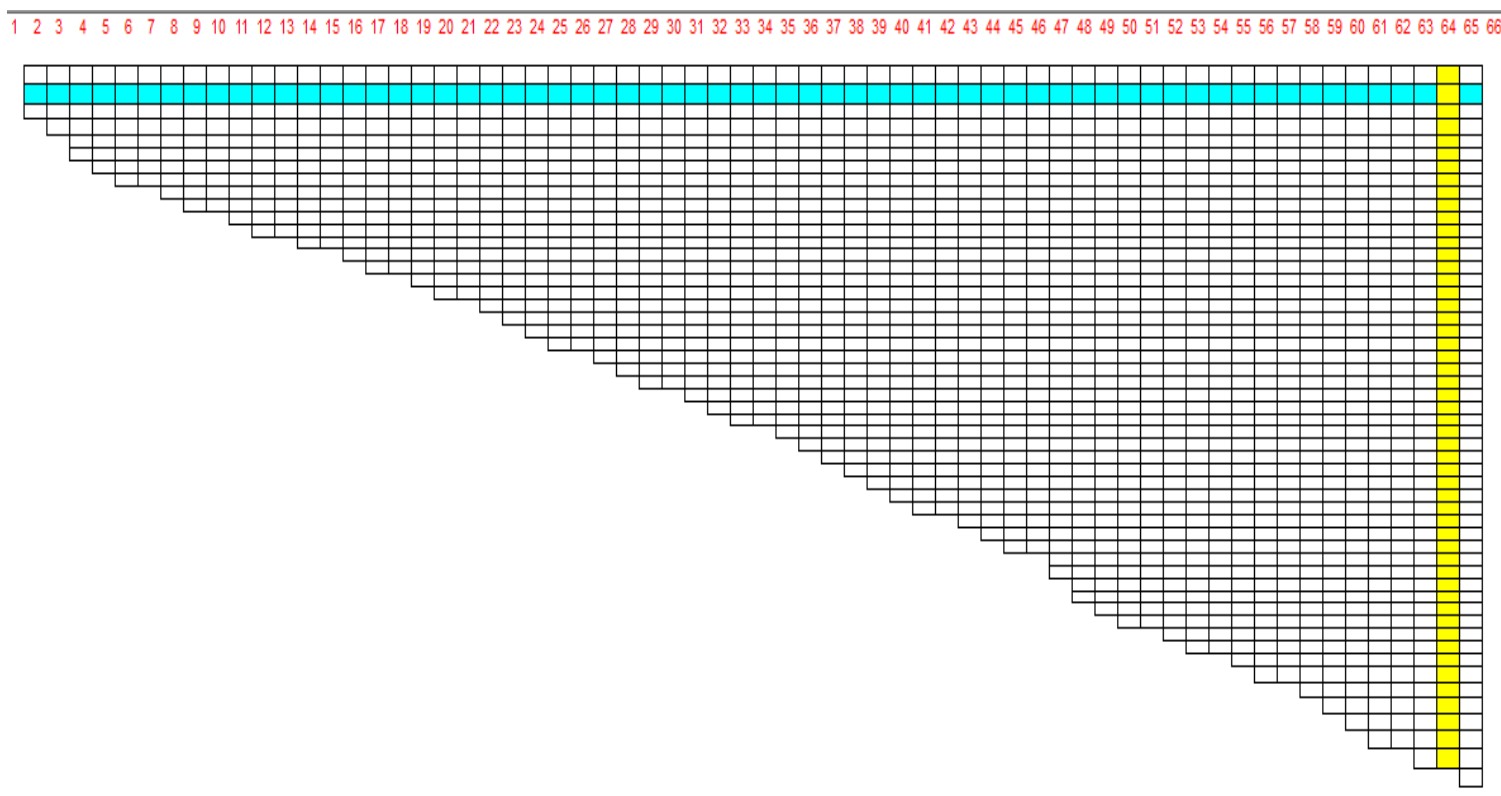

Figure 12. Model configuration side-view

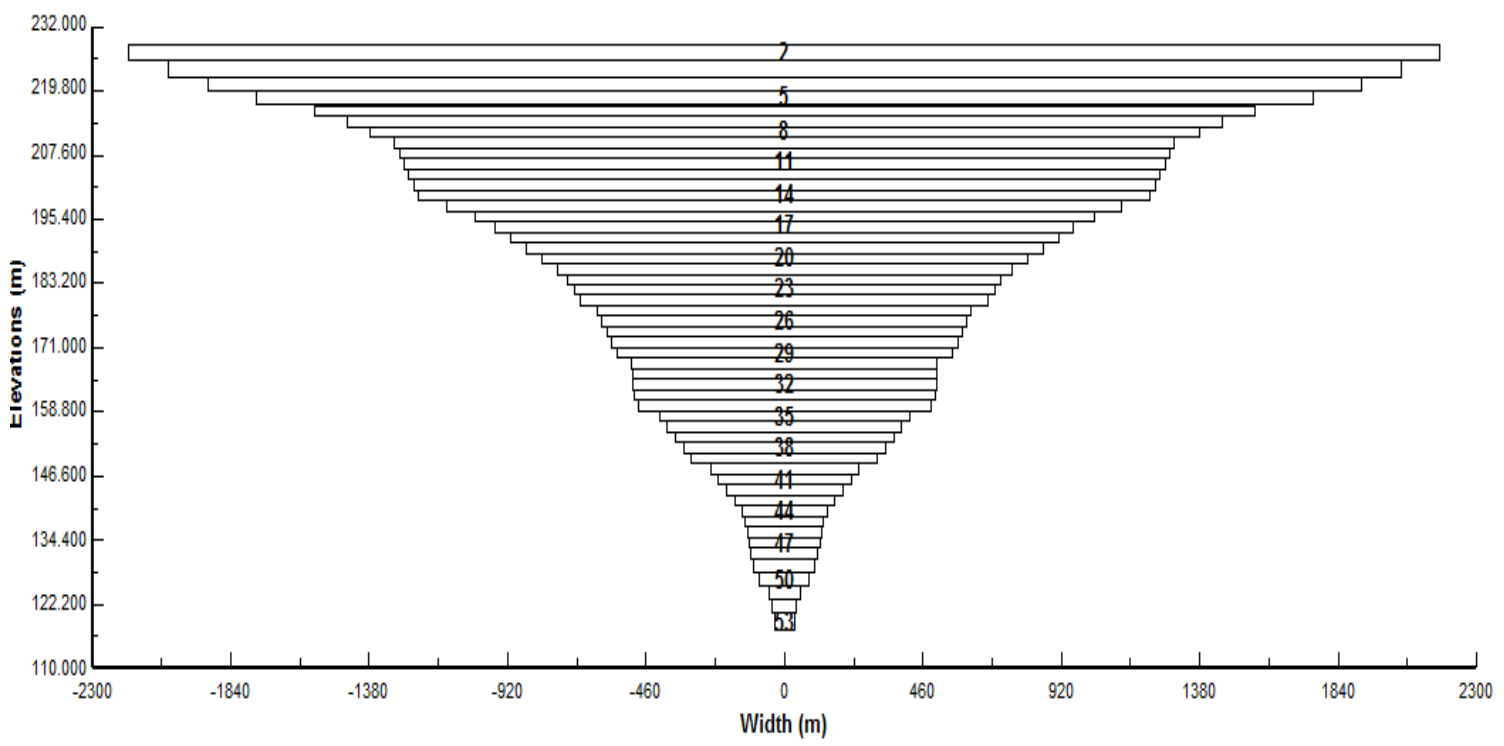

Figure 13.Vertical model segment 


\subsection{Outlet Structures}

Spillway is located in segment 65 and elevation of weir crest is $220 \mathrm{~m}$. The general equation for calculating flow over a weir takes the following form:

$$
Q=\alpha_{1} \Delta H^{\beta_{1}}
$$

Where:

$$
\begin{aligned}
& \alpha_{1}=\text { empirical parameter }=10 \\
& \beta_{1}=\text { empirical parameter }=1.5 \\
& \Delta \mathrm{h}=\mathrm{Zu}-\mathrm{Zsp}, \mathrm{m} \\
& \mathrm{Z}_{\mathrm{u}}=\text { upstream head, } \mathrm{m} \\
& \mathrm{Z}_{\mathrm{sp}}=\text { the spillway crest elevation, } \mathrm{m}
\end{aligned}
$$

And for submerged conditions:

$$
Q=\alpha_{2} \Delta H^{\beta_{2}}
$$

Where

$$
\begin{gathered}
\alpha_{2}=\text { empirical parameter }=20 \\
\beta_{2}=\text { empirical parameter }=1
\end{gathered}
$$

the spillway is at the down-stream end of the segment 65 (Fig. 14). In this case the water surface elevations are computed based on the right hand side of segment 65 . This water surface elevation is estimated based on the slope of the water surface at 65 and 64. Also, momentum from the outflow is preserved as in a downstream structure withdrawal and inflows/outflows for the downstream spillway is set to place the inflows into a layer with similar density. 


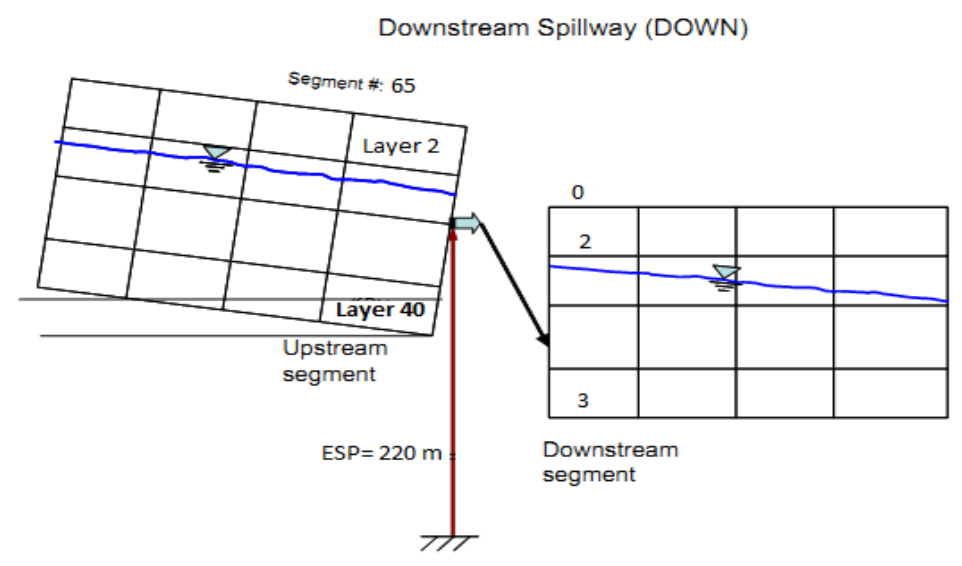

Figure 14.The layout of spillways set as a downstream (Cole and Wells, 2013)

Moreover, withdrawal will occur between layer 24 and 26 at the segment 45 in elevation of $177.5 \mathrm{~m}$. Two structures have been located in to handle selective withdrawal between layer 30 and 35 through first one and between layer 18 and 27 through the second structure.

\subsection{Air Temperature}

Air temperature data collected at Karkheh Reservoir over the full model period is shown in Figure 15.

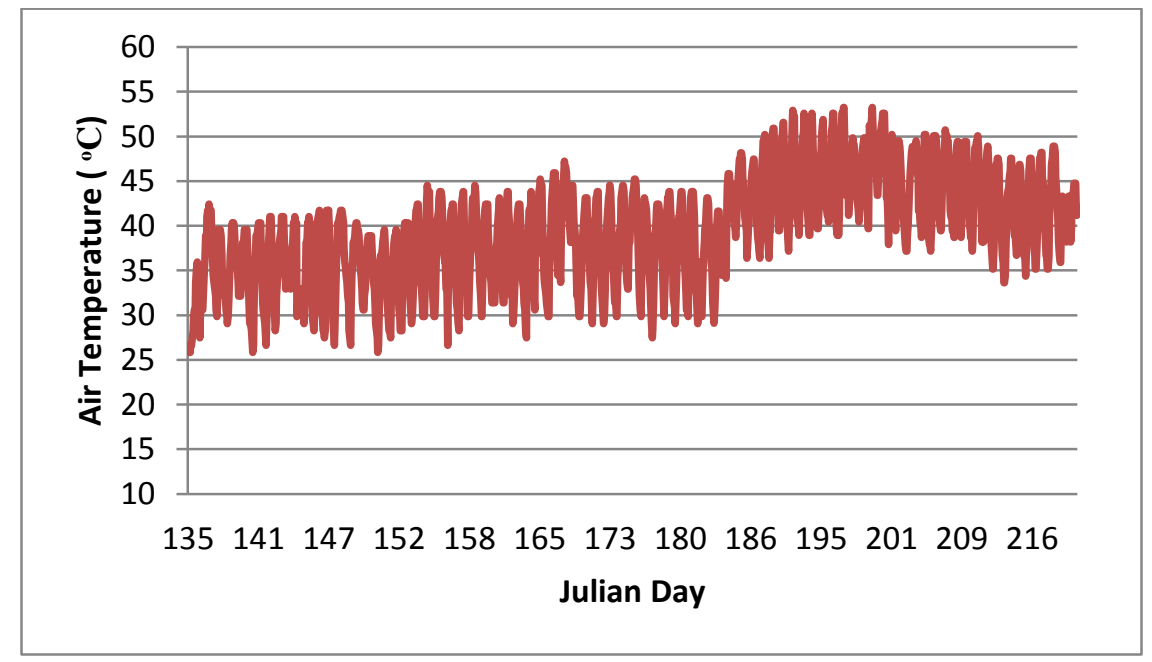




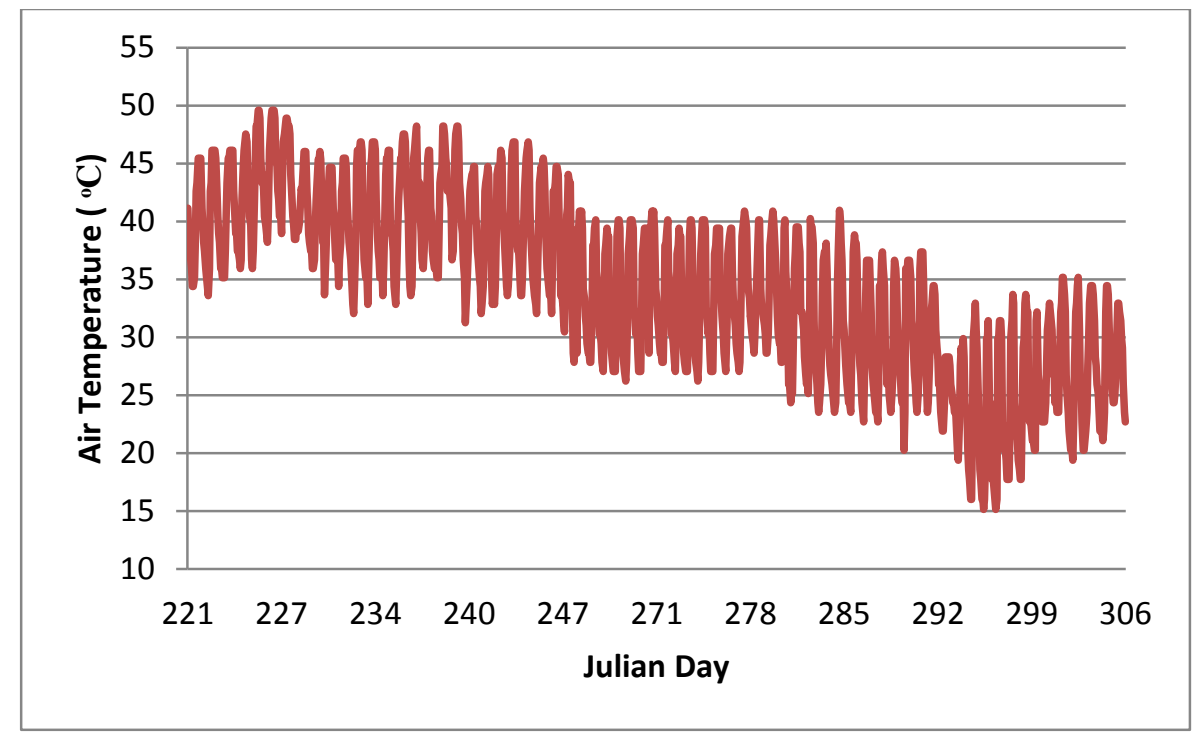

Figure 15. Karkheh Reservoir air temperature (Iran Water and Power Company)

Figure 16 shows the dew-point temperature at Karkheh Reservoir calculated using relative humidity data from Karkheh Meteorology Station. Dew-point temperature is calculated using the relationship between temperature and RH as shown in Equation 10 (Singh (1992) Elementary Hydrology):

$$
R H=\left[\frac{112-0.1 T+T_{d}}{112+0.9 T}\right]^{8}
$$

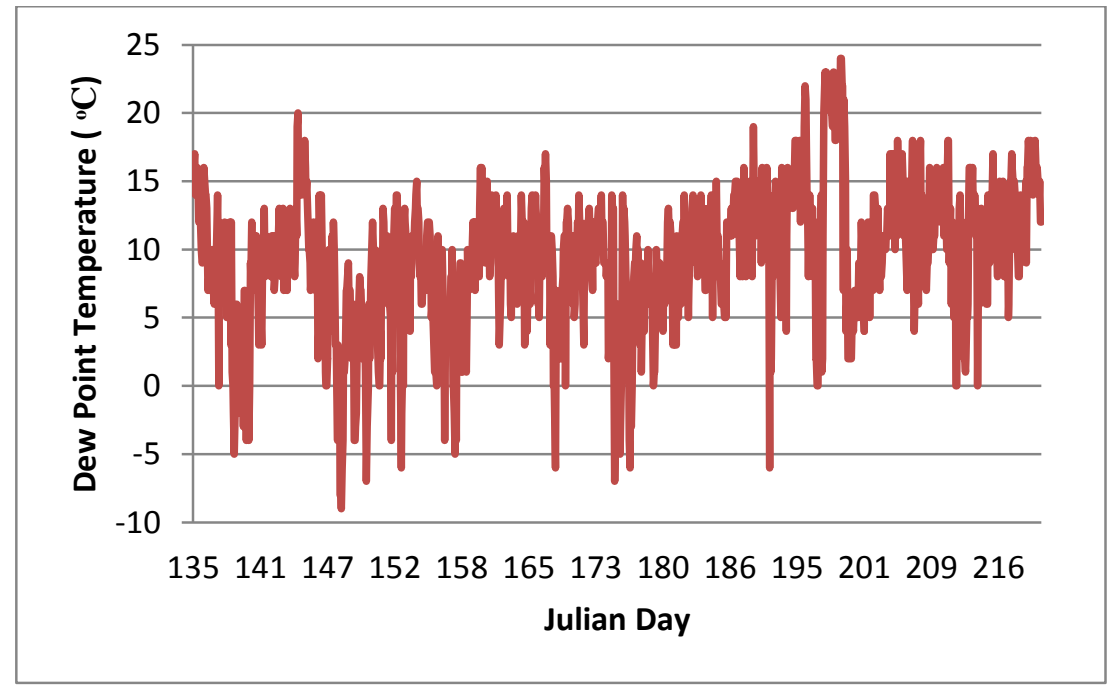




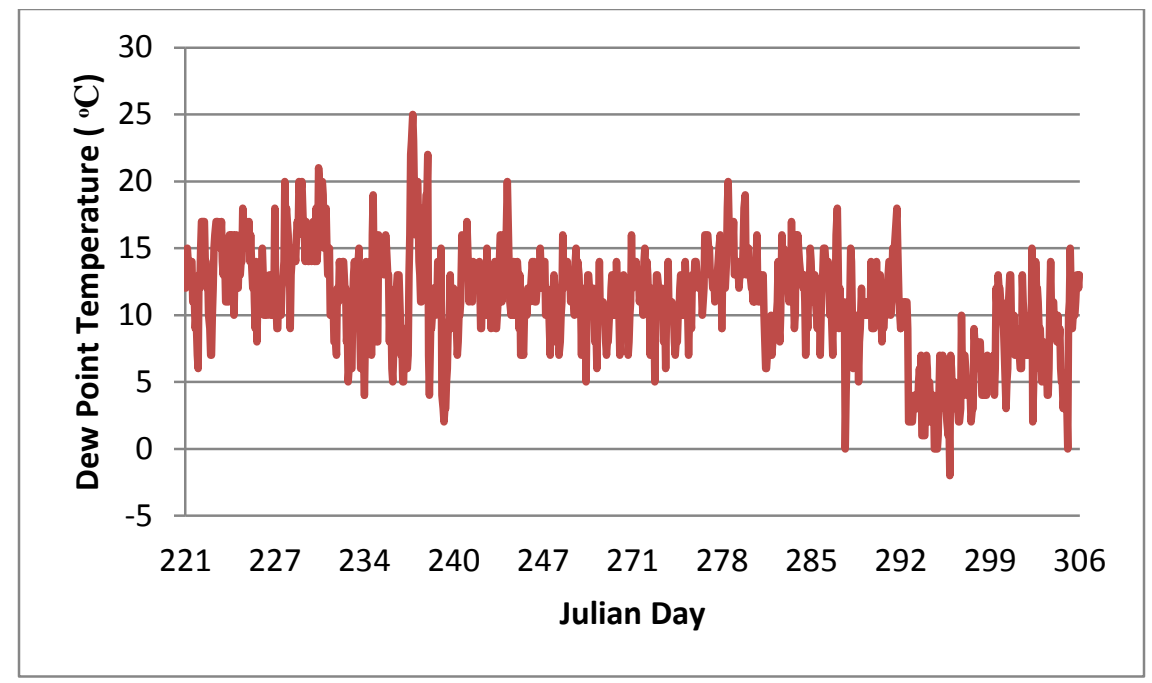

Figure 16. Karkheh Reservoir Dew Point Temperature (Iran Water and Power Company)

\subsection{Wind}

Figure 17 shows the wind velocity measured at Karkheh Reservoir sampling station over the full model period.

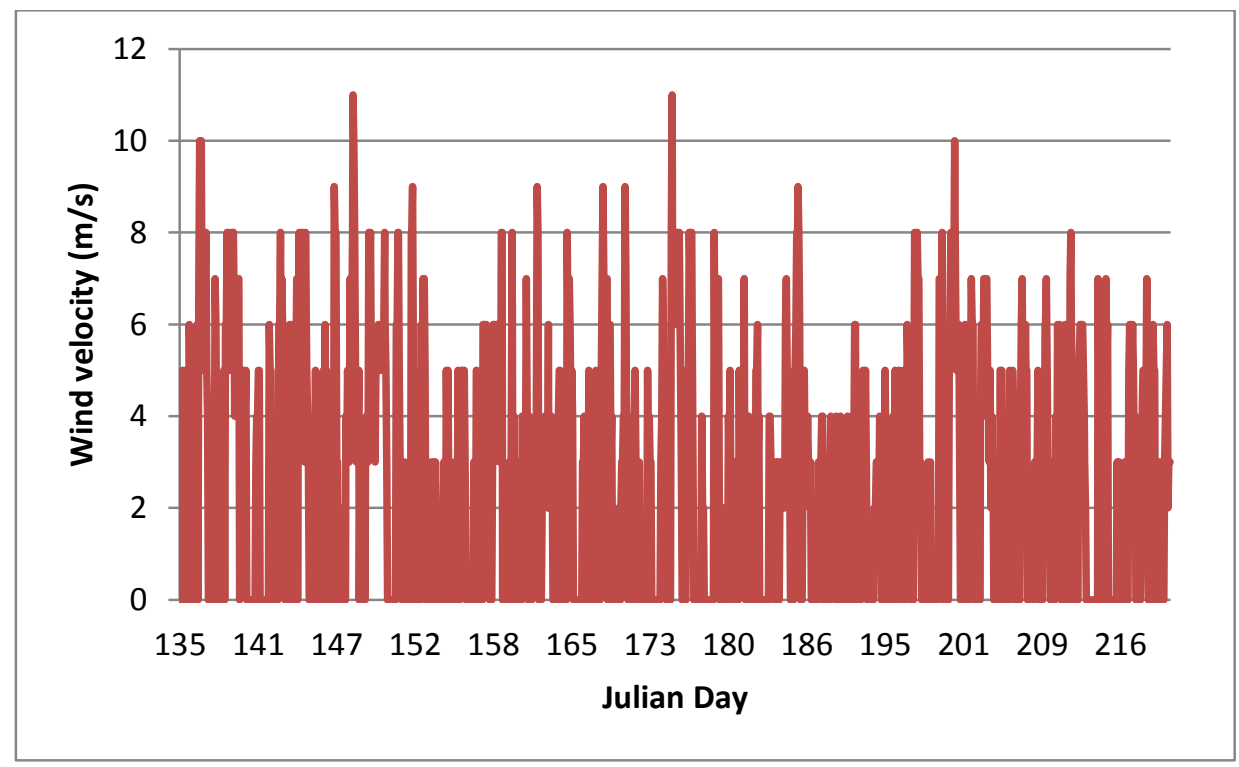




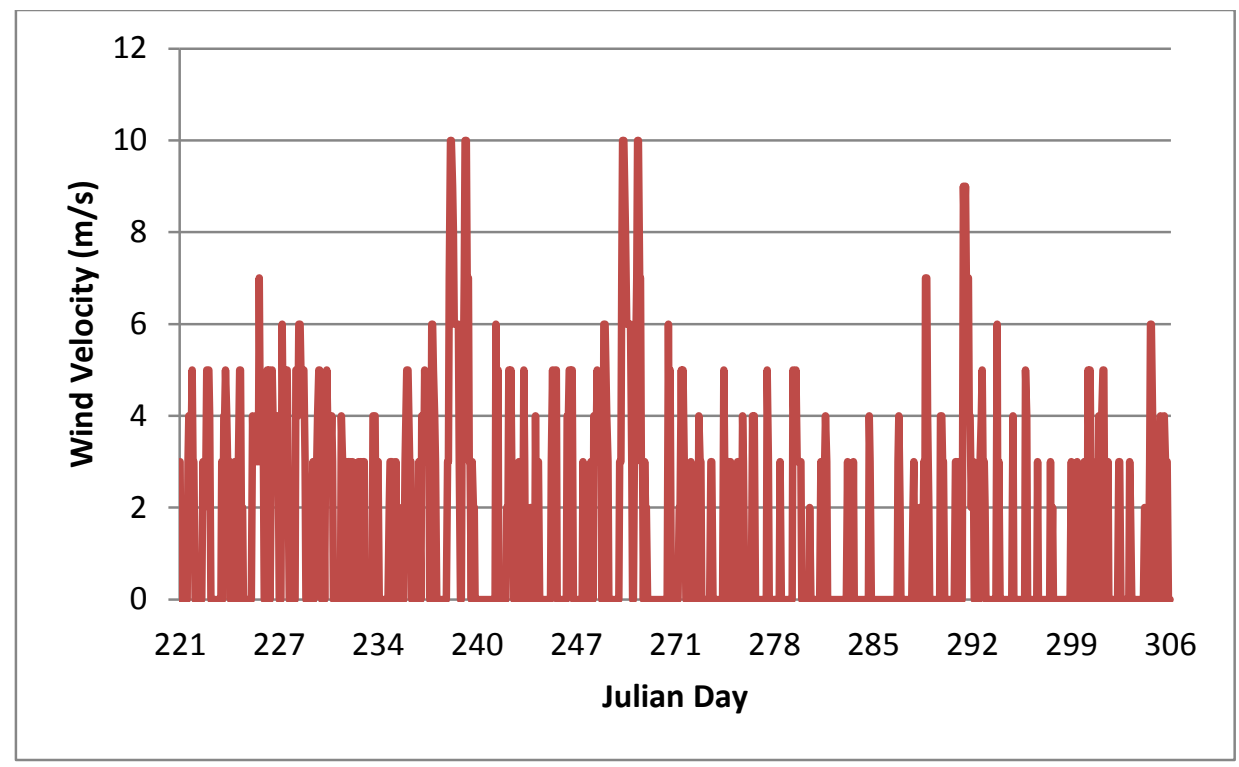

Figure 17.Karkheh Reservoir Wind Velocity (Iran Water and Power Company)

\subsection{Initial Condition Data}

The initial condition includes the initial temperature and concentration of chlorophyll a, dissolved oxygen, and nutrients (such as $\mathrm{NH}_{4}, \mathrm{NO}_{3}$, and $\mathrm{PO}_{4}$ ). A grid-wide vertical profile was specified in the vertical profile input file.

\subsection{Boundary Condition Data}

\section{Model Inflow}

The Karkheh River is the third largest river in Iran (in terms of water yield), after the Karun and Dez Rivers which reaches to The Karkheh Reservoir. Fig. 18 presents the inflow rate of Karkheh River to Karkheh Reservoir. 


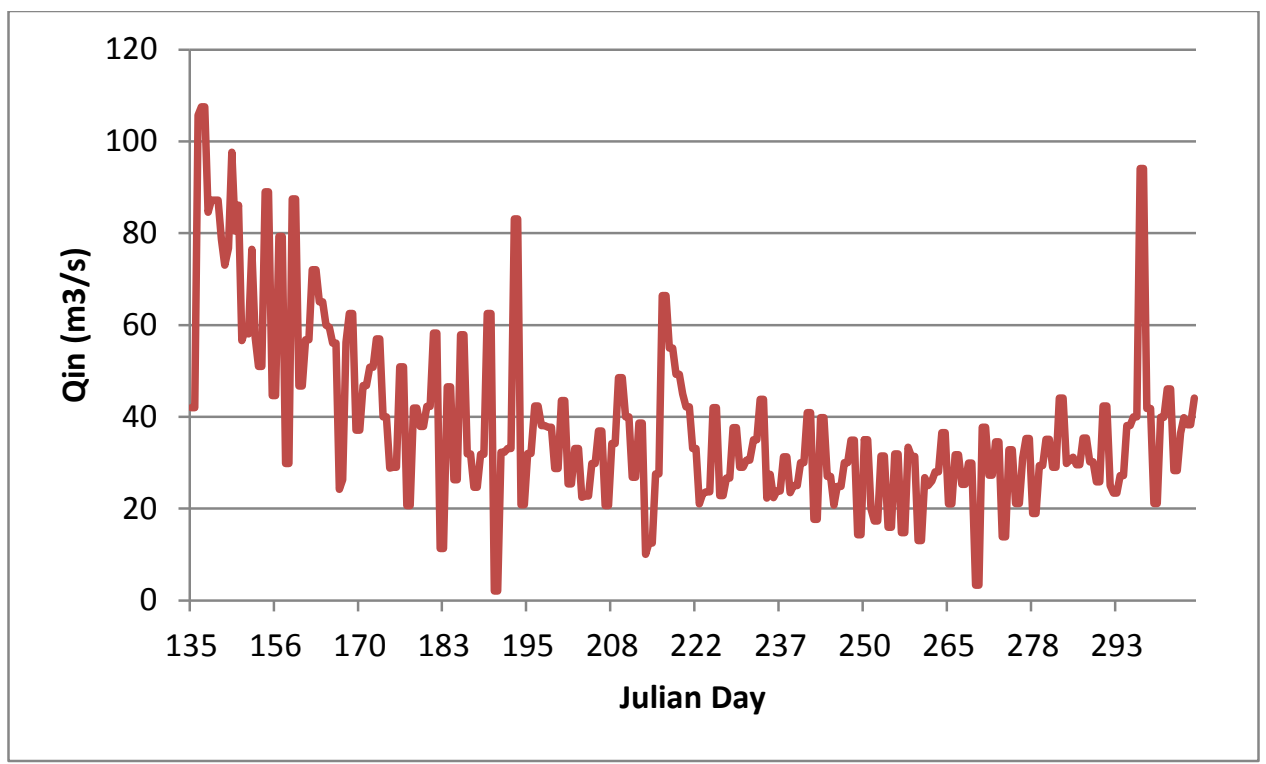

Figure 18.Karkheh River inflow to Karkheh Reservoir (Iran Water and Power Company)

\section{Inflow Temperature}

Water temperature data was available for the complete model period The Karkheh River.

Figure 19 shows a plot of recorded water temperatures on The Karkheh River.

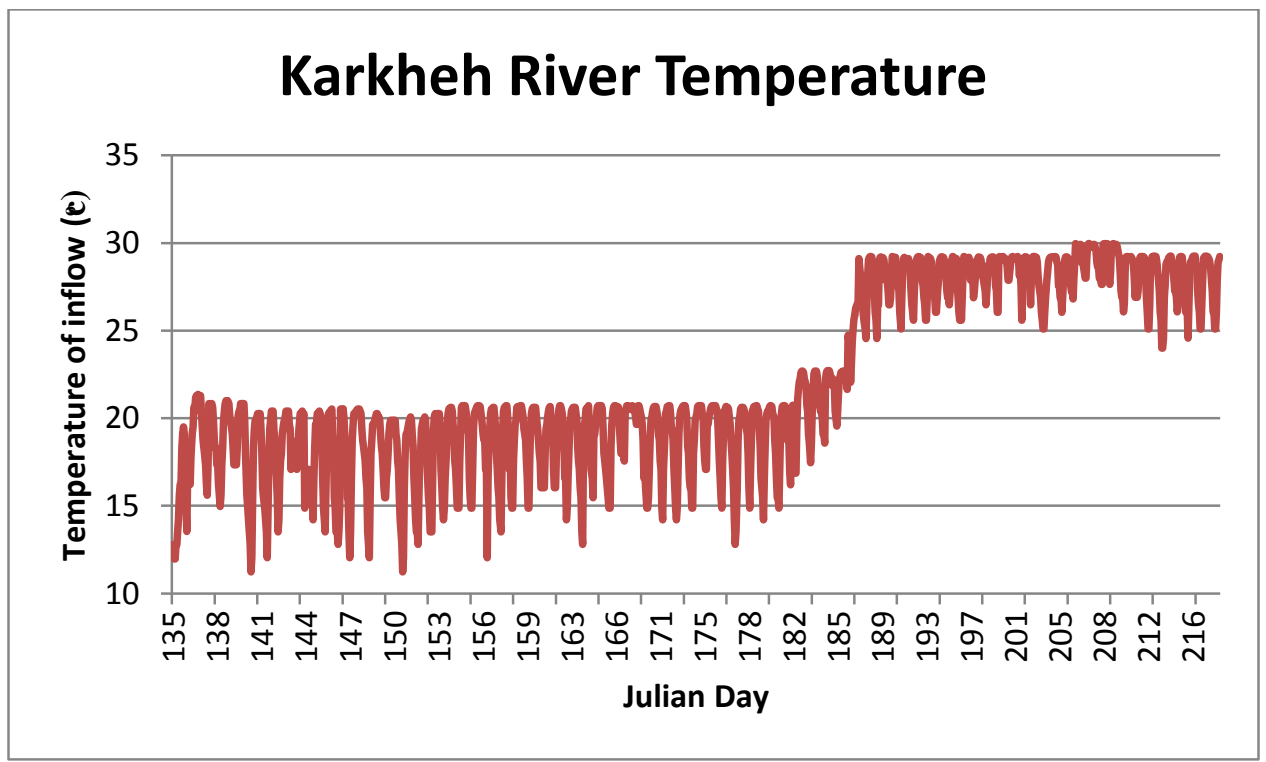




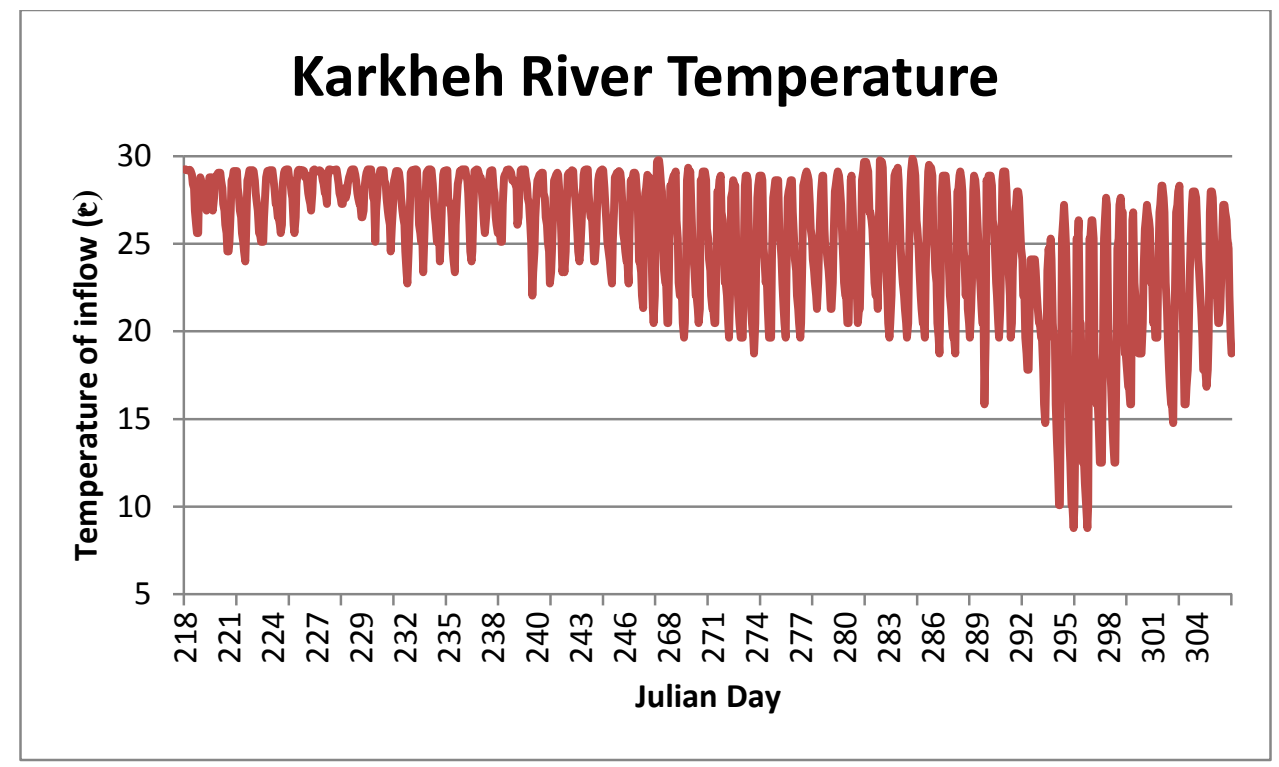

Figure 19.Karkheh River flow temperature (Iran Water and Power Company)

\section{Model Outflow}

The main outflow from The Karkheh Reservoir is released through the Dam into the Karkheh River. Figure 20 plots the stream discharge downstream from The Karkheh reservoir over the model period.

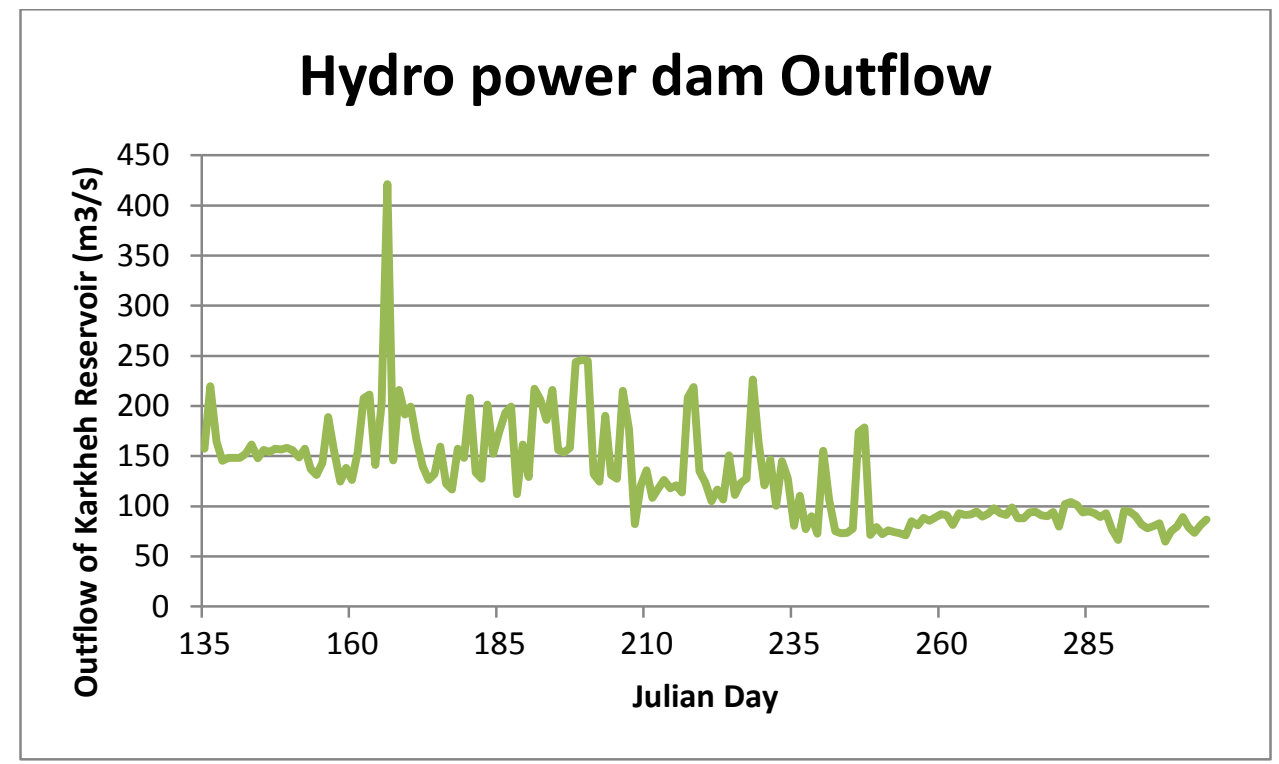

Figure 20. Karkheh Reservoir outflow (Iran Water and Power Company) 
Fig. 21 shows a close match between the simulated and measured water surface elevations in Karkheh reservoirs. So model performs quite satisfactory in predicting the actual variation both in wet and dry seasons. The water surface elevation decreases gradually and reaches the lowest in the fall. The Root Mean Square Error for given period of water surface elevation is $14 \mathrm{~cm}$.

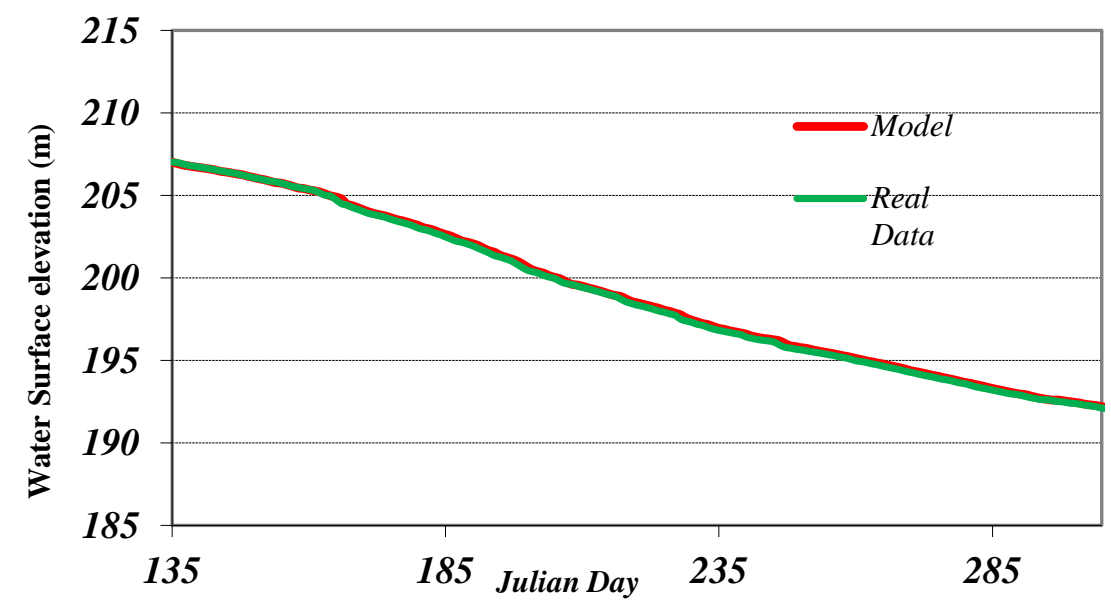

Figure 21.Water surface elevation predictions compared to observed data. 


\section{Automatic Calibration and Objective Function}

In the proposed study, model parameters are adjusted in order to achieve satisfactory agreement between the measured field data and the model predictions for temperature (T), chlorophyll a (chl a), dissolved oxygen (DO), $\mathrm{NH}_{4}-\mathrm{N}, \mathrm{NO}_{3}-\mathrm{N}$, and $\mathrm{PO}_{4}-\mathrm{P}$ concentrations in the Karkheh reservoir simultaneously. This satisfactory agreement can be expressed mathematically as:

$$
\begin{gathered}
\text { Minimize } F(\mathbf{X})=f_{T}{ }^{\prime} \times w_{T}+f_{D O}{ }^{\prime} \times w_{D O}+f_{C h l r} a^{\prime} \times w_{C h l r a} \\
+f_{P O 4}{ }^{\prime} \times w_{P O 4}+f_{N H 4}{ }^{\prime} \times w_{N H 4}+f_{N O 3}{ }^{\prime} \times w_{N O 3} \\
w_{T}+w_{D O}+w_{C h l r a}+w_{P O 4}+w_{N H 4}+w_{N O 3}=1 \\
\text { Subject to } \quad \mathrm{x}_{\text {low }}<\mathrm{x}<\mathrm{x}_{u p}
\end{gathered}
$$

Where, $F(\mathrm{X})$ is an objective function for all six normalized model state variables or decision variables; $\mathrm{w}$ is the weight (between 0 to 1 ) of all decision variables profile; $\mathbf{x}=$ $\left(x_{1}, x_{2}, \ldots, x_{D}\right)$ is the vector of decision variables or calibration parameters, and $\mathrm{D}$ is the number of parameters to be calibrated which is 17 in this research; $\mathbf{x}_{\text {low }}$ and $\mathbf{x}_{U P}$ are the lower bounds and upper bounds of the parameter sets.

The main objective of the proposed modeling is to select the most appropriate calibration parameters that is a unique vector, $\mathrm{X}$, which could minimize satisfactorily all objective functions simultaneously. In this study, the root mean square error (RMSE) represents the magnitude of prediction errors. In order to appropriately aggregate different errors from 
various variables in the formulation of an overall error function, these errors are normalized respectively to have same orders of magnitude and dimension. A general RMSE equation and normalization expression is given below applied in this research (Yongtai 2010):

$$
\begin{aligned}
R M S E & =f_{k}(\mathrm{X})=\sqrt[2]{\frac{\sum_{i=1}^{M}\left(c_{i k}-c^{*}{ }_{i k}\right)^{2}}{M}} \\
f_{k}(x)^{\prime} & =f_{k}(x) / \overline{c_{k}}
\end{aligned}
$$

Where, $f_{k}(\mathbf{x})$ represents the fitness function for each alternative combination of calibration parameters of vector $\mathrm{X}$ for variable $\mathrm{k} ; c^{*}{ }_{i k}$ is the $i^{\text {th }}$ field measurement of variable $\mathrm{k}(\mathrm{i}=1, \ldots, \mathrm{M}) ; c_{i k}$ is the simulated value corresponding to $c^{*}{ }_{i k} ; f_{k}(x)^{\prime}$ is the normalized dimensionless error functions; $\overline{c_{k}}$ is the average measurement for $\mathrm{K}^{\text {th }}$ variable; and $\mathrm{M}$ is the total number of measurements for variable $\mathrm{k}$. 


\section{Model Evaluation}

CE-QUAL-W2 is employed as a water quality and hydrodynamic simulation model. PSO is also run to produce a random generation of initial calibration parameters - particles and velocities in first swarm. In each iteration, model predictions of the state variables at different depths and segments are compared to field data on the monitoring day.

The overall objective function is evaluated by the summation of RMSE for each state variable. Whenever the number of iterations or a fitness criteria is satisfied, the simulationoptimization process is terminated. Otherwise, the PSO reproduces a new particle or a collection of new parameters for the CE-QUAL-W2 model based on PSO regulations and acceptable range of each parameters.

Then CE-QUAL-W2 is run with the new parameters to predict key water quality constituents and temperature. So in this approach, the simulation model (CE-QUAL-W2) is linked by the powerful optimization model (PSO) to overcome the high computational efforts in traditional calibration search techniques, while retaining the quality of the final calibration results. The flowchart in fig. 22 shows the steps in an automatic optimizationsimulation process. 


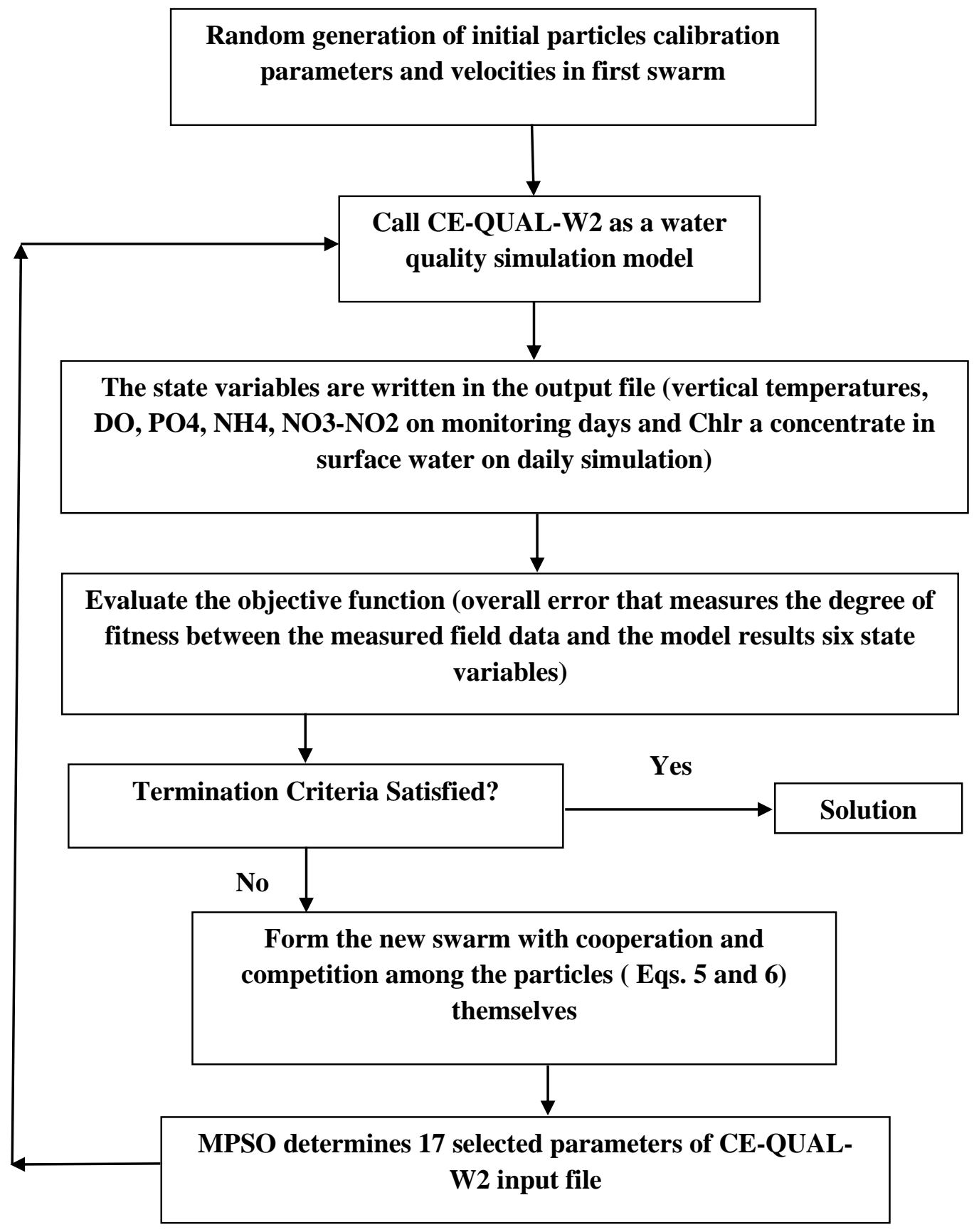

Figure 22. Flowchart of automatic calibration 
The applied measured field data were compared to model predictions between May and November 2005. In the proposed study, simulator model of Karkheh reservoir with 55 layers and 64 segments runs for 114 seconds on a CORE 7 duo CPU, 8 GB RAM, $3.7 \mathrm{GHz}$ computer to simulate this six month period. In this study, the 50 iterations with 30 particles is considered as a stopping criteria based on the running results of simulation-optimization procedure with different iteration values. Improvement of optimization results through different values of iteration is presented in fig. 23. The proposed simulation- optimization scheme achieves the best solution with 30 particles and 50 iterations after approximately 47 hours. The criterion for stopping would be also considered as a converging to the acceptable error. In this study, this criterion did not applied because the optimum value of objective function is not known.

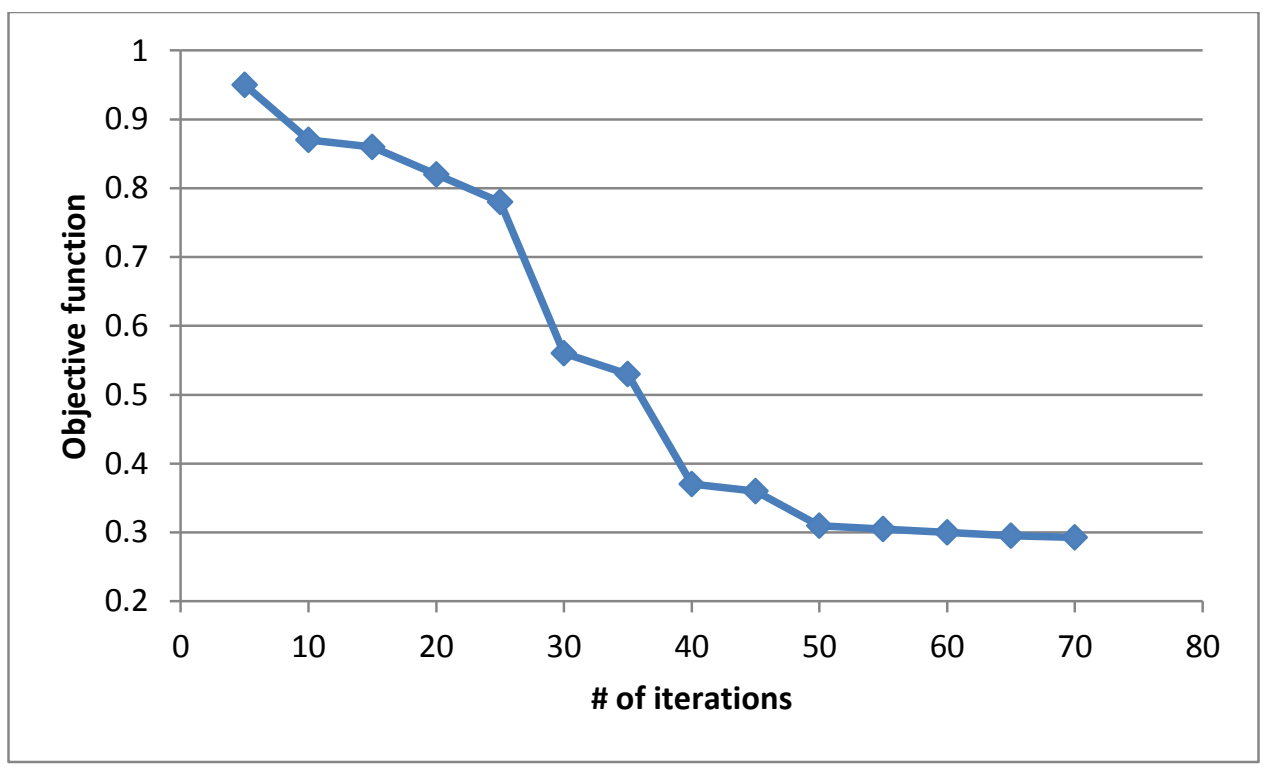

Figure 23. Improvement trend of objective function vs. increasing of calibration iteration values 


\section{Results and Discussion}

After calibration, water surface elevation is modified by changing the value of parameters related to temperature. The objective function (RMSE) of water surface elevation simulation of model after calibration is $9 \mathrm{~cm}$ which shows more agreement between model simulation and measured data after calibration (fig. 24).

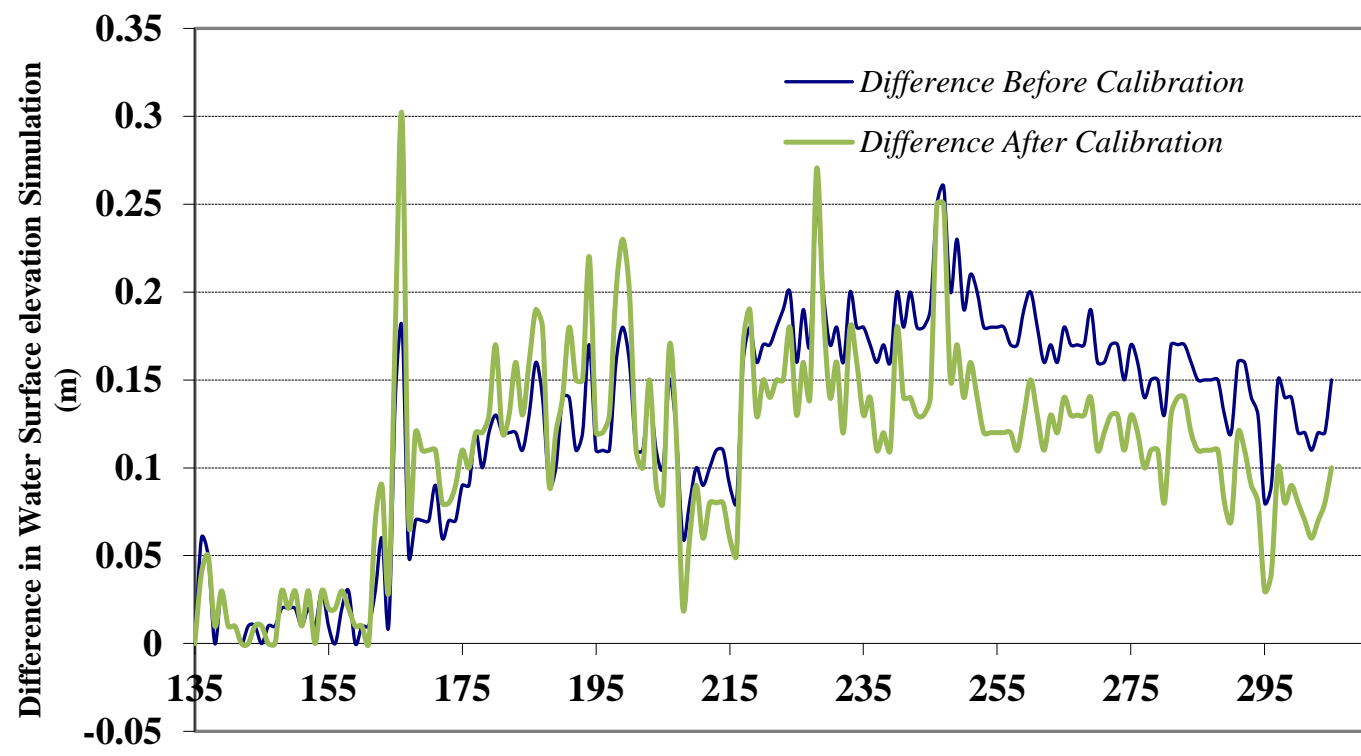

Julian Day

\section{Figure 24. Difference of water surface elevation predictions after calibration compared to before calibration}

Table 2 shows the resulted objective function for each month of six state variables after calibration. Final objective functions present automatic calibration lead to satisfying results for the calibration. Table 3 presents the calibrated value of parameters and their defined range in PSO. 
Table 2.Resulted objective functions of five state variables

\begin{tabular}{|c|c|c|c|c|c|}
\hline RMSE & TEMP ( & PO4 (mg/l) & NO3(mg/l) & NH4(mg/l) & DO(mg/l) \\
\hline May15, 2005 & 0.37902 & 0.00056 & 0.049772 & 0.088183 & 0.163033 \\
\hline July 2, 2005 & 0.598002 & 0.0763 & 0.1533 & 0.15992 & 0.52211 \\
\hline July25, 2005 & 0.722531 & 0.06016 & 0.47508 & 0.117226 & 0.4201 \\
\hline Aug15, 2005 & 0.6069 & 0.01038 & 0.1575 & 0.05191 & 0.5354 \\
\hline Sep. 4, 2005 & 0.52078 & 0.02235 & 0.2508 & 0.1444 & 0.4992 \\
\hline Oct. 2, 2005 & 0.41308 & 0.1406 & 0.2923 & 0.2796 & 0.8244 \\
\hline Average & $\mathbf{0 . 5 8 1 0 0 2}$ & $\mathbf{0 . 0 4 9 4 7 9}$ & $\mathbf{0 . 2 2 0 6 3 6}$ & $\mathbf{0 . 1 2 8 4 9 1}$ & $\mathbf{0 . 5 2 0 8 3 5}$ \\
\hline Nov. 1, 2005 & 0.8267 & 0.037 & 0.1735 & 0.0582 & 0.6816 \\
\hline
\end{tabular}

Samples of the observed and predicted thermal profiles at segment number 64 (near the dam) from May to November 2005 before and after calibration are presented in Fig. 25a and b. The calibrated model simulates vertical temperature profiles and the seasonal variation of temperature in the water column. It can be observed that the measured results and the simulated values after calibration match well. The difference of water temperature between the upper layers and lower layers was about $15^{\circ} \mathrm{C}$. 
Table 3. Calibrated value of parameters and their range

\begin{tabular}{|c|c|c|c|}
\hline $\begin{aligned} \text { Name in CE- } \\
\text { QUAL-W2 }\end{aligned}$ & Description & Range & $\begin{array}{l}\text { Calibrated } \\
\text { value }\end{array}$ \\
\hline EXH2O & $\begin{array}{l}\text { Solar radiation extinction coefficient for pure water, } \\
\qquad \mathrm{m}^{-1}\end{array}$ & $0.2-0.4$ & 0.22 \\
\hline WSC & $\begin{array}{l}\text { Wind sheltering coefficient for each segments of first } \\
\text { and last day of calibration }\end{array}$ & $0.7-1$ & $0.8,0.85$ \\
\hline BFW & B coefficient in the wind speed formulation & $0.45-0.7$ & 0.53 \\
\hline AG & Maximum algal growth rate day ${ }^{-1}$ & $0.1-4$ & 1.15 \\
\hline $\mathbf{A M}$ & Maximum algal mortality rate day ${ }^{-1}$ & $\begin{array}{c}0.01- \\
0.95\end{array}$ & 0.035 \\
\hline $\mathbf{A S}$ & Algal settling rate $\mathrm{m}$. day ${ }^{-1}$ & $0-7$ & 0.045 \\
\hline AHSN & Algal half-saturation for nitrogen limited growth, $\mathrm{g} \mathrm{m}^{3}$ & $\begin{array}{l}0.001- \\
0.05\end{array}$ & 0.026 \\
\hline AHSP & $\begin{array}{l}\text { Algal half-saturation for phosphorus limited } \\
\text { growth, } \mathrm{g} \mathrm{m}^{-3}\end{array}$ & $0.001-1$ & 0.01 \\
\hline ASAT & $\begin{array}{l}\text { Light saturation intensity at maximum photosynthetic } \\
\text { rate w. } \mathrm{m}^{-2}\end{array}$ & $10-100$ & 85 \\
\hline ACHL & Ratio between algal biomass and chlorophyll a & $0-1$ & 0.122 \\
\hline SED & Sediment decay rate & $0.1-1$ & 0.43 \\
\hline FSOD & $\begin{array}{l}\text { Fraction of the zero-order SOD (sediment oxygen } \\
\text { demand) rate used; }\end{array}$ & $0.01-2$ & 0.655 \\
\hline PO4R & $\begin{array}{l}\text { Sediment release rate of phosphorus under anaerobic } \\
\text { conditions; }\end{array}$ & $\begin{array}{c}0.001- \\
0.03\end{array}$ & 0.02 \\
\hline NH4R & $\begin{array}{l}\text { The sediment release rate of ammonium under } \\
\text { anaerobic conditions, specified as a fraction of SOD; }\end{array}$ & $\begin{array}{l}0.001- \\
0.4\end{array}$ & 0.01 \\
\hline NH4DK & Ammonium decay rate, day ${ }^{-1}$ & $\begin{array}{c}0.001- \\
0.8\end{array}$ & 0.265 \\
\hline NO3DK & Nitrate decay rate, day $^{-1}$; & $\begin{array}{l}0.05- \\
0.15\end{array}$ & 0.078 \\
\hline NO3S & Denitrification rate from sediments, mday $^{-1}$; & $0.01-2$ & 0.015 \\
\hline
\end{tabular}



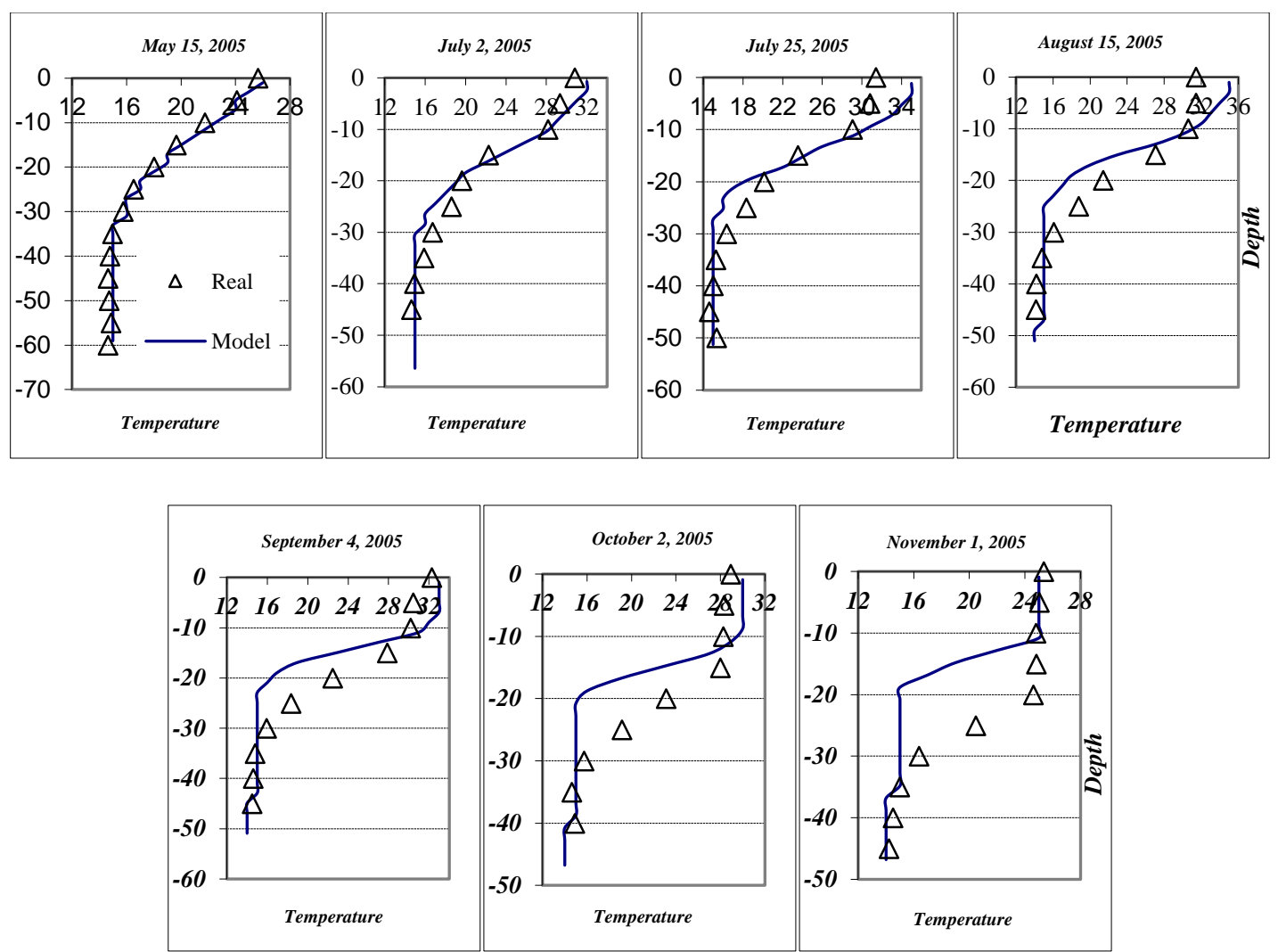

Figure 25 a. Temperature profiles compared to model predictions near the reservoir dam (Before Calibration)
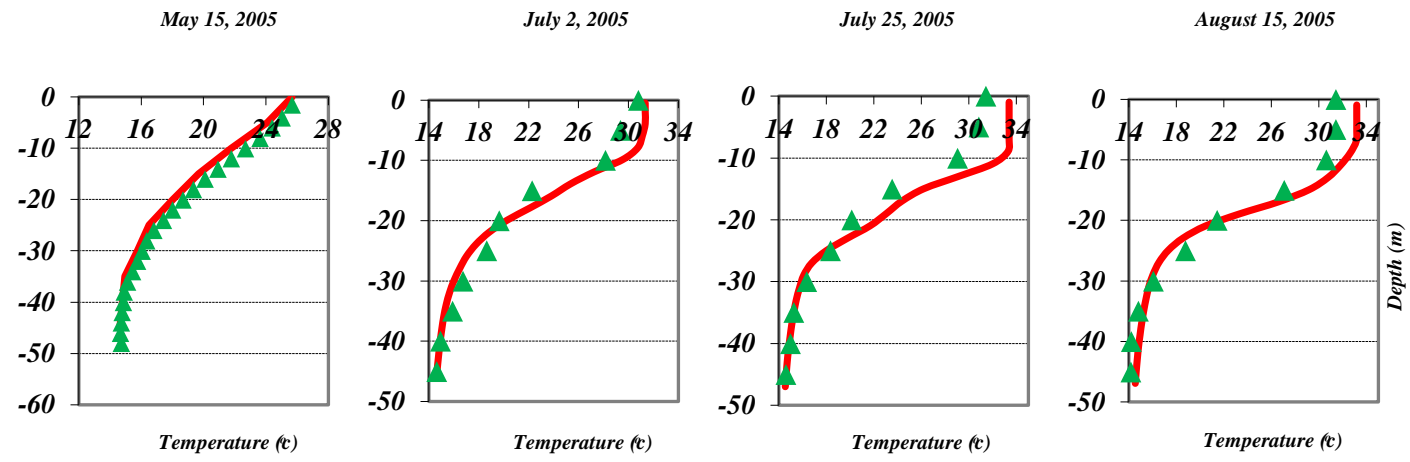


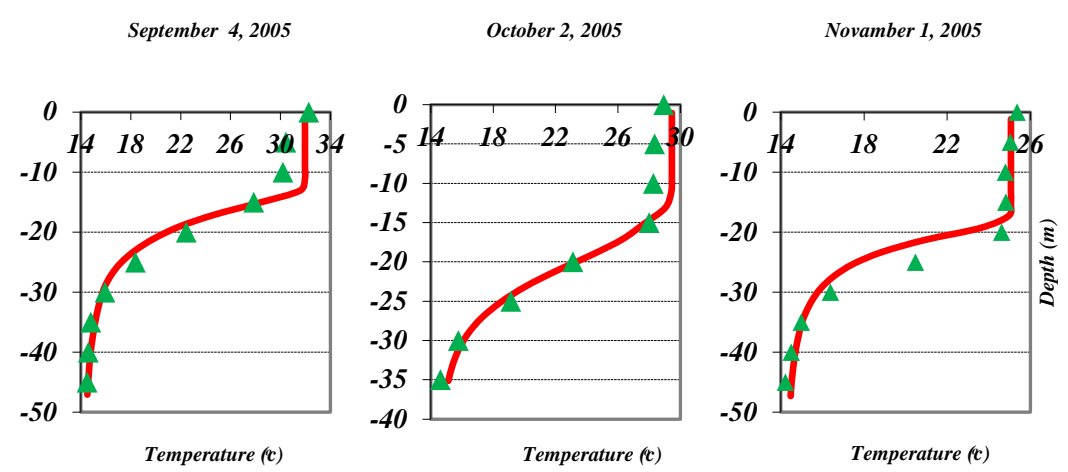

Figure 25 b. Temperature profiles compared to model predictions near the reservoir dam (After Calibration)

Figs. 26a and b show simulated and measured chlorophyll a before and after calibration at the surface. Chlorophyll a concentration approaches a peak during summer and then declines. Results after calibration show the reasonable agreement between measured and simulated after calibration. The Root Mean Square Error during given period of Chlorophyll a concentration in surface is $0.2311 \mu \mathrm{g} / \mathrm{L}$. Figure $27 \mathrm{a}$ and $\mathrm{b}$ present the snapshots of DO profiles at model segment 64 (near the dam). The seasonal variation of DO in the reservoir after calibration is well simulated and the model results match the DO data well. The algae photosynthesis process affects oxygen concentration in the system: higher concentration of algae in the system higher DO concentration in the water body. Since light penetration to the lower layer is limited, chlorophyll a oxygen production and DO concentration is reduced by increasing depth. 


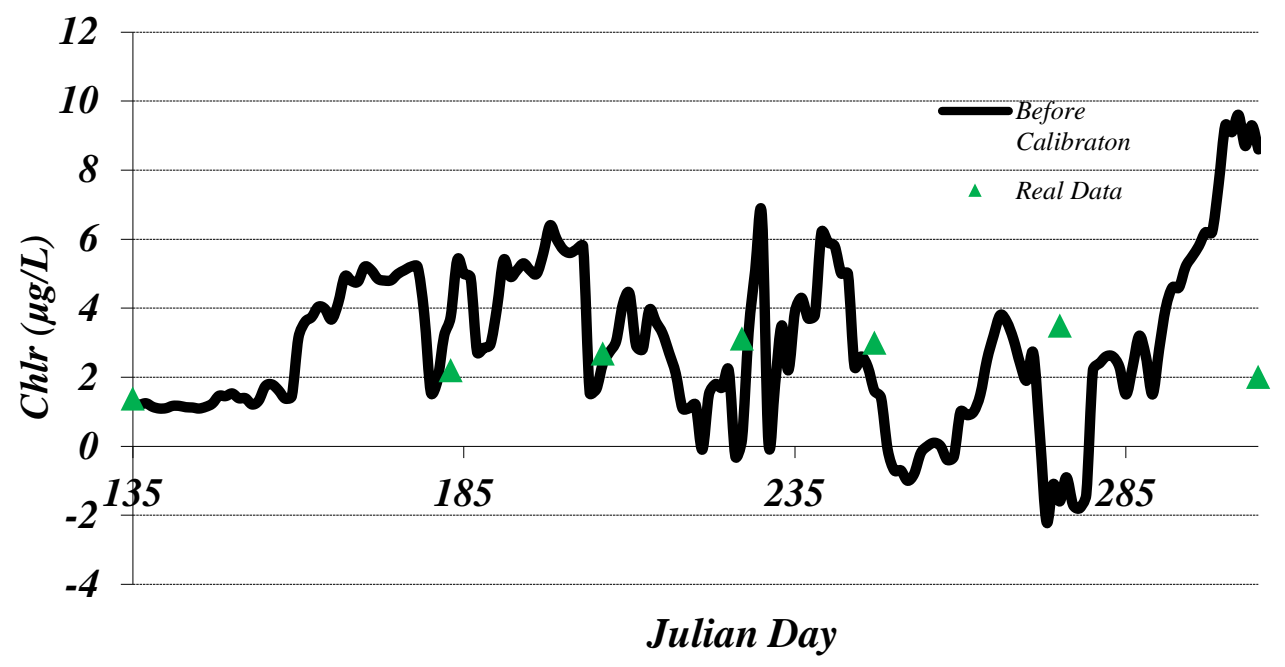

Figure 26 a. Comparing Chlr a simulation with observed data before calibration

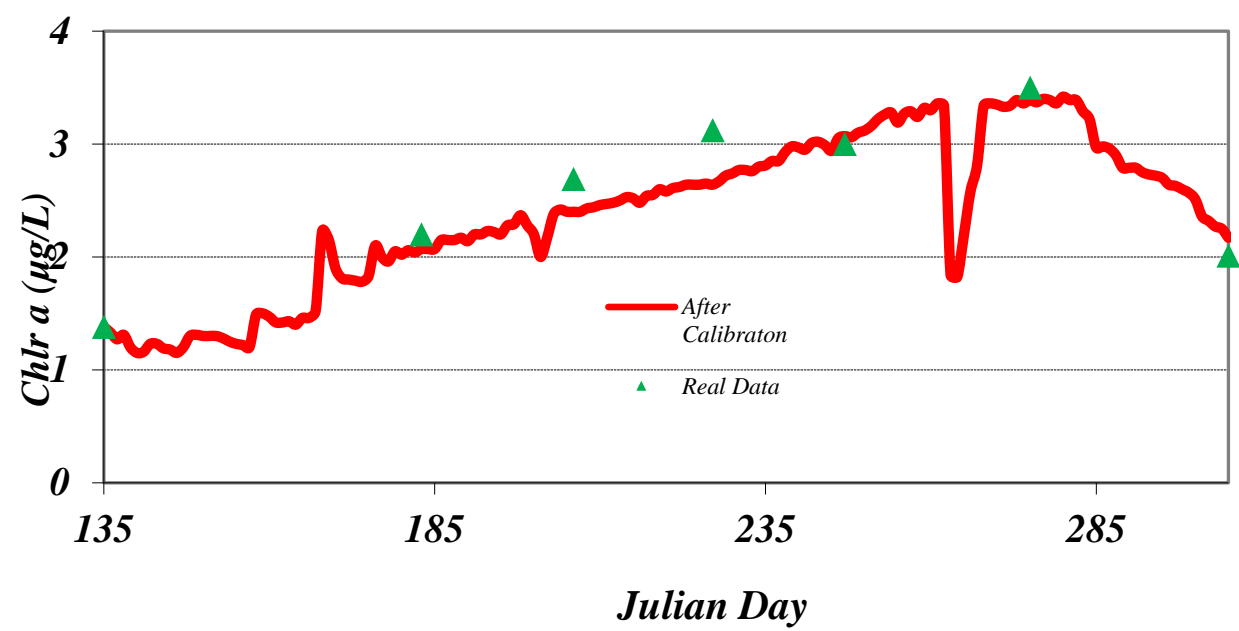

Figure 26 b. Comparing ChIr a simulation with observed data after calibration

The water quality results about $\mathrm{NH}_{4}, \mathrm{PO}_{4}$, and $\mathrm{NO}_{3}$ compared with field data at segment 64 (at dam site) are presented in Fig. 28 to 30, respectively. Dissolved orthophosphorus, ammonia, and nitrite/nitrate concentrations measured in the field are also well matched by the model results after calibration. 

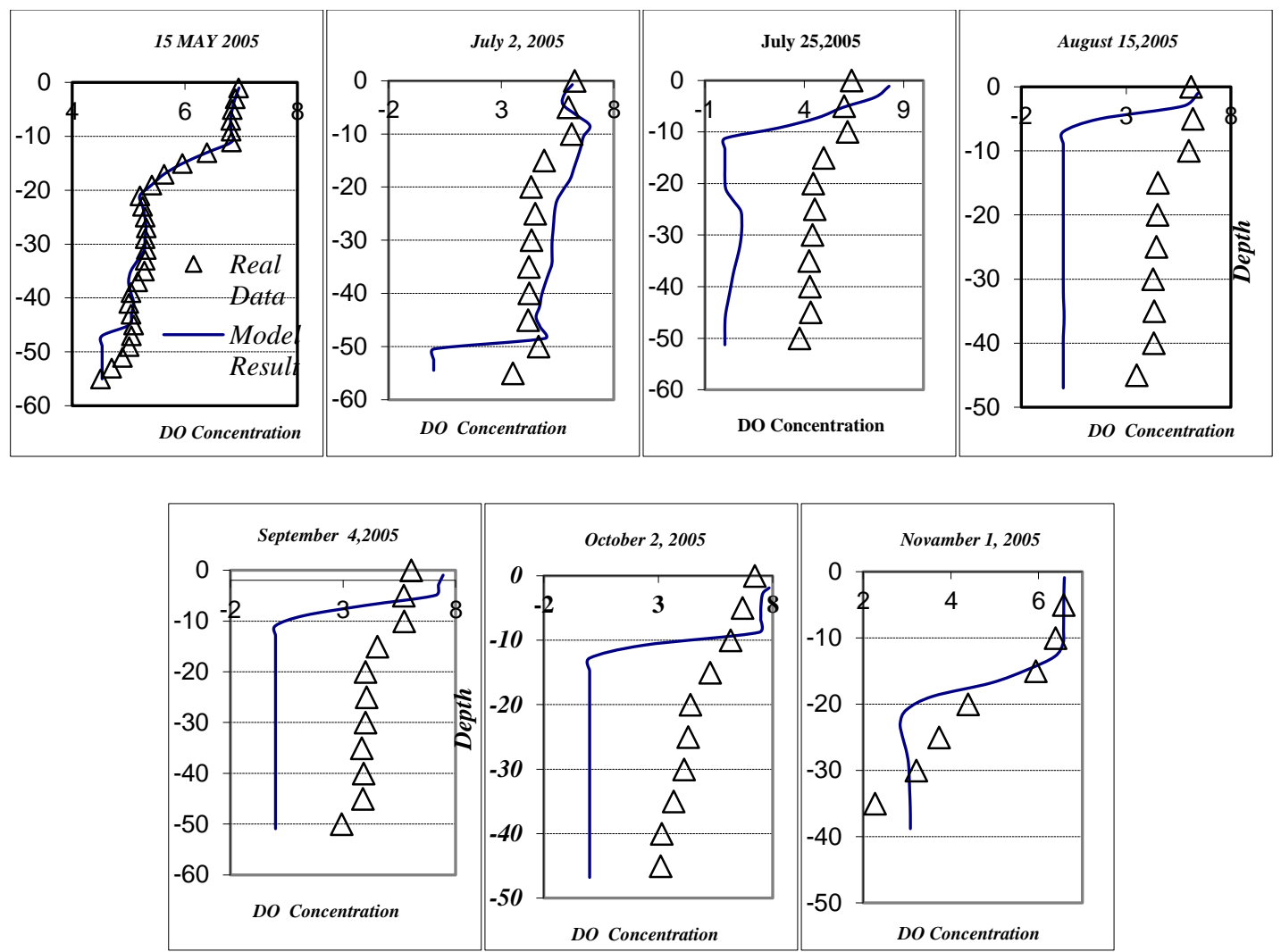

Figure 27 a. Comparing DO simulation with observed data before calibration
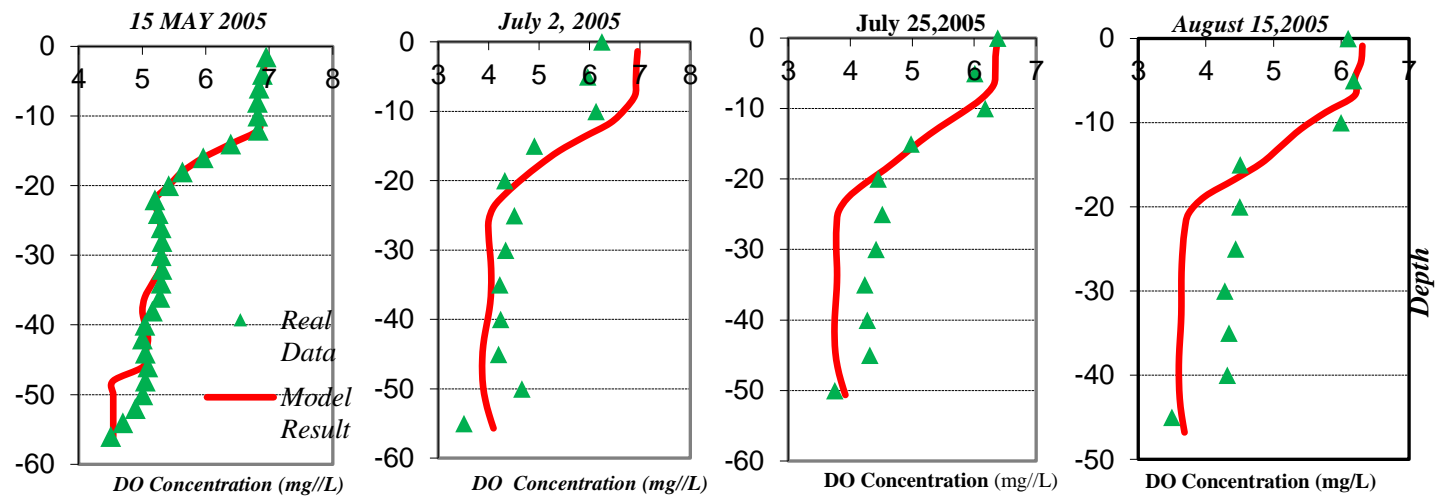

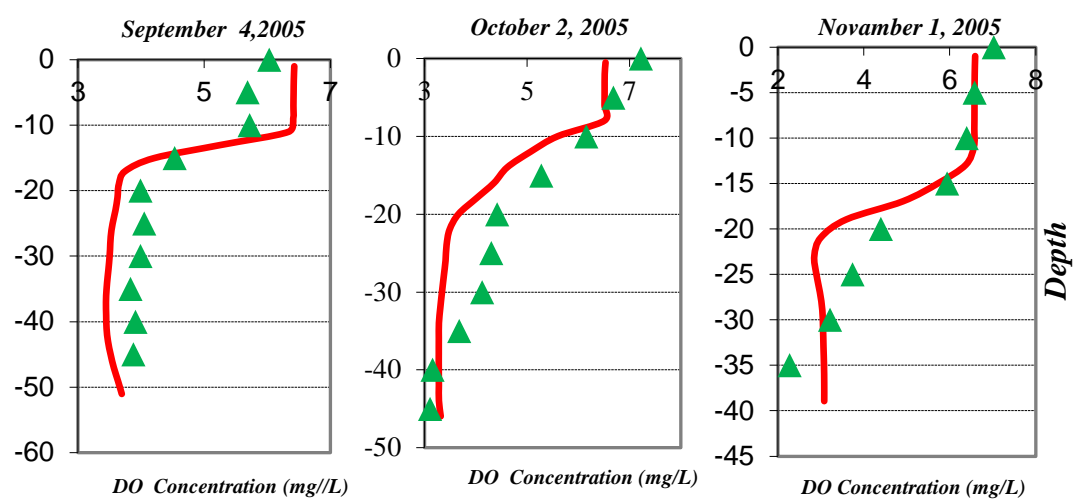

Figure 27 b. Comparing DO simulation with observed data after calibration
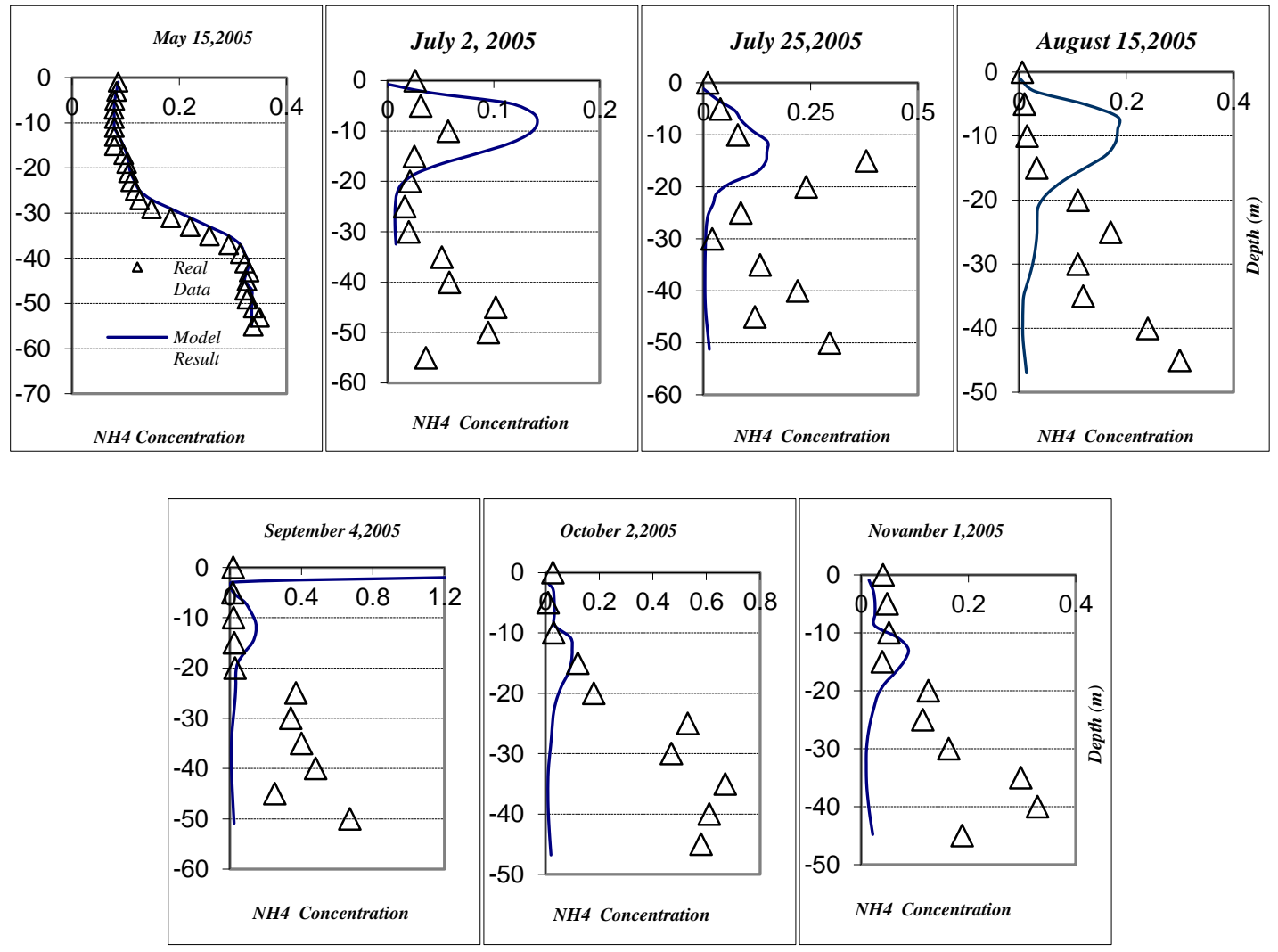

Figure 28 a. Comparing NH4 simulation with observed data before calibration 

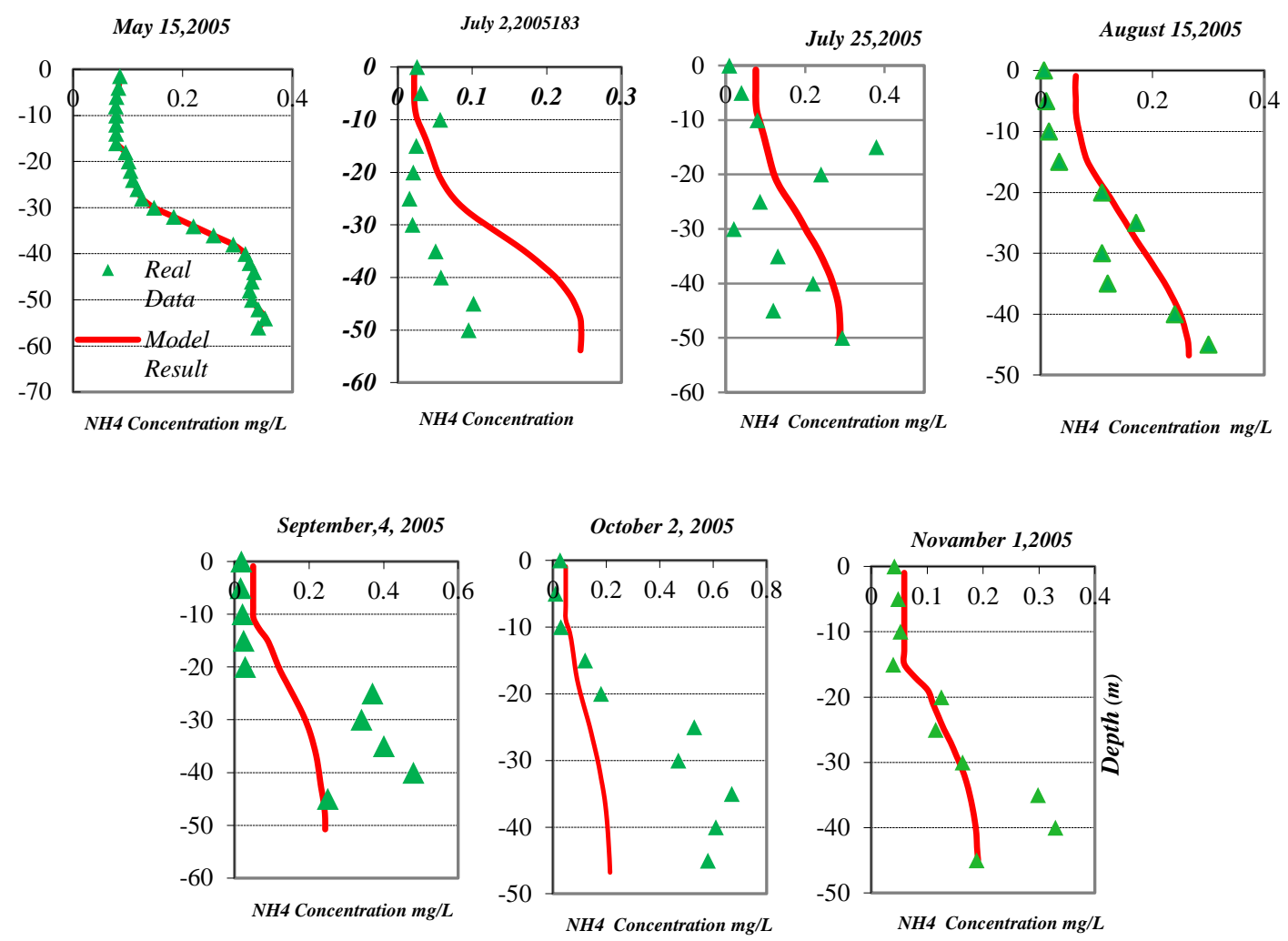

Figure 28 b. Comparing NH4 simulation with observed data after calibration
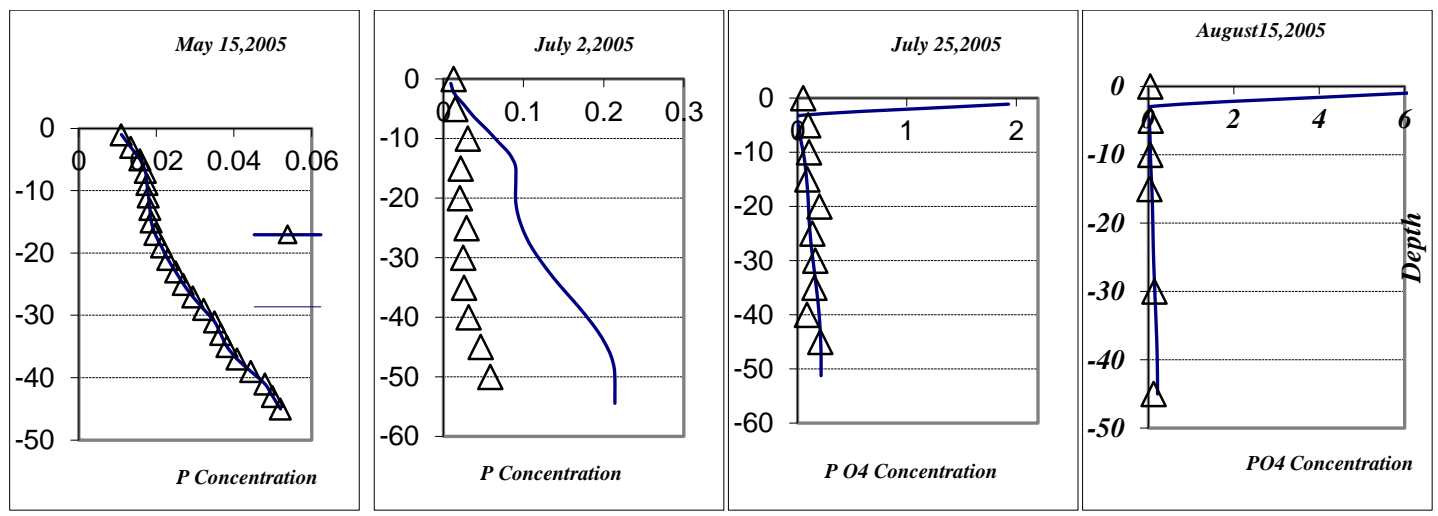


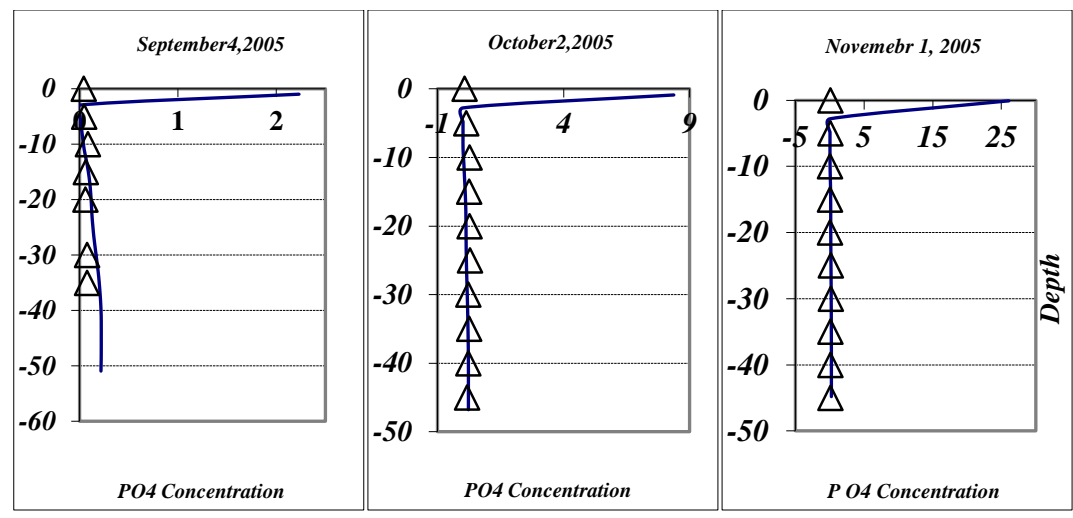

Figure 29 a. Comparing PO4 simulation with observed data before calibration
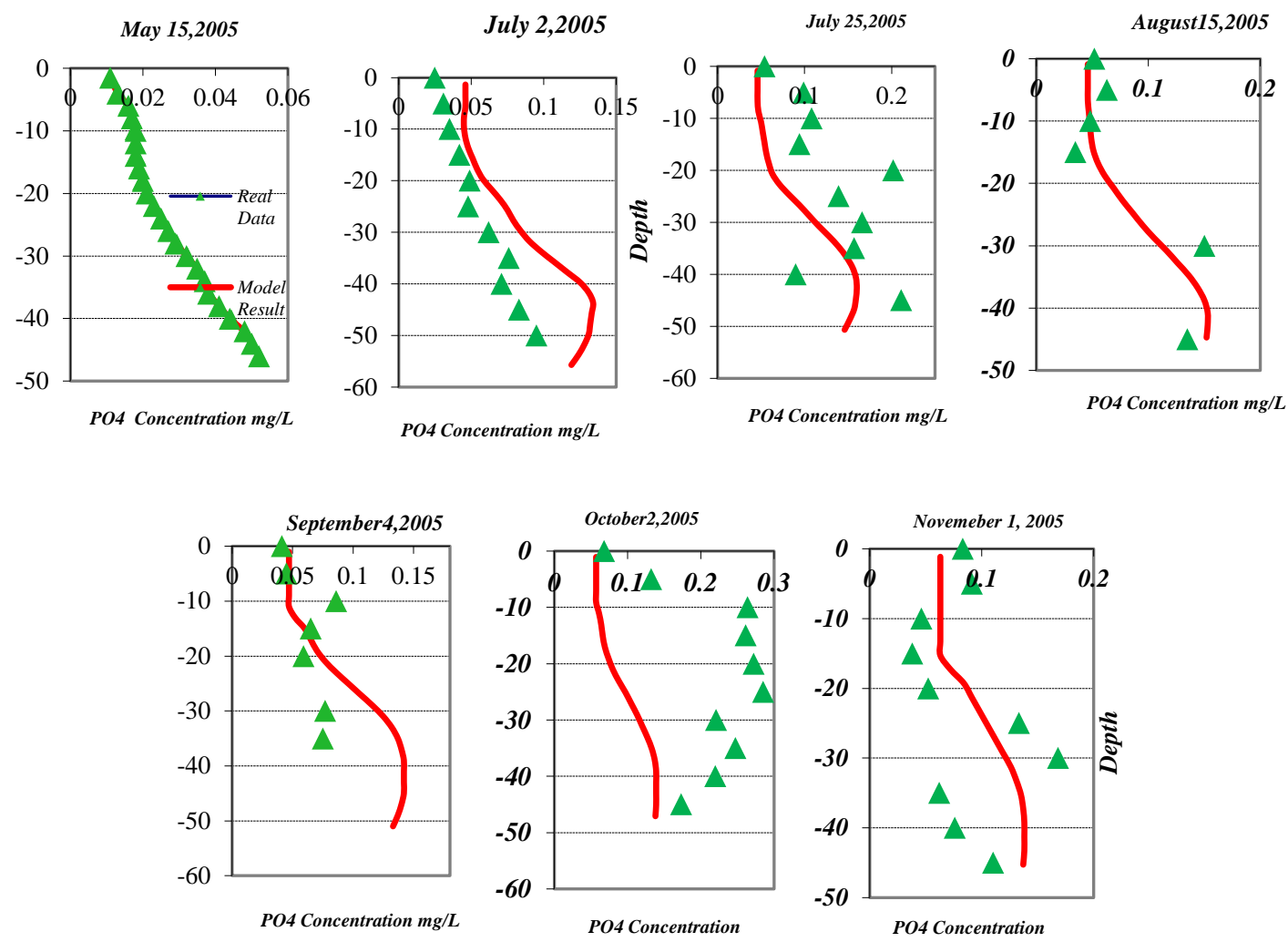

Figure 29 b. Comparing PO4 simulation with observed data after calibration 

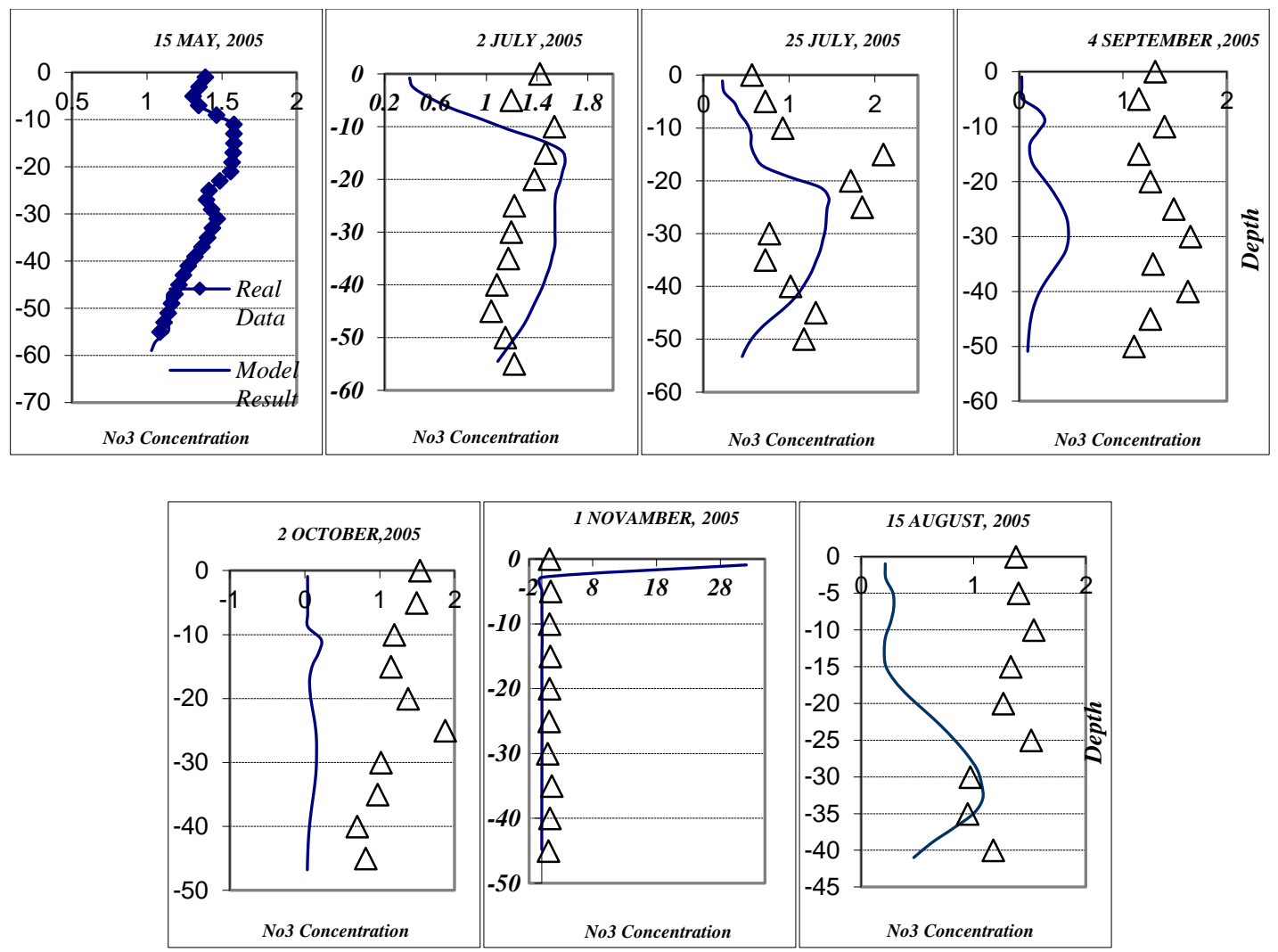

Figure 30 a. Comparing NO3-NO2 simulation with observed data before calibration
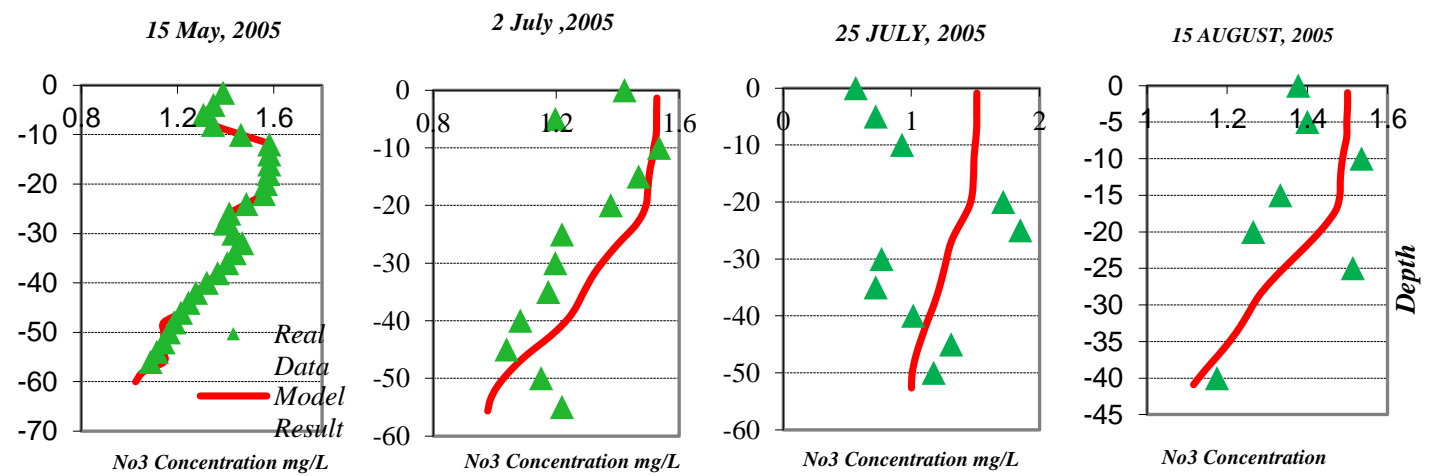

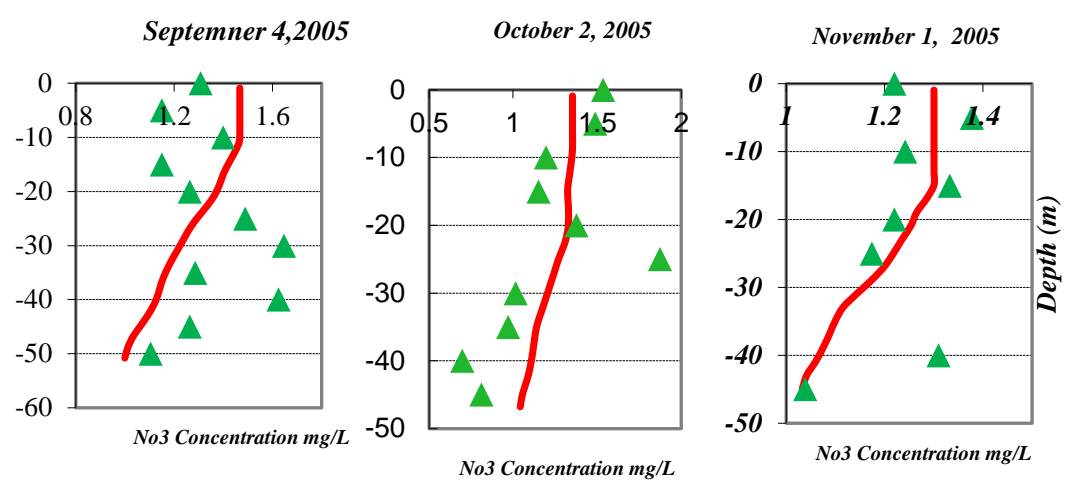

Figure 30 b. Comparing NO3-NO2 simulation with observed data after calibration

\subsection{Various weighting factor}

To explore the effect of weighting factors and also to improve the objective function related to ammonium and phosphate, the higher weighting factor is assigned to ammonium and phosphate than others. Table 4 shows the results of dimensionless average of objective function of six state variables for seven months with two different weighting factors. The objective function corresponded to ammonium and phosphate reduced by around $25 \%$ and the objective function of others increased by around $15 \%$ which is not that much significant. The new combination of weighting factors has led to more appropriate agreement between model and field data.

Table 4. The objective function and corresponded weighting factors

\begin{tabular}{|c|c|c|c|c|c|c|}
\hline Weight/ RMSE & TEMP & PO4 & NO3 & NH4 & DO & ChIr a \\
\hline Weight & $1 / 6$ & $1 / 6$ & $1 / 6$ & $1 / 6$ & $1 / 6$ & $1 / 6$ \\
\hline Model 1 RMSE & 0.088 & 0.65 & 0.19 & 0.73 & 0.12 & 0.03 \\
\hline Weight & $1 / 12$ & $1 / 3$ & $1 / 12$ & $1 / 3$ & $1 / 12$ & $1 / 12$ \\
\hline Model 2 RMSE & 0.101 & 0.48 & 0.209 & 0.55 & 0.136 & 0.035 \\
\hline
\end{tabular}


The vertical profile of temperature, Phosphate, Ammonium, Nitrite/ Nitrate, Dissolved oxygen and also chl a vs. time for one day of simulation are presented in fig. 31 . Based on figure below, it is clear that model 2 has predicted phosphate and ammonium with higher agreement with field data. So, we can set weighting factor of each state variable based on the importance degree of that state variable to receive better result about that one.
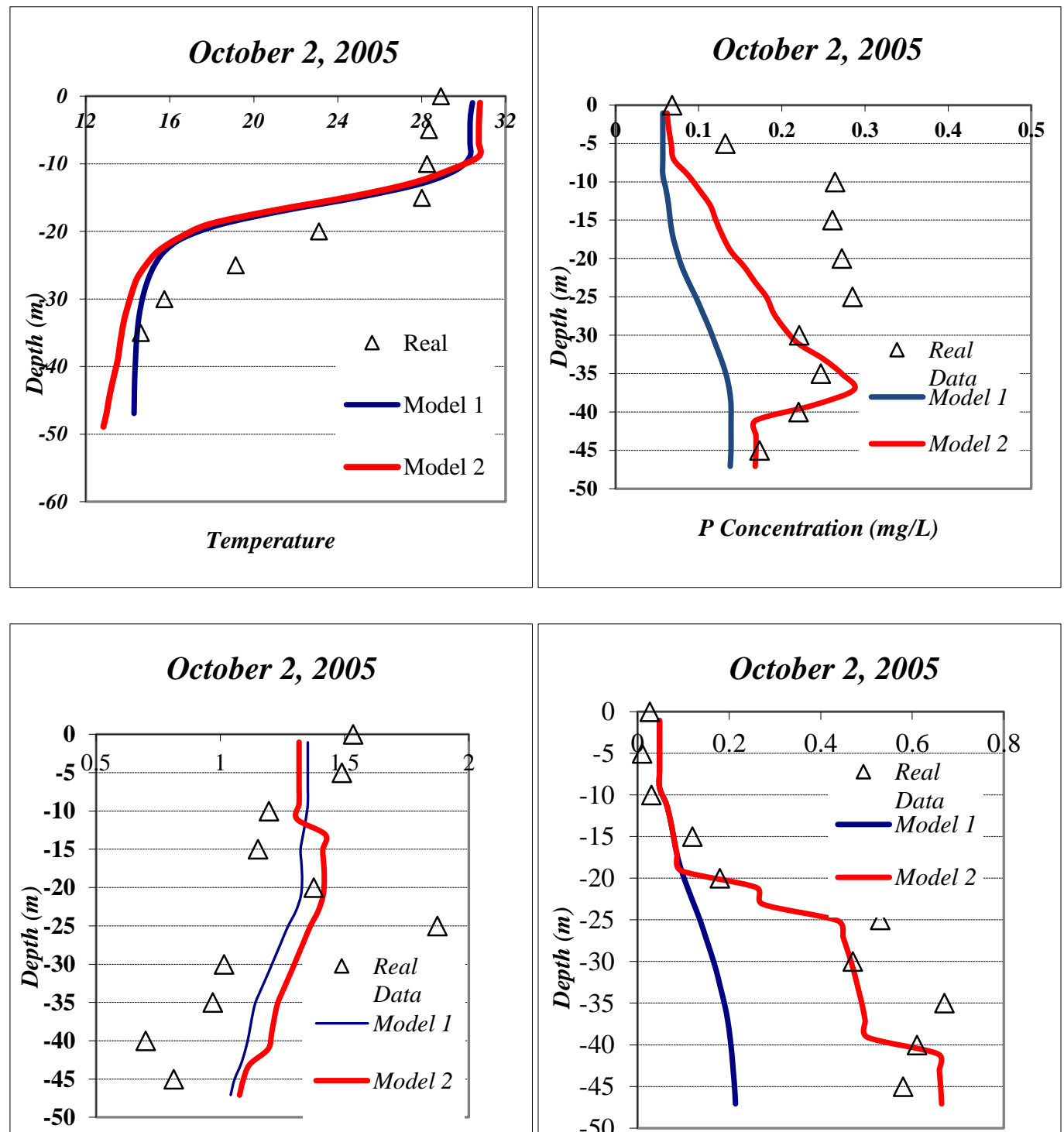

No3 Concentration $(\mathrm{mg} / \mathrm{l})$

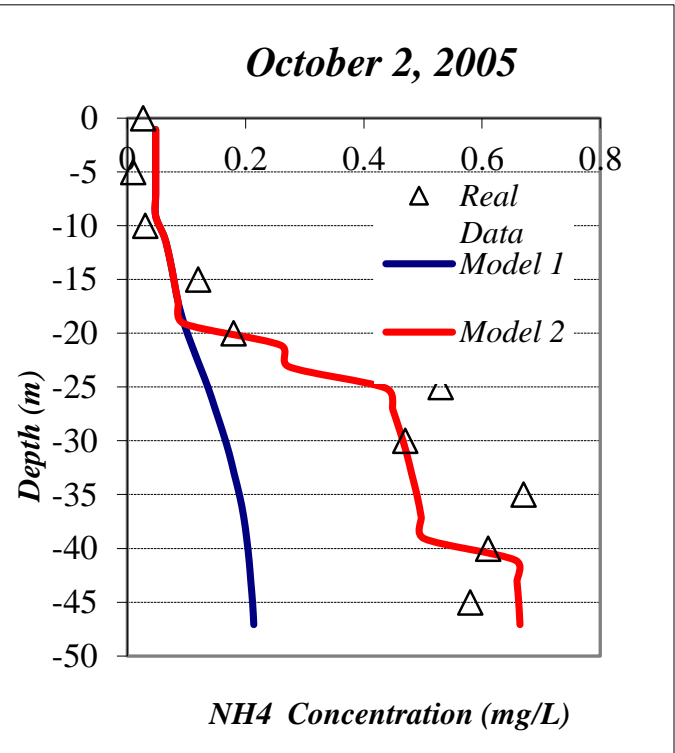



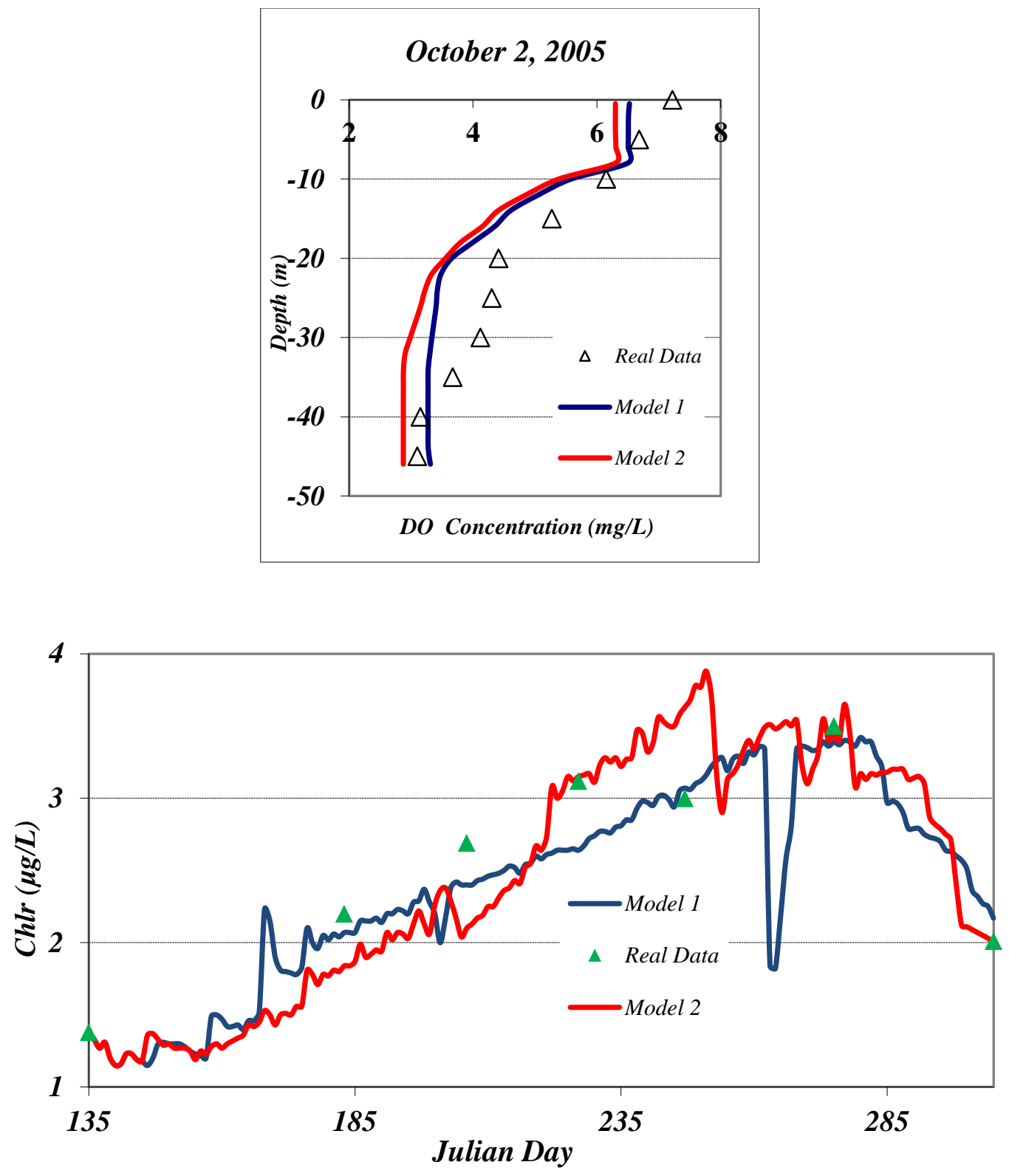

Figure 31. Comparing all state variables profile of model 1 and 2 


\section{Summary and Conclusions}

The two-dimensional hydrodynamic and water quality model, CE-QUAL-W2, (Cole and Wells, 2013) was configured for the Karkheh Reservoir in Iran. The model was calibrated with an automatic multi-objective particle swarm optimization algorithm using field data from May to November 2005. The resulted overall dimensionless objective function was 0.3 in this study. By using the parameter set from the optimization model, comparisons of model predictions to field data for temperature, chlorophyll a, dissolved oxygen and nutrients showed that the algorithm converged on a set of model parameters that led to reasonable agreement between field data and model predictions.

In comparison to the most similar and recent research, Yongtai Huang and Lei Liu (2010) calibrated water quality model (CE-QUAL-W2) of Lake Maumelle in central Arkansas with Hybrid Genetic Algorithm and Neural Network Approach for temperature and concentrations of DO, ammonium ( $\mathrm{NH} 4)$, nitrate plus nitrite $(\mathrm{NO} 3+\mathrm{NO} 2), \mathrm{TP}$, and chlorophyll a (Chla). After 2000 iterations, they achieved the best solution with the average dimensionless objective function of 0.5 for the same six state variables that is two times higher than the average dimensionless objective function of the best solution $(\mathrm{F}(\mathrm{x})=0.3)$ achieved in the proposed study. This comparison can give us an idea that how the proposed method was successful in finding the accurate parameter and decreasing time consumed in optimization. However, the judgment would be more reasonable if comparison was done by different method but the same case study and same data. 
Once the model is calibrated, the model can then be used to forecast strategies to improve water quality. Since phosphorus has been determined as the limiting nutrient (Kuo et al., 2006), to improve water quality in the reservoir, phosphorus loads should be controlled. Since the majority of the nutrients reaching the Karkheh Reservoir are from agriculture in the watershed, the model can then be used to forecast the effect of applying proper agricultural and soil conservation management techniques in the watershed. The proposed simulation- optimization scheme achieves the best solution with 1500 iterations. The CEQUAL-W2 model of Karkheh reservoir can be converted to a model with 6 or 7 branches. So, calibration results of a simple model vs. a complex model can be investigated in the terms of time efficiency and accuracy in the further steps.

As mentioned previously, the accuracy of calibration results of Karkheh Reservoir model is highly dependent on initial condition. So using field data of other months or even model of other water bodies as a new bench mark can be led to the more fairly judgment about the performance of proposed optimization method in the calibration of water quality and hydrodynamic model.

This procedure also can be applied in multi-site simulation calibration process if data be available for other monitoring sites. It can be helpful to make sure calibration procedure is done uniformly in whole water body. For simultaneous multi-site automatic calibration, two types of calibration methods can be applied; finding the weighted summation of objective function values calculated at each monitoring site which is the single-objective optimization method or using multi-objective evolutionary algorithms to optimize the 
different objective functions calculated at multiple sites simultaneously, and finding a set of multiple Pareto optimal solutions.

Using single objective optimization method can lead to bias of the objective function value at one site when optimizing objective function values at other sites. On the other hand, by using the multi-objective optimization method, we encounter several objective function values at each monitoring site. Therefore, the use of multi-site observed data to evaluate model performance deserves further research in the future. 


\section{References}

Afshar, A., Kazemi, H., and Saadatpour, M. (2011). "Particle Swarm Optimization for Automatic Calibration of Large Scale Water Quality Model (CE-QUALW2):Application to Karkheh Reservoir, Iran," J. of Water Resource Management, 25,452-474.

Afshar, A., and Saadatpour, M. (2009b). "Reservoir eutrophication modelling, sensitivity analysis, and assessment; application to Karkheh Reservoir, Iran.” J. Environ. Eng. Sci., 26(7), 1227-1238.

Ahmad, M. and Giordano, M. (2010). "CPWF Project Report, Karkheh Basin Focal Project, Project Number 57” International Water Management Institute.

Auer, M. T., M.T.; Johnson, N. A., Penn, M. R. and Effler, S. (1993). "Measurement and verification of rates of sediment phosphorus release for a hypereutrophic urban lake. Hydrobiologia", Vol. 253, 1-3.

Baker T, Dycus D (2004) Use of monitoring information to identify and implement water quality improvement. In: National monitoring conference, Chattanooga, TN, 17-20 May

Beutel, M. (2006) "Inhibition of ammonia release from anoxic profundal sediments in lakes using hypolimnetic oxygenation”. doi:10.1016/j.ecoleng.2006.05.009.

Bowles, D.S.; Grenney, W.J. (1978) "Steady state river quality modeling by sequential extended Kalman filters" Water Resources Research, 14 (1): 84-96.

Bozorg Haddad, O., Afshar, A., and Mariño, M.A. (2006). "Honey-bees mating optimization (HBMO) algorithm: a new heuristic approach for water resources optimization.” Water Resour. Manag. 20(5), 661-680.

Chang, F.J., Chen, L., and Chang, L.C. (2005). “Optimizing the reservoir operating rule curves by genetic algorithms”. Hydrol Process, 19(11), 2277-89.

Chung, S.W., Oh, J.K., 2006. Calibration of CE-QUAL-W2 for a monomictic reservoir in monsoon climate area. Water Sci. Technol. 54 (12), 1291e1298

Cooper, V.A.; Nguyen V.T.V.; Nicell, J.A. (1997) "Evaluation of global optimization methods for conceptual rainfall-runoff model calibration." Water Science and Technology, 36 (5): 53-60.

Cole, T.M., Wells S.A. (2013). "CE-QUAL- W2: A Two-Dimensional, Laterally Averaged, Hydrodynamic and Water Quality Model, Version 3.7.1" Department of 
Civil and Environmental Engineering, Portland State University, Portland, OR. http://www.cee.pdx.edu/w2/.

Clerc, M., \& Kennedy, J. (2002). "The particle swarm-explosion, stability, and convergence in a multidimensional complex space." IEEE Transaction on Evolutionary Computation, 6(1), 58-73.

Deb K. (1990) "Multi-Objective Genetic Algorithms: Problem Difficulties and Construction of Test Problems". Evolutionary Computation, 7(3):205-230.

Diogo, P.A., Fonseca, M., and Coelho, P.S. (2008). "Mateus NS, Almeida MC, Rodrigues AC. Reservoir phosphorous sources evaluation and water quality modeling in a trans boundry watershed." Desalination, 200-226.

Diogo, P.A., Fonseca, M., and Coelho, P.S. (2008). "Mateus NS, Almeida MC, Rodrigues AC. Reservoir phosphorous sources evaluation and water quality modeling in a trans boundry watershed.” Desalination, 200-226.

Eberhart, R.C. and Kennedy, J. (1995). “A New Optimizer using Particle Swarm Theory.” Proceedings Sixth Symposium on Micro Machine and Human Science, IEEE Service Center, Piscataway, NJ, 39-43.

Eberhart, R. C., \& Shi, Y. (2000)."Comparing inertia weights and constriction factors in particle swarm ptimization." In Proceedings of the IEEE congress on evolutionary computation (CEC) (pp. 84-88), San Diego, CA. Piscataway: IEEE.

Eberhart, R. C., \& Shi, Y. (2001). "Tracking and optimizing dynamic systems with particle swarms." In Proceedings of the IEEE congress on evolutionary computation (CEC) (pp. 94-100), Seoul, Korea. Piscataway: IEEE.

Etemad-Shahidi A, Afshar A, Alikia H, Moshfeghi H (2009) Total dissolved solid modeling; Karkheh reservoir case example. Int J Environ Res 3:671-680

EPA 1985. Rates, Constants and Kinetics in Surface Water Quality Modeling, Environmental Research Laboratory, EPA/600/3-85/040, Athens, Ga.

Gelda RK, Effler SW (2007) Testing and application of a two-dimensional hydrothermal model for a water supply reservoir: implication of sedimentation. Environ Eng Sci 6:73-84 
Goldberg, D.E. (1989) "Genetic algorithms in search, optimization and machine learning." Massachusetts: Addison Wesley Longman.

Hayes, D.F., Labadie, J.W., Sanders, T.G., and Brown, J.K. (1998). "Enhancing water quality in hydropower system operations", Water Resource Res. 34, 471.

Heppner, F. and U. Grenander (1990). "A stochastic nonlinear model for coordinated bird flocks.” In S. Krasner, Ed., The Ubiquity of Chaos. AAAS Publications, Washington, DC.

Iran Water and Power Company (2006) "Technical and research report, phase I, reservoir eutrophication, modelling and management; application to Karkheh Reservoir."

Isazadeh, S., Tajrish, M., Abrishamchi, A., and Ahmadi, M. (2005). "Application of phosphorous simulation models to latian reservoir." Water and waste water 54,316.

Izquierdo, J., Montalvo i., Pérez r., Tavera M., (2008). "Optimization in water systems: a PSO approach." In Proc. 2008 Spring simulation multi conference, Ottawa, Canada, 239-246.

James, William F. ; Berko, John W. ; Eakin, Harry L. (1995). "Phosphorus Loading in Lake Pepin (Minnesota-Wisconsin)." Final report ADA304855. Army Engineer Waterways Experiment Station, Vicksburg MS.

Karamouz, M., Ahmadi, A., and Moridi, A., (2009). "Probabilistic reservoir operation using Bayesian stochastic model and support vector machine." Adv. Water Resour., 32, 1588-600.

Kim, Lee-Hyung; Choi, Euiso; Gil, Kyung-Ik; and Stenstrom, M. K.. (2004). "Phosphorus release rates from sediments and pollutant characteristics in Han River, Seoul, Korea.” doi:10.1016/j.scitotenv.2003.08.018.

Kuo, J.T., Wang, Y.Y., and Lung, W.S. (2006). "A hybrid neural-genetic algorithm for reservoir water quality management." Water Research, 40, 1367-1376.

Little, K.W.; Williams, R.E. (1992) "Least-squares calibration of QUAL2E." Water Environment Research, 64 (2): 179-185. 
Liu WC, Chen WB, Kimura N (2008) Impact of phosphorus load reduction on water quality in a stratified reservoir-eutrophication modeling study. Environ Monit Assess 159:393-406

Mahinthakumar, G. and Sayeed, M. (2005) " Hybrid Genetic Algorithm- Local Search Methods for Solving Graoundwater Source Identification Inverse Problems.” J. Water Resource Planning Manage, 131(1), 45-57.

Mulligan, A.E.; Brown, L.C. (1998) "Genetic Algorithms for Calibrating Water Quality Models.” Journal of Environmental Engineering, 124 (3): 202-211.

Nielsen EJ (2005) Algal succession and nutrient dynamics in elephant butte reservoir. M.Sc. thesis, Brigham Young University

Poli R.,Kennedy J., Blackwell T., (2007) "Particle swarm optimization , An overview,Swarm Intell," Swarm Intell 1: 33-57

Reynolds, C. W. (1987) "Flocks, herds and schools: a distributed behavioral model." Computer Graphics, 21(4):25-34.

Sen, S., Haggard, B.E., Chaubey, I., Brye, K.R., Matlock, M.D., Costello, T.A. (2004) "Preliminary estimation of sediment phosphorus flux in Beaver Lake, Northwest Arkansas." In: Proceedings of American Society of Agricultural Engineers, August 1-4, 2004, Ottawa, Ontario, Canada. 2004 CDROM.

Schindler, D.W. (1971) "Food Quality and Zooplankton Nutrition", J. of Animal Ecology, Vol 40, pp 598-595.

Schindler, D.W., et al. (1973) "Eutrophication of Lake 227 by Addition of Phosphate and Nitrate: The Second, Third and Fourth Years of Enrichment, 1970, 1971, 1972", J. of the Fisheries Research Board of Canada, Vol 30, pp 1415-1428.

Shi, Y., \& Eberhart, R. C. (1998b). “A modified particle swarm optimizer.” In Proceedings of the IEEE international conference on evolutionary computation (pp. 69-73). Piscataway: IEEE. 
Shourian M, Mousavi SJ, Tahershamsi A (2008) Basin-wide water resources planning by integrating PSO algorithm and MODSIM. Water Resour Manage 22:1347-1366

Spears, Bryan M.; Carvalho, Laurence; Perkins, Rupert; Kirika, Alex; Paterson, David M.. (2007) "Sediment phosphorus cycling in a large shallow lake: spatio-temporal variation in phosphorus pools and release." Hydrobiologia, 584. 37-48. doi:10.1007/s10750007-0610-0

Sullivan, A.B., and Rounds, S.A. (2005). "Modeling hydrodynamics, T, and water quality in Henry Hagg Lake, Oregon 2000-3." http://pubs.usgs.gov/sir/2004/5261

Van Griensven, A.; Francos, A.; Bauwens, W. (2002) "Sensitivity analysis and autocalibration of an integral dynamic model for river water quality." Water Science and Technology, 43 (7): 321-328.

Van Griensven, A.; Bauwens, W. (2001) "Integral water quality modeling of catchments." Water Science and Technology, 43 (7): 321-328.

Vollenweider, R.A. (1968) "Scientific Fundamentals of the Eutrophication of Lakes and Flowing Waters, with Particular Reference to Nitrogen and Phosphorus as Factors in Eutrophication", Tech. Rept. OECD, DAS/CSI/68.27, Paris, France.

Wood, D.M.; Houck, M.H.; Bell, J.M. (1990) “Automated calibration and use of a streamquality simulation model.” Journal of Environmental Engineering, 116 (2): 236-249.

Wilson, E.O. (1975). “Sociobiology: The new synthesis." Cambridge, MA: Belknap Press.

Yih, S.M.; Davidson, B. (1975) "Identification in nonlinear, distributed parameter water quality models." Water Resources Research, 11 (5): 693-704.

Yongtai H, Lei L (2010) Multiobjective water quality model calibration using a hybrid genetic algorithm and neural network-based approach. J Environ Eng 136(10):10201031

Zheng, Y.-L., Ma, L.-H., Zhang, L.-Y., \& Qian, J.-X. (2003). "On the convergence analysis and parameter selection in particle swarm optimization." In Proceedings of the IEEE 
international conference on machine learning and cybernetics (pp. 1802-1807). Piscataway: IEEE. 


\section{Appendix A}

Control File of CE-QUAL-W2 model of Karkheh Reservoir:

PSU W2 Model Version 3.7

TITLE C TITLE

Karkhe River

Water Quality Simulation

Default hydraulic coefficients

Default light absorption/extinction coefficients

Temperature simulation

Eutrophician study

The Data was provided by Ab-Niroo

Simuldation was done during Ordibehesht until Azar

$1384 / 2 / 27$ or 2005

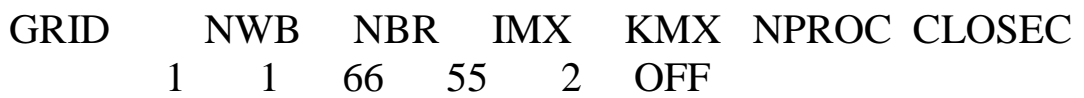

IN/OUTFL NTR NST NIW NWD NGT NSP NPI NPU

$\begin{array}{llllllll}0 & 2 & 0 & 1 & 0 & 1 & 0 & 0\end{array}$

CONSTITU NGC NSS NAL NEP NBOD NMC NZP

$\begin{array}{lllllll}0 & 1 & 1 & 0 & 1 & 0 & 0\end{array}$

MISCELL NDAY SELECTC HABTATC ENVIRPC AERATEC INITUWL

171 OFF OFF OFF OFF OFF

TIME CON TMSTRT TMEND YEAR

$135.000305 .000 \quad 2005$

DLT CON NDT DLTMIN DLTINTR

11.00000 OFF

DLT DATE DLTD DLTD DLTD DLTD DLTD DLTD DLTD DLTD DLTD

135.000

DLT MAX DLTMAX DLTMAX DLTMAX DLTMAX DLTMAX DLTMAX

DLTMAX DLTMAX DLTMAX 86400.0

DLT FRN DLTF DLTF DLTF DLTF DLTF DLTF DLTF DLTF DLTF 0.50000 


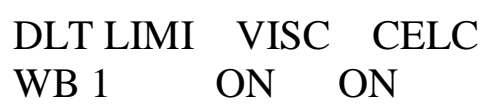

BRANCHG US DS UHS DHS UQB DQB NLMIN SLOPE SLOPEC

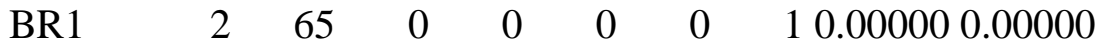

LOCATION LAT LONG EBOT BS BE JBDN

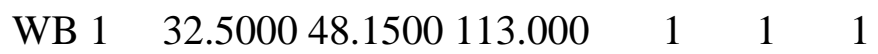

INIT CND T2I ICEI WTYPEC GRIDC

WB $1 \quad-2.00000 .00000$ FRESH RECT

CALCULAT VBC EBC MBC PQC EVC PRC

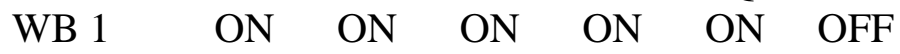

DEAD SEA WINDC QINC QOUTC HEATC

WB 1 ON ON ON ON

INTERPOL QINIC DTRIC HDIC

BR1 ON ON ON

HEAT EXCH SLHTC SROC RHEVAP METIC FETCHC AFW BFW CFW WINDH

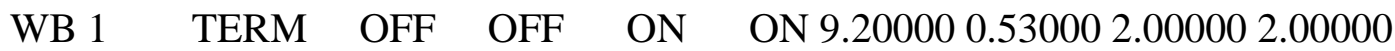

ICE COVE ICEC SLICEC ALBEDO HWICE BICE GICE ICEMIN ICET2

WB 1 OFF DETAIL 0.2500010 .00000 .600000 .070000 .050003 .00000

TRANSPOR SLTRC THETA

WB 1 ULTIMATE 0.55000

HYD COEF AX DX CBHE TSED FI TSEDF FRICC Z0

WB 11.000001 .000000 .3000010 .00000 .015001 .00000 CHEZY 0.00100

EDDY VISC AZC AZSLC AZMAX FBC E ARODI STRCKLR BOUNDFR TKECAL

WB $1 \quad$ W2 IMP $1.00000 \quad 39.535000 .4300024 .000010 .0000 \quad$ IMP

N STRUC NSTR DYNELEV

BR1 2 OFF

STR INT STRIC STRIC STRIC STRIC STRIC STRIC STRIC STRIC STRIC

BR $1 \quad$ ON ON 
STR TOP KTSTR KTSTR KTSTR KTSTR KTSTR KTSTR KTSTR KTSTR KTSTR

BR1 $\quad 30 \quad 18$

STR BOT KBSTR KBSTR KBSTR KBSTR KBSTR KBSTR KBSTR KBSTR KBSTR

BR1 $\quad 35 \quad 27$

STR SINK SINKC SINKC SINKC SINKC SINKC SINKC SINKC SINKC SINKC

BR1 POINT POINT

STR ELEV ESTR ESTR ESTR ESTR ESTR ESTR ESTR ESTR ESTR BR1 162.000182 .300

STR WIDT WSTR WSTR WSTR WSTR WSTR WSTR WSTR WSTR WSTR

BR1 50.000050 .0000

PIPES IUPI IDPI EUPI EDPI WPI DLXPI FPI FMINPI WTHLC DYNPIPE

PIPE UP PUPIC ETUPI EBUPI KTUPI KBUPI

PIPE DOWN PDPIC ETDPI EBDPI KTDPI KBDPI

SPILLWAY IUSP IDSP ESP A1SP B1SP A2SP B2SP WTHLC

$\begin{array}{llllll}\mathrm{SP} 1 & 65 & 0220.00010 .00001 .5000020 .0000 & 1.00000 & \text { DOWN }\end{array}$

SPILL UP PUSPC ETUSP EBUSP KTUSP KBUSP

SP 1 DENSITY $220.0000 .00000 \quad 2 \quad 40$

SPILL DOWN PDSPC ETUSP EBUSP KTDSP KBDSP

SP $1 \quad$ DENSITY $0.000000 .00000 \quad 2 \quad 3$

SPILL GAS GASSPC EQSP AGASSP BGASSP CGASSP

SP $1 \quad$ OFF $\quad 00.000000 .000000 .00000$

GATES IUGT IDGT EGT A1GT B1GT G1GT A2GT B2GT G2GT WTHLC 
GATE WEIR GTA1 GTB1 GTA2 GTB2 DYNVAR GTIC

GATE UP PUGTC ETUGT EBUGT KTUGT KBUGT

GATE DOWN PDGTC ETDGT EBDGT KTDGT KBDGT

GATE GAS GASGTC EQGT AGASGT BGASGT CGASGT

PUMPS 1 IUPU IDPU EPU STRTPU ENDPU EONPU EOFFPU QPU WTHLC DYNPUMP

PUMPS 2 PPUC ETPU EBPU KTPU KBPU

$\begin{array}{lllllllll}\text { WEIR SEG IWR IWR } & \text { IWR } & \text { IWR } & \text { IWR } & \text { IWR } & \text { IWR } & \text { IWR } & \text { IWR }\end{array}$

WEIR TOP KTWR KTWR KTWR KTWR KTWR KTWR KTWR KTWR KTWR

WEIR BOT KBWR KBWR KBWR KBWR KBWR KBWR KBWR KBWR KBWR

WD INT WDIC WDIC WDIC WDIC WDIC WDIC WDIC WDIC WDIC

$\mathrm{ON}$

WD SEG IWD IWD IWD IWD IWD IWD IWD IWD IWD 45

WD ELEV EWD EWD EWD EWD EWD EWD EWD EWD EWD

177.500

WD TOP KTWD KTWD KTWD KTWD KTWD KTWD KTWD KTWD KTWD 24 


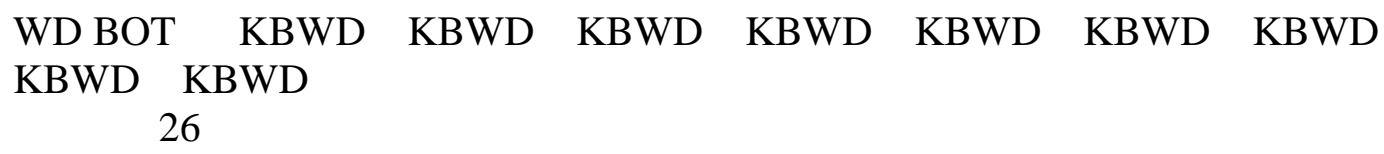

TRIB PLA PTRC PTRC PTRC PTRC PTRC PTRC PTRC PTRC PTRC DENSITY

TRIB INT TRIC TRIC TRIC TRIC TRIC TRIC TRIC TRIC TRIC ON

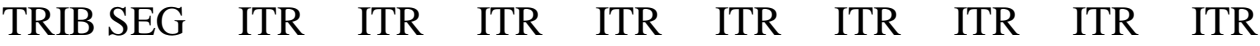
34

TRIB TOP ELTRT ELTRT ELTRT ELTRT ELTRT ELTRT ELTRT ELTRT ELTRT

230.000

TRIB BOT ELTRB ELTRB ELTRB ELTRB ELTRB ELTRB ELTRB ELTRB ELTRB

178.000

DST TRIB DTRC DTRC DTRC DTRC DTRC DTRC DTRC DTRC DTRC

BR $1 \quad$ OFF

HYD PRIN HPRWBC HPRWBC HPRWBC HPRWBC HPRWBC HPRWBC HPRWBC HPRWBC HPRWBC

NVIOL OFF

$\mathrm{U} \quad \mathrm{OFF}$

W OFF

$\mathrm{T} \quad \mathrm{ON}$

RHO OFF

AZ OFF

SHEAR OFF

ST OFF

SB OFF

ADMX OFF

DM OFF

HDG OFF

ADMZ OFF

HPG OFF

GRAV OFF

SNP PRINT SNPC NSNP NISNP 
WB $1 \quad$ ON 74

SNP DATE SNPD SNPD SNPD SNPD SNPD SNPD SNPD SNPD SNPD

WB $1 \quad 135.000183 .400206 .400227 .400247 .400275 .400305 .400$

SNP FREQ SNPF SNPF SNPF SNPF SNPF SNPF SNPF SNPF SNPF WB $1 \quad 1000.001000 .001000 .001000 .001000 .001000 .001000 .00$

SNP SEG ISNP ISNP ISNP ISNP ISNP ISNP ISNP ISNP ISNP $\begin{array}{lllll}\text { WB } 1 & 36 & 43 & 52 & 64\end{array}$

SCR PRINT SCRC NSCR

WB $1 \quad$ ON 1

SCR DATE SCRD SCRD SCRD SCRD SCRD SCRD SCRD SCRD SCRD

WB $1 \quad 50.0000$

SCR FREQ SCRF SCRF SCRF SCRF SCRF SCRF SCRF SCRF SCRF WB 110.0000

PRF PLOT PRFC NPRF NIPRF

WB $1 \quad$ OFF 14

PRF DATE PRFD PRFD PRFD PRFD PRFD PRFD PRFD PRFD PRFD

WB $1 \quad 130.000$

PRF FREQ PRFF PRFF PRFF PRFF PRFF PRFF PRFF PRFF PRFF WB 11.00000

PRF SEG IPRF IPRF IPRF IPRF IPRF IPRF IPRF IPRF IPRF

WB $1 \quad 36 \quad 43 \quad 52 \quad 64$

SPR PLOT SPRC NSPR NISPR

WB $1 \quad$ OFF 111

SPR DATE SPRD SPRD SPRD SPRD SPRD SPRD SPRD SPRD SPRD

WB $1 \quad 50.0000$

SPR FREQ SPRF $\quad$ SPRF $\quad$ SPRF $\quad$ SPRF $\quad$ SPRF $\quad$ SPRF $\quad$ SPRF $\quad$ SPRF $\quad$ SPRF WB $1 \quad 1.00000$ 
SPR SEG ISPR ISPR ISPR ISPR ISPR ISPR ISPR ISPR ISPR WB $1 \quad 63$

VPL PLOT VPLC NVPL

WB 1 ON 1

VPLDATE VPLD VPLD VPLD VPLD VPLD VPLD VPLD VPLD VPLD

WB $1 \quad 63.5000$

VPL FREQ VPLF VPLF VPLF VPLF VPLF VPLF VPLF VPLF VPLF WB 11.00000

CPL PLOT CPLC NCPL TECPLOT

WB 1 OFF 1 OFF

CPLDATE CPLD CPLD CPLD CPLD CPLD CPLD CPLD CPLD CPLD

WB $1 \quad 63.5000$

CPL FREQ CPLF CPLF CPLF CPLF CPLF CPLF CPLF CPLF CPLF WB 11.00000

WB 1 ON 6

FLX DATE FLXD FLXD FLXD FLXD FLXD FLXD FLXD FLXD FLXD

WB $1 \quad 135.000183 .000206 .000247 .000275 .000305 .000$

FLX FREQ FLXF FLXF FLXF FLXF FLXF FLXF FLXF FLXF FLXF WB 150.000050 .000050 .000050 .000050 .000050 .0000

TSR PLOT TSRC NTSR NITSR ON 11

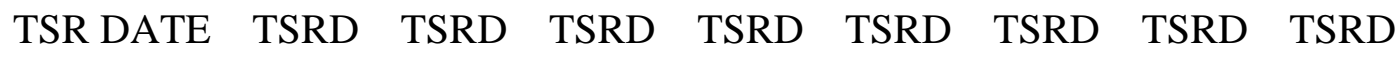
TSRD 50.0000

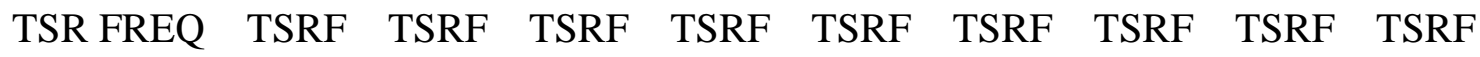
1.00000

TSR SEG ITSR ITSR ITSR ITSR ITSR ITSR ITSR ITSR ITSR 64 
TSR LAYE ETSR ETSR ETSR ETSR ETSR ETSR ETSR ETSR ETSR 0.00000

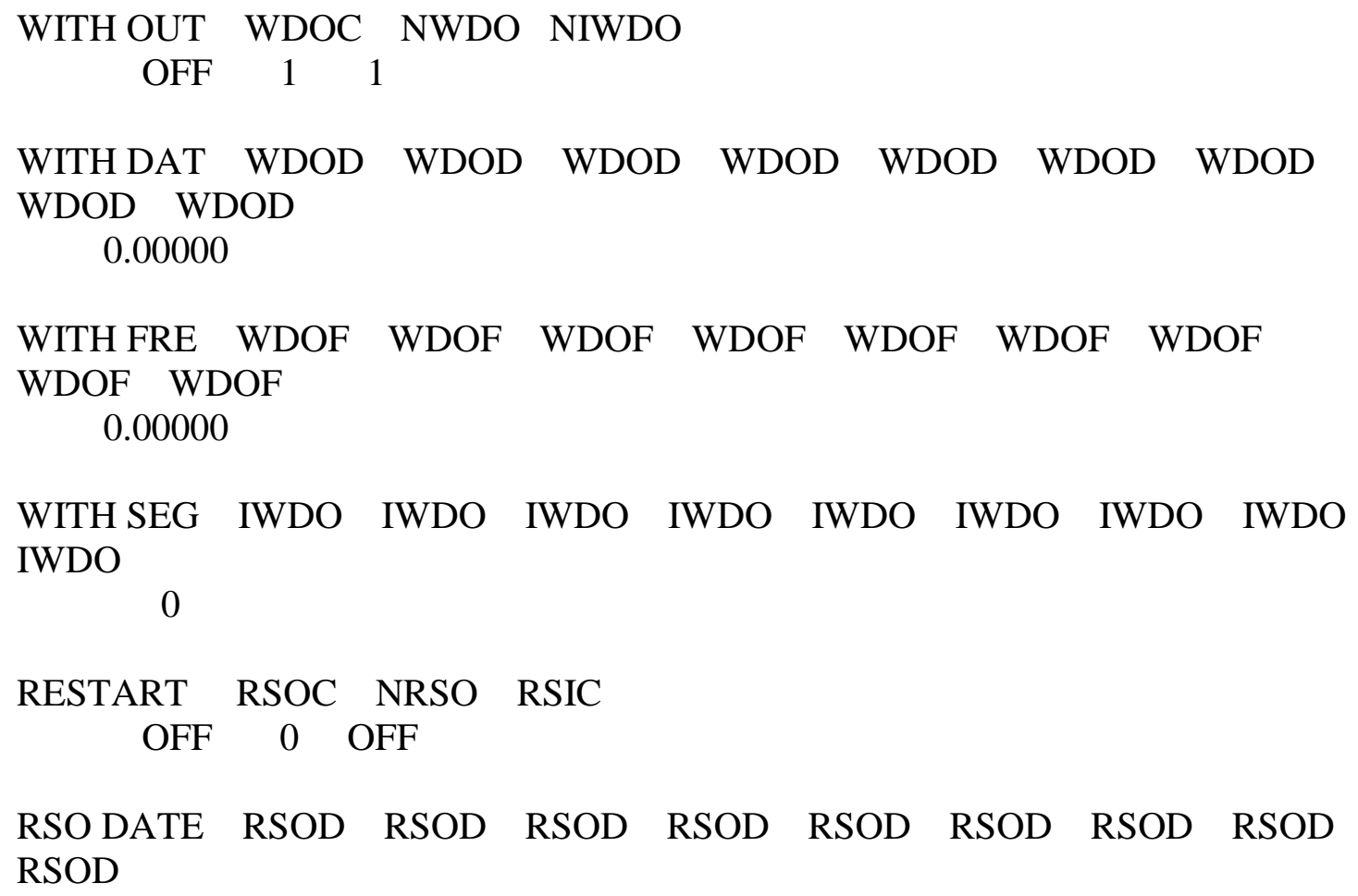




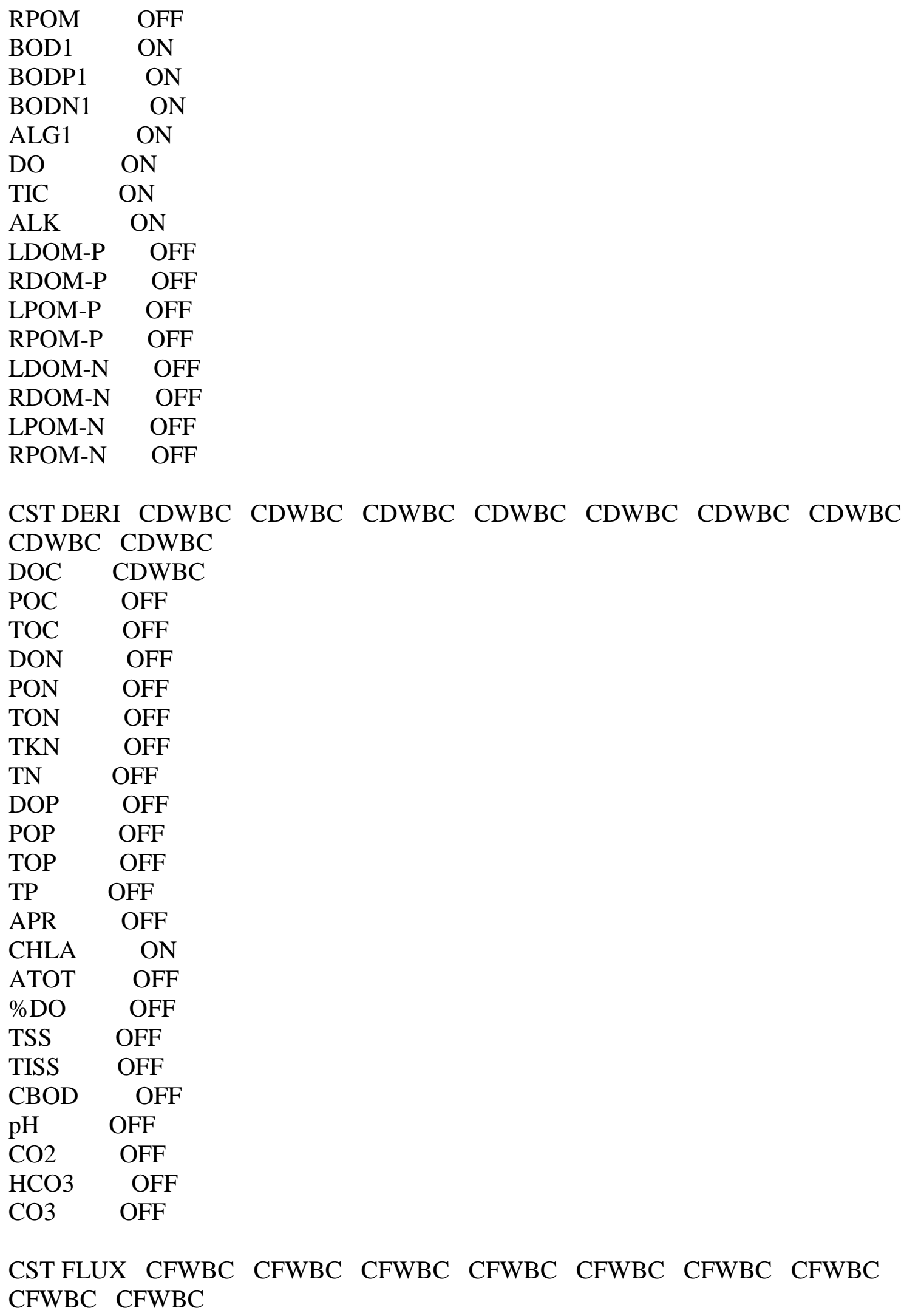

CST FLUX CFWBC CFWBC CFWBC CFWBC CFWBC CFWBC CFWBC CFWBC CFWBC 


$\begin{array}{lc}\text { TISSIN } & \text { CFWBC } \\ \text { TISSOUT } & \text { OFF } \\ \text { PO4AR } & \text { ON } \\ \text { PO4AG } & \text { ON } \\ \text { PO4AP } & \text { ON } \\ \text { PO4ER } & \text { ON } \\ \text { PO4EG } & \text { ON } \\ \text { PO4EP } & \text { ON } \\ \text { PO4POM } & \text { ON } \\ \text { PO4DOM } & \text { ON } \\ \text { PO4OM } & \text { ON } \\ \text { PO4SED } & \text { ON } \\ \text { PO4SOD } & \text { ON } \\ \text { PO4SET } & \text { ON } \\ \text { NH4NITR } & \text { ON } \\ \text { NH4AR } & \text { ON } \\ \text { NH4AG } & \text { ON } \\ \text { NH4AP } & \text { ON } \\ \text { NH4ER } & \text { ON } \\ \text { NH4EG } & \text { ON } \\ \text { NH4EP } & \text { ON } \\ \text { NH4POM } & \text { ON } \\ \text { NH4DOM } & \text { ON } \\ \text { NH4OM } & \text { ON } \\ \text { NH4SED } & \text { ON } \\ \text { NH4SOD } & \text { ON } \\ \text { NO3DEN } & \text { ON } \\ \text { NO3AG } & \text { ON } \\ \text { NO3EG } & \text { ON } \\ \text { NO3SED } & \text { ON } \\ \text { DSIAG } & \text { OFF } \\ \text { DSIEG } & \text { OFF } \\ \text { DSIPIS } & \text { OFF } \\ \text { DSISED } & \text { OFF } \\ \text { DSISOD } & \text { OFF } \\ \text { DSISET } & \text { OFF } \\ \text { PSIAM } & \text { OFF } \\ \text { PSINET } & \text { OFF } \\ \text { PSIDK } & \text { OFF } \\ \text { FESET } & \text { OFF } \\ \text { FESED } & \text { OFF } \\ \text { LDOMDK } & \text { OFF } \\ \text { LRDOM } & \text { OFF } \\ \text { RDOMDK } & \text { OFF } \\ \text { LDOMAP } & \text { OFF } \\ & \\ \text { NDOM }\end{array}$




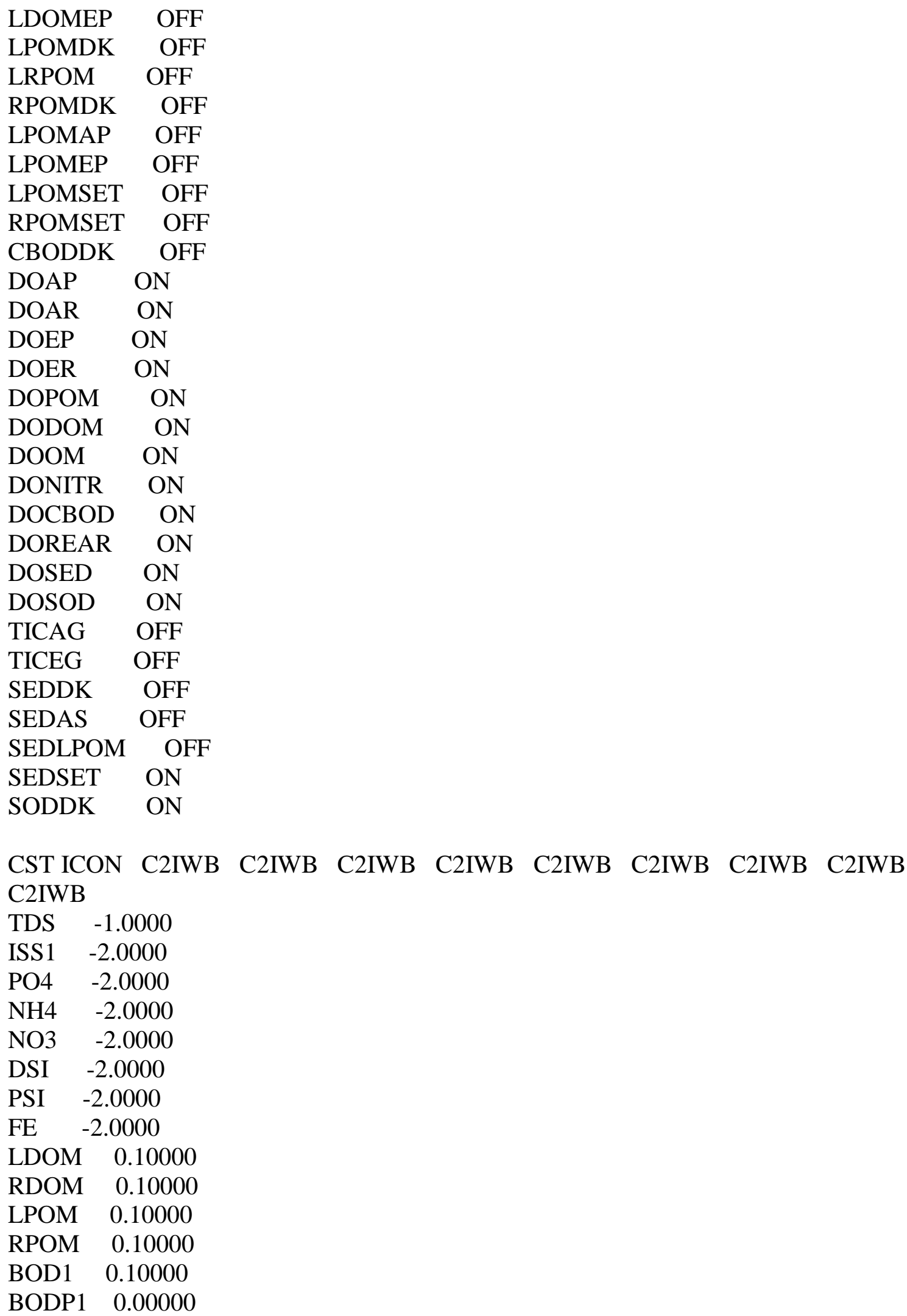




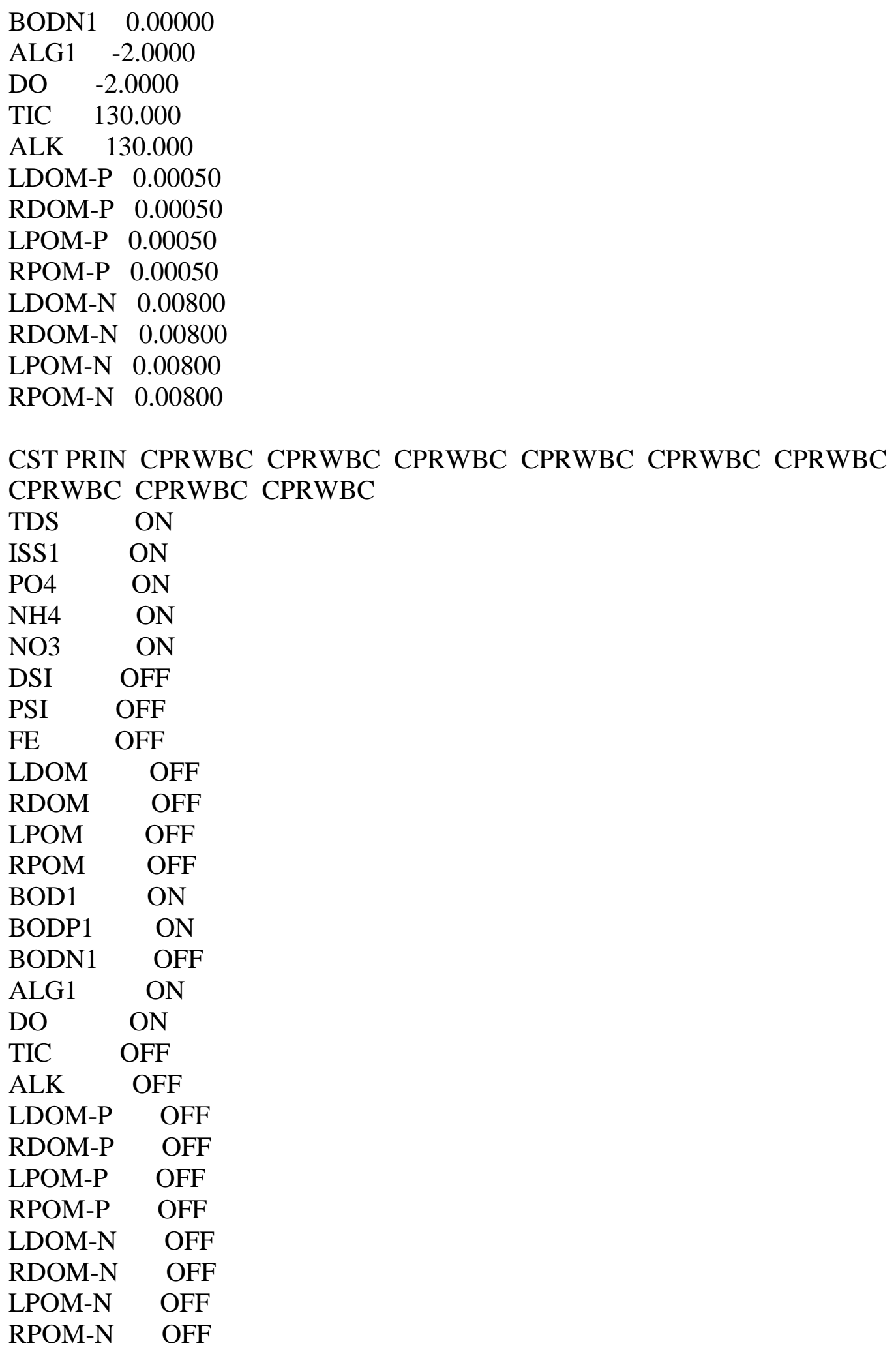


CIN CON CINBRC CINBRC CINBRC CINBRC CINBRC CINBRC CINBRC CINBRC CINBRC

TDS ON

ISS1 ON

$\mathrm{PO} 4 \mathrm{ON}$

$\mathrm{NH} 4 \quad \mathrm{ON}$

NO3 ON

DSI OFF

PSI OFF

FE OFF

LDOM OFF

RDOM OFF

LPOM OFF

RPOM OFF

BOD1 ON

BODP1 ON

BODN1 ON

ALG1 ON

DO ON

TIC OFF

ALK OFF

LDOM-P OFF

RDOM-P OFF

LPOM-P OFF

RPOM-P OFF

LDOM-N OFF

RDOM-N OFF

LPOM-N OFF

RPOM-N OFF

CTR CON CTRTRC CTRTRC CTRTRC CTRTRC CTRTRC CTRTRC CTRTRC CTRTRC CTRTRC

TDS OFF

ISS1 OFF

$\mathrm{PO} 4 \quad \mathrm{OFF}$

$\mathrm{NH} 4 \quad$ CTRTRC

NO3 OFF

DSI OFF

PSI OFF

FE OFF

LDOM OFF

RDOM OFF

LPOM OFF

RPOM OFF

BOD1 OFF 


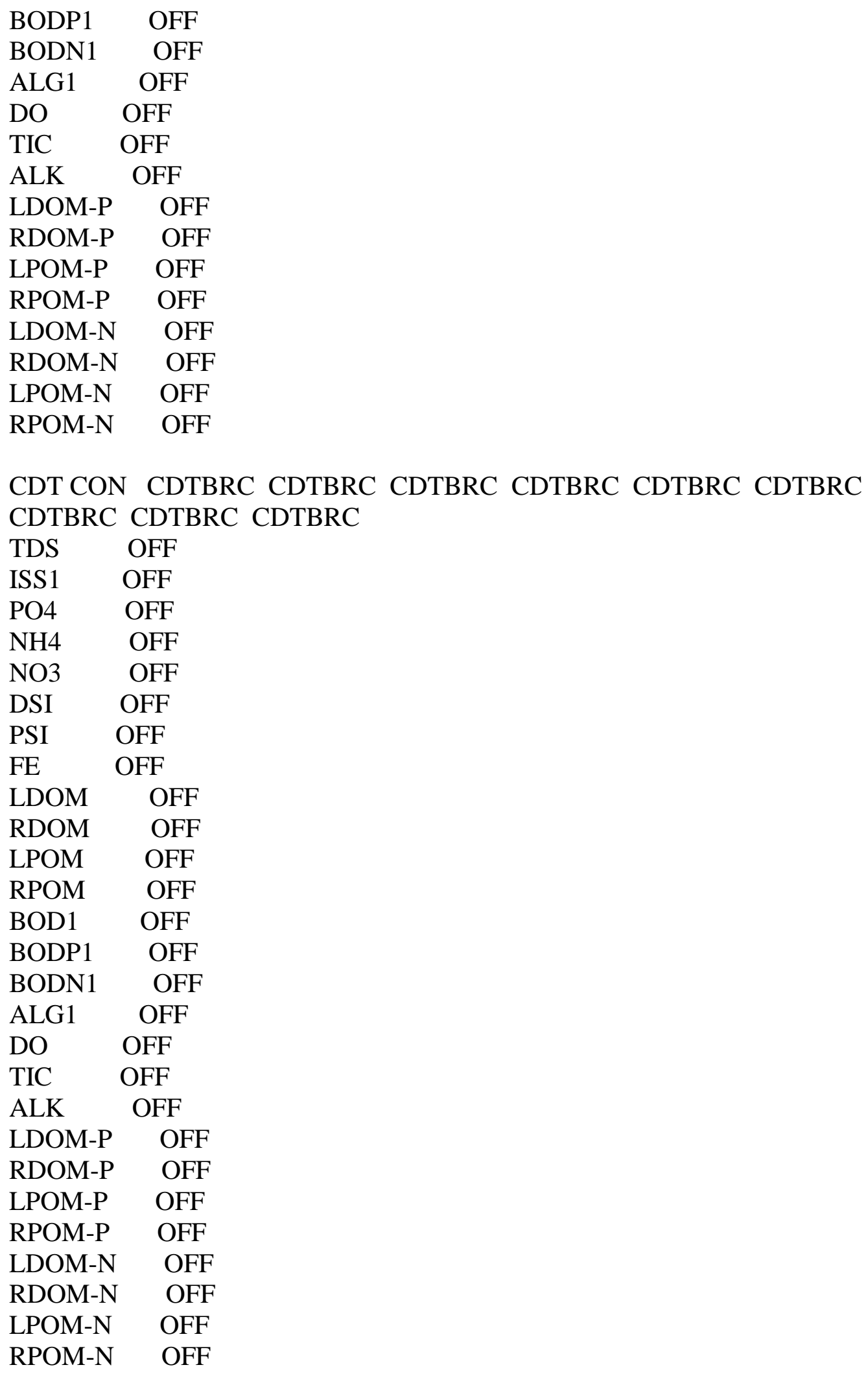


CPR CON CPRBRC CPRBRC CPRBRC CPRBRC CPRBRC CPRBRC CPRBRC CPRBRC CPRBRC

$\begin{array}{lc}\text { TDS } & \text { OFF } \\ \text { ISS1 } & \text { OFF } \\ \text { PO4 } & \text { OFF } \\ \text { NH4 } & \text { OFF } \\ \text { NO3 } & \text { OFF } \\ \text { DSI } & \text { OFF } \\ \text { PSI } & \text { OFF } \\ \text { FE } & \text { OFF } \\ \text { LDOM } & \text { OFF } \\ \text { RDOM } & \text { OFF } \\ \text { LPOM } & \text { OFF } \\ \text { RPOM } & \text { OFF } \\ \text { BOD1 } & \text { OFF } \\ \text { BODP1 } & \text { OFF } \\ \text { BODN1 } & \text { OFF } \\ \text { ALG1 } & \text { OFF } \\ \text { DO } & \text { OFF } \\ \text { TIC } & \text { OFF } \\ \text { ALK } & \text { OFF } \\ \text { LDOM-P } & \text { OFF } \\ \text { RDOM-P } & \text { OFF } \\ \text { LPOM-P } & \text { OFF } \\ \text { RPOM-P } & \text { OFF } \\ \text { LDOM-N } & \text { OFF } \\ \text { RDOM-N } & \text { OFF } \\ \text { LPOM-N } & \text { OFF } \\ \text { RPOM-N } & \text { OFF }\end{array}$

EX COEF EXH2O EXSS EXOM BETA EXC EXIC WB $1 \quad 0.220000 .010000 .400000 .45000 \quad$ OFF OFF

ALG EX EXA EXA EXA EXA EXA EXA 0.20000

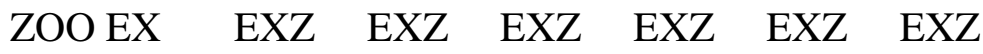
0.00000

MACRO EX EXM EXM EXM EXM $\quad$ EXM EXM 0.00000

GENERIC CGQ10 CG0DK CG1DK CGS CG $1 \quad 0.000000 .000000 .000000 .00000$ 
S SOLIDS SSS SEDRC TAUCR

SS\# 11.00000 OFF 1.00000

ALGAL RATE AG AR AE AM AS AHSP AHSN AHSSI ASAT

ALG1 1.150000 .040000 .040000 .035000 .045000 .010000 .026000 .0000085 .000

ALGAL TEMP AT1 AT2 AT3 AT4 AK1 AK2 AK3 AK4

ALG1 5.00000 25.0000 35.0000 40.0000 0.10000 0.99000 0.99000 0.10000

ALG STOI ALGP ALGN ALGC ALGSI ACHLA ALPOM ANEQN ANPR ALG1 $0.005000 .080000 .450000 .180000 .1220000 .80000 \quad 20.00100$

EPIPHYTE EPIC EPIC EPIC EPIC EPIC EPIC EPIC EPIC EPIC EPI1 MP AT1

EPIPRIN EPRC EPRC EPRC EPRC EPRC EPRC EPRC EPRC EPRC EPI1 OFF

EPI INIT EPICI EPICI EPICI EPICI EPICI EPICI EPICI EPICI EPICI EPI1 0.00000

EPI RATE EG ER EE EM EB EHSP EHSN EHSSI

EPI1 0.000000 .000000 .000000 .000000 .000000 .000000 .000000 .00000

EPI HALF ESAT EHS ENEQN ENPR

EPI1 $0.000000 .00000 \quad 00.00000$

EPI TEMP ET1 ET2 ET3 ET4 EK1 EK2 EK3 EK4

EPI1 0.000000 .000000 .000000 .000000 .000000 .000000 .000000 .00000

EPISTOI EP EN EC ESI ECHLA EPOM

EPI1 0.000000 .000000 .000000 .000000 .000000 .00000

ZOOP RATE ZG ZR ZM ZEFF PREFP ZOOMIN ZS2P

Zoo1 1.500000 .100000 .010000 .500000 .500000 .010000 .30000

ZOOP ALGP PREFA PREFA PREFA PREFA PREFA PREFA PREFA PREFA PREFA

Zoo1 $\quad 0.00000$

ZOOP ZOOP PREFZ PREFZ PREFZ PREFZ PREFZ PREFZ PREFZ PREFZ PREFZ

Zoo1 $\quad 0.00000$

$\begin{array}{lllllllll}\text { ZOOP TEMP } & \text { ZT1 } & \text { ZT2 } & \text { ZT3 } & \text { ZT4 } & \text { ZK1 } & \text { ZK2 } & \text { ZK3 } & \text { ZK4 }\end{array}$ 
Zoo1 0.0000015 .000020 .000036 .00000 .010000 .900000 .990000 .10000

ZOOP STOI ZP ZN ZC

Zoo1 $\quad 0.015000 .080000 .45000$

MACROPHY MACWBC MACWBC MACWBC MACWBC MACWBC MACWBC MACWBC MACWBC MACWBC

Mac1 OFF

MAC PRIN MPRWBC MPRWBC MPRWBC MPRWBC MPRWBC MPRWBC MPRWBC MPRWBC MPRWBC

Mac1 OFF

MAC INI MACWBCI MACWBCI MACWBCI MACWBCI MACWBCI MACWBCI MACWBCI MACWBCI MACWBCI

Mac1 0.00000

MAC RATE MG MR MM MSAT MHSP MHSN MHSC MPOM LRPMAC

Mac1 0.000000 .000000 .000000 .000000 .000000 .000000 .000000 .000000 .00000

MAC SED PSED NSED

Mac1 0.000000 .00000

MAC DIST MBMP MMAX

Mac1 0.000000 .00000

MAC DRAG CDDRAG DMV DWSA ANORM

Mac1 0.000000 .000000 .000000 .00000

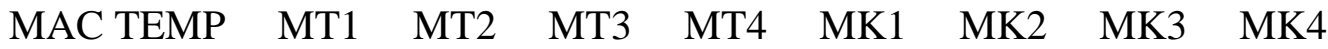

Mac1 0.000000 .000000 .000000 .000000 .000000 .000000 .000000 .00000

MAC STOICH MP MN MC

Mac1 0.000000 .000000 .00000

DOM LDOMDK RDOMDK LRDDK

WB $1 \quad 0.100000 .001000 .01000$

POM LPOMDK RPOMDK LRPDK POMS

WB $1 \quad 0.080000 .001000 .001000 .50000$

OM STOIC ORGP ORGN ORGC ORGSI

WB $1 \quad 0.005000 .080000 .450000 .18000$ 
OM RATE OMT1 OMT2 OMK1 OMK2

WB $1 \quad 4.0000025 .00000 .100000 .99000$

CBOD KBOD TBOD RBOD CBODS

BOD $1 \quad 0.100001 .020001 .850000 .00000$

CBOD STOIC BODP BODN BODC

BOD 10.004000 .060000 .32000

PHOSPHOR PO4R PARTP

WB $1 \quad 0.020000 .00000$

AMMONIUM NH4R NH4DK

WB $1 \quad 0.010000 .26500$

NH4 RATE NH4T1 NH4T2 NH4K1 NH4K2 WB $1 \quad 5.0000025 .00000 .100000 .99000$

NITRATE NO3DK NO3S FNO3SED

WB $1 \quad 0.078000 .015000 .00000$

NO3 RATE NO3T1 NO3T2 NO3K1 NO3K2

WB $1 \quad 5.0000025 .00000 .100000 .99000$

SILICA DSIR PSIS PSIDK PARTSI

WB $1 \quad 0.100000 .000000 .300000 .20000$

IRON FER FES

WB $1 \quad 0.500002 .00000$

SED CO2 CO2R

WB 11.00000

STOICH 1 O2NH4 O2OM

WB $1 \quad 4.570001 .40000$

STOICH 2 O2AR O2AG

ALG1 1.100001 .40000

STOICH 3 O2ER O2EG

EPI1 0.000000 .00000

STOICH 4 O2ZR

Zoop1 1.10000 
STOICH 5 O2MR O2MG

Mac1 0.000000 .00000

O2 LIMIT O2LIM

0.10000

SEDIMENT SEDC SEDPRC SEDCI SEDS SEDK FSOD FSED SEDBR DYNSEDK

WB $1 \quad$ ON $\quad$ ON $0.000000 .100000 .430000 .655000 .655000 .01000 \quad$ OFF

SOD RATE SODT1 SODT2 SODK1 SODK2

WB $1 \quad 4.0000030 .00000 .100000 .99000$

S DEMAND SOD SOD SOD SOD SOD SOD SOD SOD SOD

0.300000 .300000 .300000 .300000 .300000 .300000 .300000 .300000 .30000

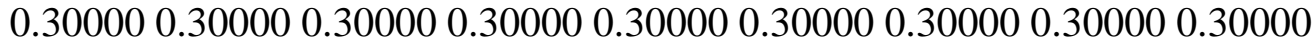

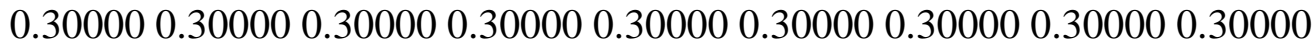

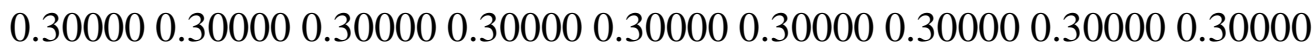

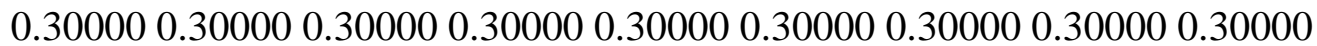

0.300000 .300000 .300000 .300000 .300000 .300000 .300000 .300000 .30000

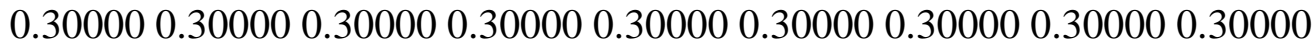

0.300000 .300000 .30000

REAERATION TYPE EQN\# COEF1 COEF2 COEF3 COEF4

WB 1 LAKE 50.000000 .000000 .000000 .00000

RSI FILE RSIFN

rsi.npt - not used

QWD FILE.

QWDFN

qwd_dasht.npt

QGT FILE QGTFN

qgt.npt - not used

WSC FILE

WSCFN.

wsc.npt

SHD FILE.

SHDFN

shd.npt

BTH FILE.

BTHFN

WB 1 bth_1.npt

MET FILE

METFN 
WB 1 met_1.npt

EXT FILE.

EXTFN..

WB 1 ext_1.npt - not used

VPR FILE.

..VPRFN.

WB 1 vpr_1.npt

LPR FILE.

.LPRFN.

WB 1 lpr_1.npt

QIN FILE.

QINFN.

BR1 qin_br1.npt

TIN FILE TINFN

BR1 tin_br1.npt

CIN FILE CINFN

BR1 cin_br1.npt

QOT FILE. QOTFN.

BR1 qot_br1.npt

QTR FILE. QTRFN

TR1 qtr_tr1.npt - not used

TTR FILE. .TTRFN

TR1 ttr_tr1.npt - not used

CTR FILE.

.CTRFN

TR1 ctr_br1.npt - not used

QDT FILE. QDTFN.

BR1 qin_br1.npt

TDT FILE. .TDTFN

BR1 tdt_br1.npt

CDT FILE .CDTFN

BR1 cdt_br1.npt

PRE FILE. .PREFN

BR1 pre_br1.npt

TPR FILE. .TPRFN 
BR1 tpr_br1.npt

CPR FILE.

CPRFN..

BR1 cpr_br1.npt

EUH FILE.

EUHFN.

BR1 euh_br1.npt

TUH FILE

TUHFN

BR1 tuh_br1.npt

CUH FILE.

.CUHFN

BR1 cuh_br1.npt

EDH FILE

EDHFN

BR1 edh_br1.npt

TDH FILE

TDHFN

BR1 tdh_br1.npt

CDH FILE

.CDHFN

BR1 cdh_br1.npt

SNP FILE.

SNPFN

WB 1 snp_br1.opt

PRF FILE

PRFFN

WB 1 prf_1.opt

VPL FILE.

VPLFN

WB 1 W2Linkage1.w2l

CPL FILE.

CPLFN

WB 1 cpl_1.opt

SPR FILE.

SPRFN

WB 1 spr_1.opt

FLX FILE.

FLXFN

WB 1 flx_1.opt

TSR FILE TSRFN

tsr.opt

WDO FILE WDOFN

wdo.opt 


\section{Appendix B}

PSO code

subroutine pso

\section{USE DFPORT \\ USE DFLIB \\ USE MSIMSL}

REAL, allocatable:: x(:,:),pbest(:,:),gbest(:),NO1DAY(:)

REAL, allocatable:: velocity (:,:),fx(:,:),w(:),velocity_p(:,:)

REAL, allocatable:: iij(:),objectivefun2(:),funct(:)

REAL, allocatable:: objectivefun(:),matr(:,:),bound_min(:)

REAL, allocatable:: vmax(:),vmin(:),bound_max(:)

DIMENSION:: DEPTH1(500),Temprature1(500),depth11(50,50)

DIMENSION:: DEPTH2(500),Temprature2(500), depth22(50,50)

DIMENSION:: kj(50),temprature11(50,50),temprature22(50,50)

integer:: r,particle,var,iterationmax,p,m,j,num_particle,iii

integer:: num_iter,num_iter1,a

real:: iter,itermax,S,perv

!*******************************************

open(unit=7, file ="input_pso.txt",status ="old")

open(unit=3, file $=$ "output.txt",status $=$ "unknown")

OPEN(2555,FILE='DECVAR3.DAT',STATUS='UNKNOWN')

open(2252,file='COEEFICIENT.DAT', status='unknown')

open $(888$,file $=$ 'check2.dat')

open(114, file='objfun.dat',status='unknown')

open(666,file='realdata.npt',status='old')

open(555, file='modelRes.dat', status='unknown')

open(113, file='dec.dat', status='unknown')

open (22222, file='checkObj.dat', status='unknown')

open (4, file='variable.dat', status='unknown')

open ( 5 , file $=$ 'velocity.dat', status='unknown')

open(unit=1, file ="for diagram.dat",status ="unknown")

!@@@@@@@@@@@@@@@@@@@@@@@@@@@@@@@@@@@@@@ @@

$\operatorname{read}(7, *)$ iterationmax

$\operatorname{read}(7, *) \mathrm{p}$ 


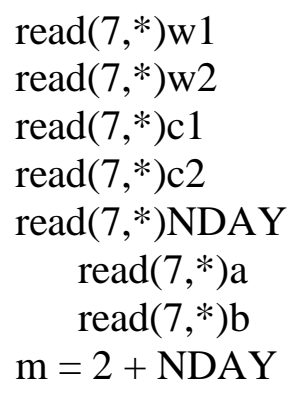

!@@@@@@@@@@@@@@@@@@@@@@@@@@@@@@@@@@@@@@ @@

!@@@@@@@@@@@@@@@@@@@@@@@@@@@@@@@@@@@@@@ @@

$\operatorname{ALLOCATE}(x(p, m), p b e s t(p, m), \operatorname{gbest}(m), \operatorname{matr}(p, m)$, bound_max $(m))$

ALLOCATE ( velocity $(\mathrm{p}, \mathrm{m}), \mathrm{fx}(\mathrm{p}, \mathrm{m}), \mathrm{w}($ iterationmax $), \mathrm{iij}(\mathrm{p}))$

ALLOCATE ( funct(p),velocity_p(p,m),NO1DAY(m),vmax(m),vmin(m))

ALLOCATE ( objectivefun2(p),objectivefun(p),bound_min(m))

!@@@@@@@@@@@@@@@@@@@@@@@@@@@@@@@@@@@@@@ @@

!@@@@@@@@@@@@@@@@@@@@@@@@@@@@@@@@@@@@@@ @@

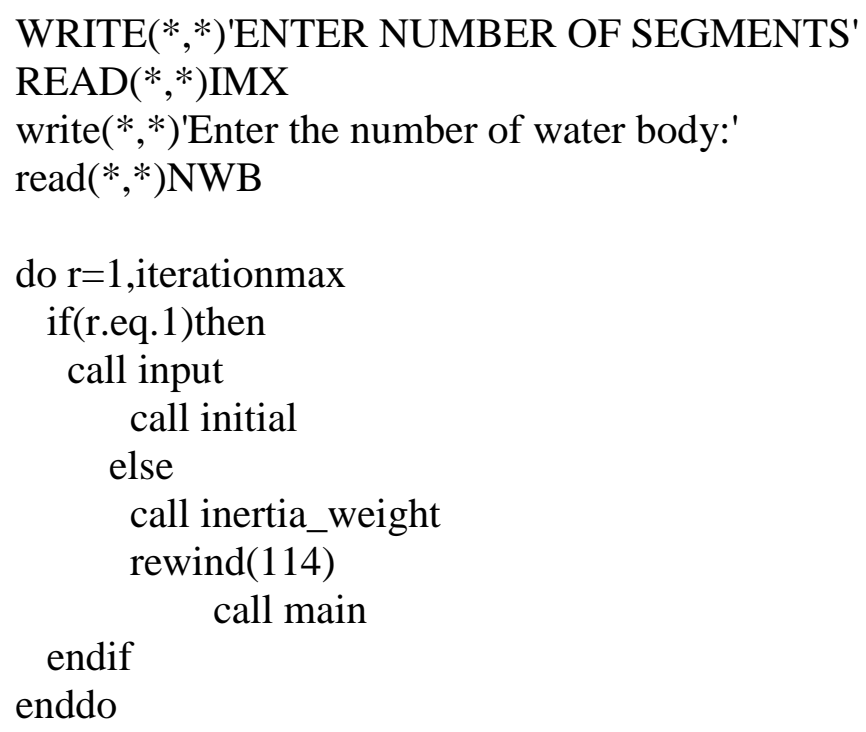


!@@@@@@@@@@@@@@@@@@@@@@@@@@@@@@@@@@@@@@ @@

!@@@@@@@@@@@@@@@@@@@@@@@@@@@@@@@@@@@@@@ @@

\section{CONTAINS}

!@@@@@@@@@@@@@@@@@@@@@@@@@@@@@@@@@@@@@@ @@

!@@@@@@@@@@@@@@@@@@@@@@@@@@@@@@@@@@@@@@ @@

!@@@@@@@@@@@@@@@@@@@@@@@@@@@@@@@@@@@@@@ @@

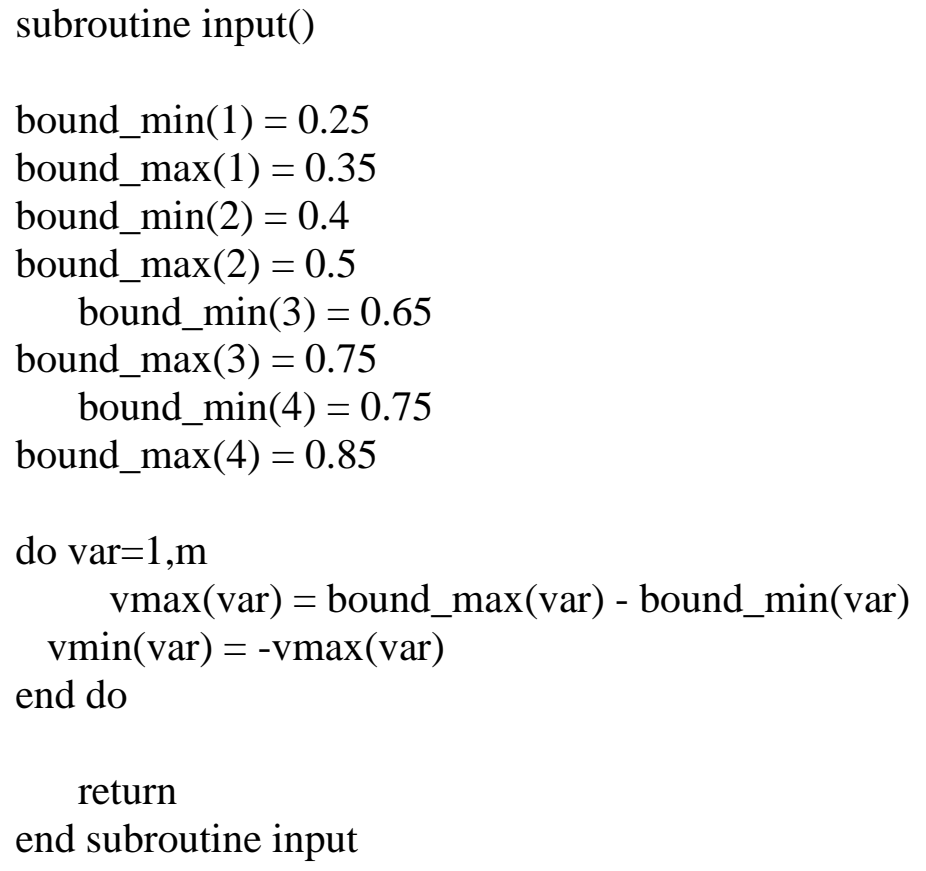

!@@@@@@@@@@@@@@@@@@@@@@@@@@@@@@@@@@@@@@ @@

!@@@@@@@@@@@@@@@@@@@@@@@@@@@@@@@@@@@@@@ @@ 
!@@@@@@@@@@@@@@@@@@@@@@@@@@@@@@@@@@@@@@ @@

subroutine inertia_weight()

itermax = iterationmax !this changing variables happend beacause if mathmatical operation be done on 2 integers the answer is integer.

iter $=\mathrm{r}$

$\mathrm{w}(\mathrm{r})=(\mathrm{w} 1-\mathrm{w} 2)^{*}($ itermax - iter $) /$ itermax $+\mathrm{w} 2$

return

end subroutine inertia_weight

!@@@@@@@@@@@@@@@@@@@@@@@@@@@@@@@@@@@@@@ @@

!@@@@@@@@@@@@@@@@@@@@@@@@@@@@@@@@@@@@@@ @@

!@@@@@@@@@@@@@@@@@@@@@@@@@@@@@@@@@@@@@@ @@

subroutine initial()

CALL RANDOM_SEED()

OPEN(222,FILE='VARS.DAT',STATUS='UNKNOWN')

do particle $=1, p$

objectivefun $2($ particle $)=0$

iii $=0$

do $\operatorname{var}=1,2$

CALL RANDOM_NUMBER(S)

$\mathrm{x}($ particle, $\mathrm{var})=$ bound_min $($ var $)+($ bound_max $($ var $)$

$\&$

- bound_min(var) $)^{*} \mathrm{~S}$

pbest $($ particle, var $)=x($ particle, var $)$

write(222,'(f8.2)') x(particle,var)

write $\left(4,{ }^{*}\right) \mathrm{x}($ particle,var)

velocity_p $($ particle,, var $)=\operatorname{vmax}($ var $)$

end do 


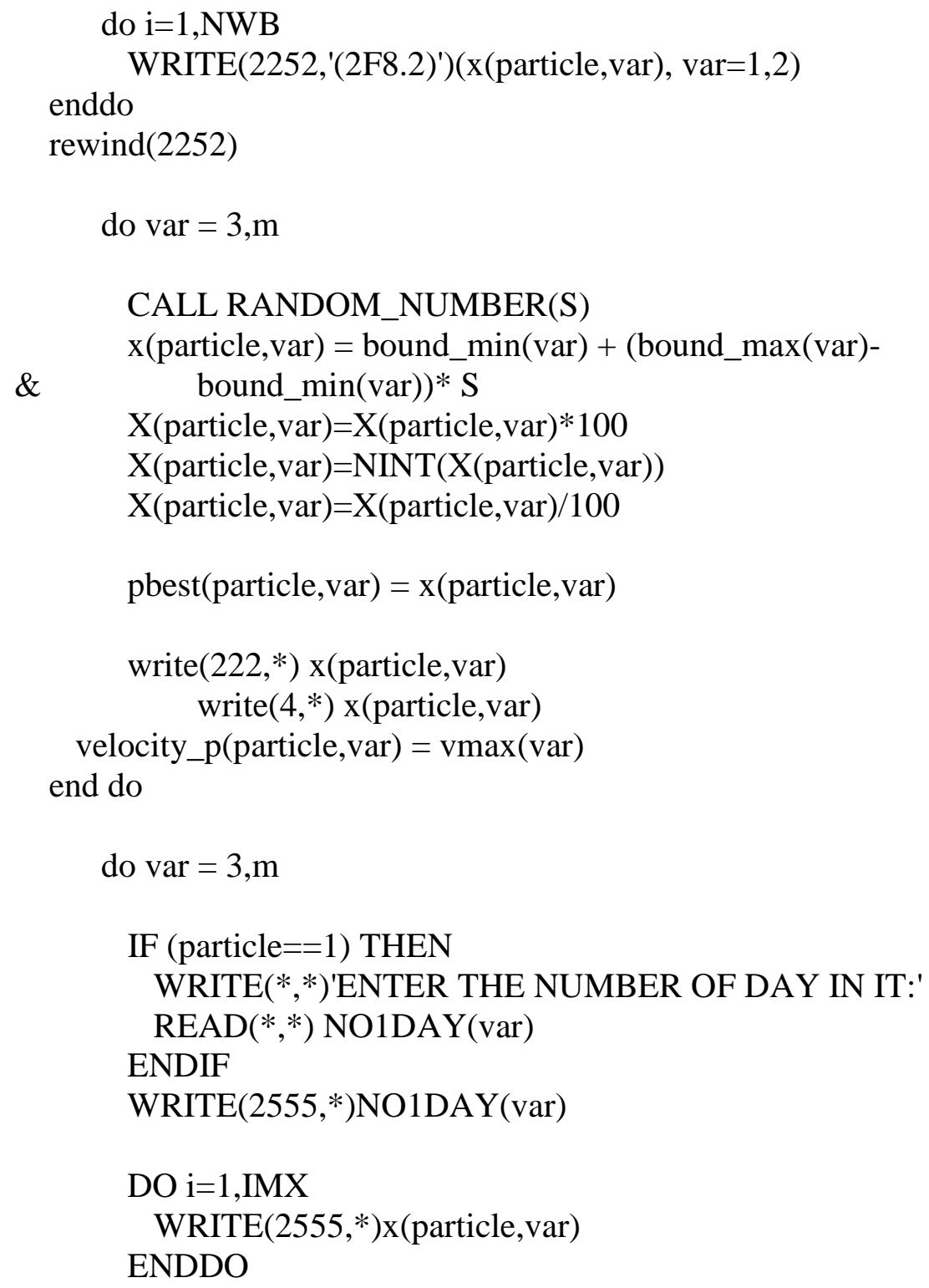




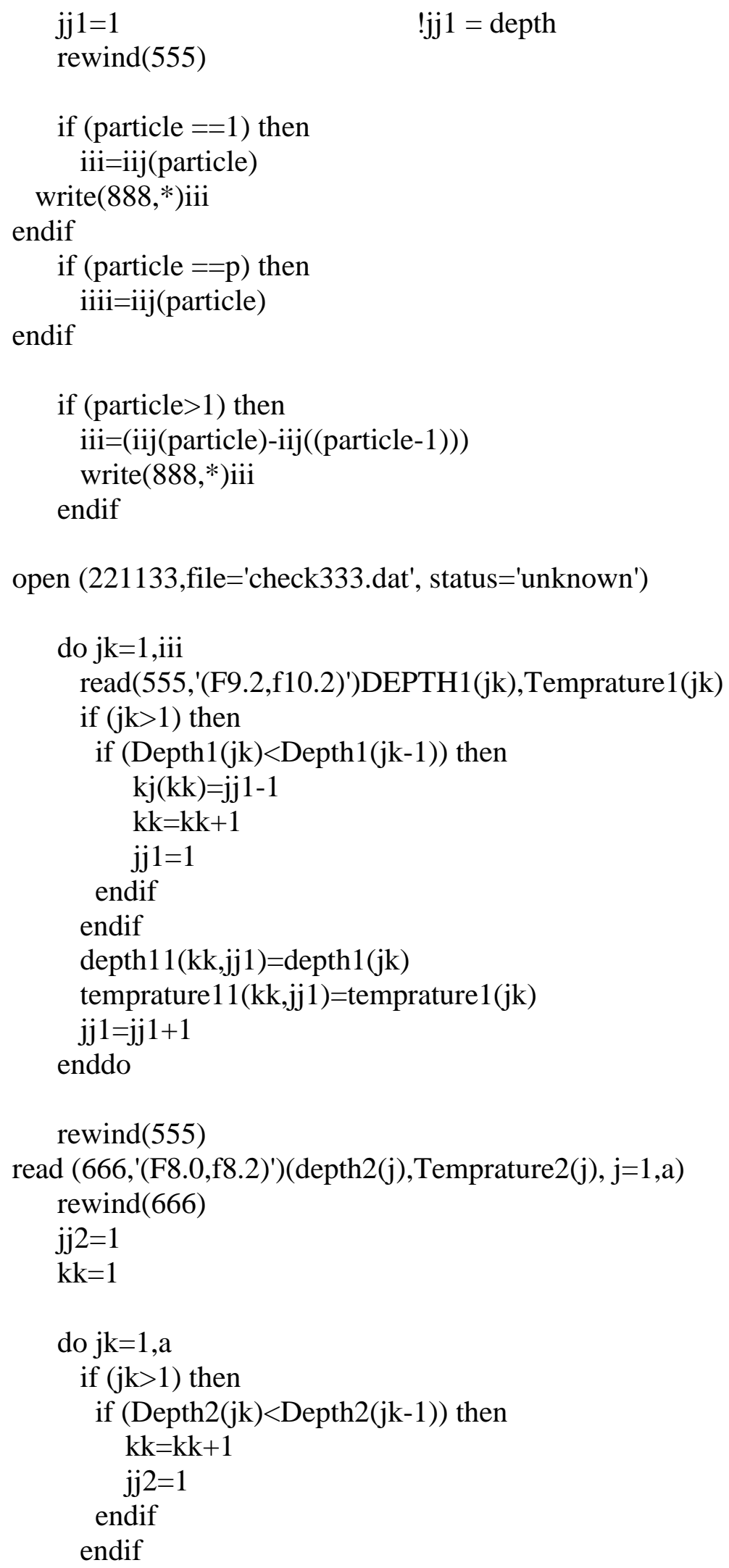




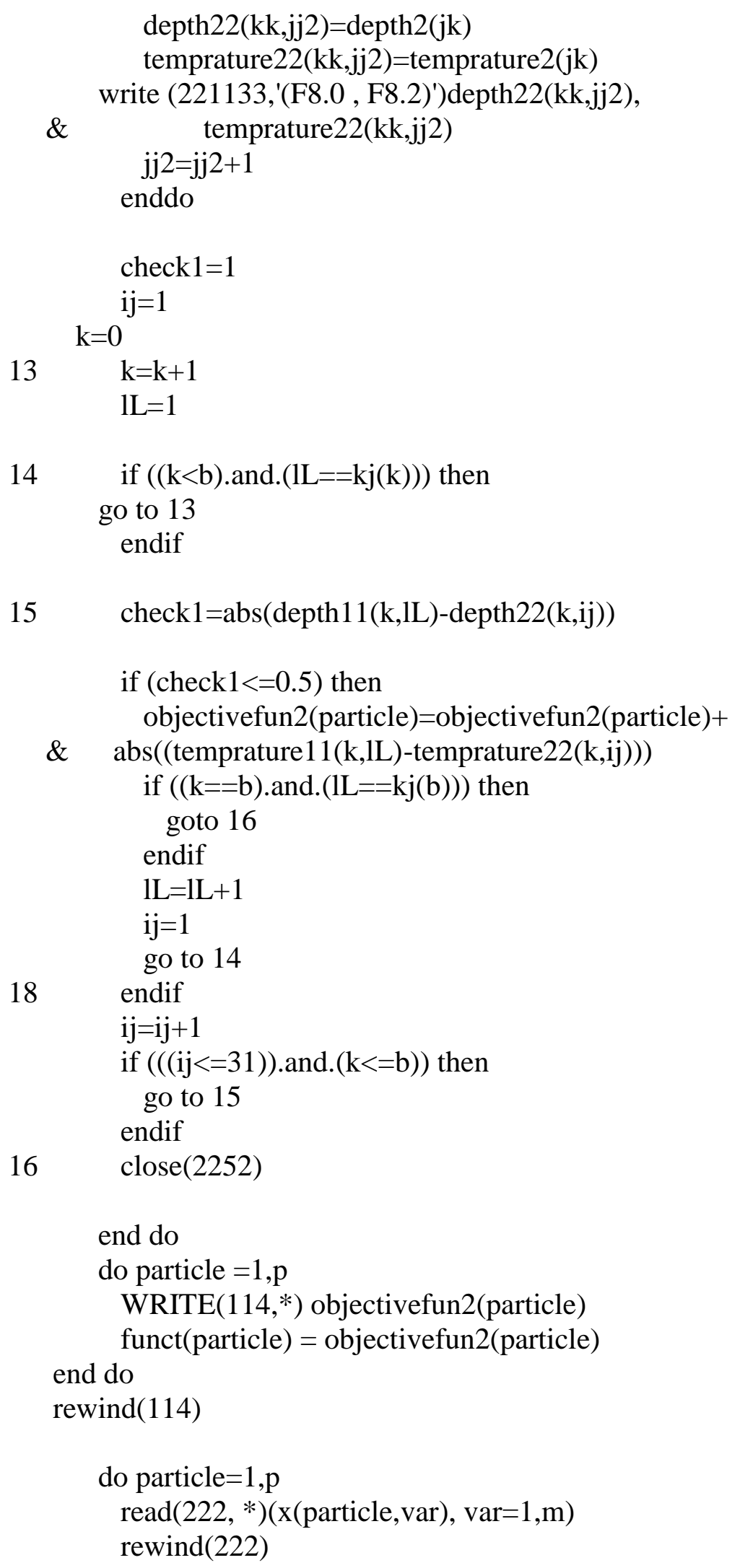

$15 \operatorname{check} 1=\operatorname{abs}(\operatorname{depth} 11(\mathrm{k}, \mathrm{lL})-\operatorname{depth} 22(\mathrm{k}, \mathrm{ij}))$

if $($ check $1<=0.5)$ then objectivefun $2($ particle $)=$ objectivefun $2($ particle $)+$ 


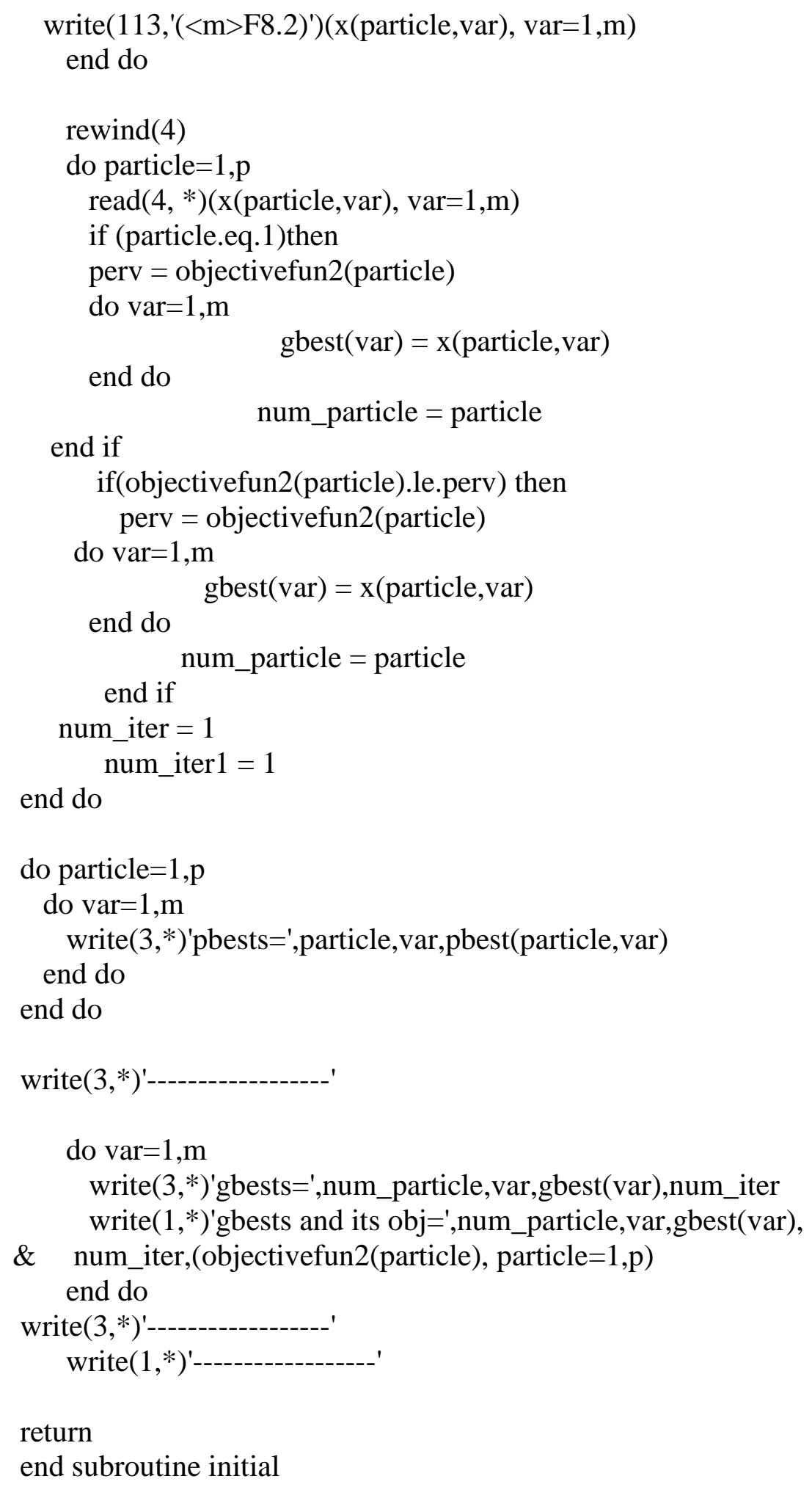


!@@@@@@@@@@@@@@@@@@@@@@@@@@@@@@@@@@@@@@ @@

!@@@@@@@@@@@@@@@@@@@@@@@@@@@@@@@@@@@@@@ @@

!@@@@@@@@@@@@@@@@@@@@@@@@@@@@@@@@@@@@@@ @@

subroutine main()

\title{
OPEN(222,FILE='VARS.DAT',STATUS='UNKNOWN')
}
do particle $=1, \mathrm{p}$ objectivefun $2($ particle $)=0$
do $\operatorname{var}=1,2$

CALL RANDOM_NUMBER (S)

\section{CALL RANDOM_NUMBER (S1)}

\author{
velocity $($ particle, var $)=\mathrm{w}(\mathrm{r}) *$ velocity_p $($ particle, var $)+$ \\ $\& \quad \mathrm{c} 1 * \mathrm{~S} *($ pbest $($ particle,, $\mathrm{var})-\mathrm{x}($ particle,var $))+\mathrm{c} 2 * \mathrm{~S} 1 *$ \\ \& (gbest(var)- x(particle,var)) \\ if (velocity(particle,var).lt.vmin(var)) then \\ velocity $($ particle, var $)=\operatorname{vmin}($ var $)$ \\ end if \\ if (velocity(particle,var).gt.vmax(var)) then \\ velocity $($ particle, var $)=\operatorname{vmax}($ var $)$ \\ end if \\ velocity_p(particle,var $)=$ velocity $($ particle, var $)$ \\ $\mathrm{x}($ particle, $\mathrm{var})=\mathrm{x}($ particle, $\mathrm{var})+$ velocity $($ particle, var $)$ \\ if ((x(particle,var).1t.bound_min(var)).or.(x(particle,var). \\ $\& \quad$ gt.bound_max(var) $))$ then \\ CALL RANDOM_NUMBER(S) \\ $\mathrm{x}($ particle, $\mathrm{var})=$ bound_min $(\mathrm{var})+$ \\ $\&$

$$
\text { (bound_max(var)-bound_min(var))*S }
$$ \\ end if
}

write(222,'(f8.2)') x(particle,var) 
write $\left(4,{ }^{*}\right) \mathrm{x}($ particle,var),particle, $\mathrm{r}$

matr $($ particle, $\mathrm{var})=\mathrm{x}($ particle, $\mathrm{var})$

end do

do $\mathrm{i}=1, \mathrm{NWB}$

WRITE $\left(2252,,^{\prime}(2 \mathrm{~F} 8.2)^{\prime}\right)(\mathrm{x}($ particle,var), var=1,2)

enddo

rewind(2252)

do $\operatorname{var}=3, \mathrm{~m}$

CALL RANDOM_NUMBER (S)

CALL RANDOM_NUMBER (S1)

velocity $($ particle, var $)=w(r) *$ velocity_p $($ particle, var $)+\mathrm{c}^{*}$ *

\& $\quad \mathrm{S}^{*}$ (pbest(particle,var)- $\mathrm{x}($ particle,var $\left.)\right)+$

\& $\quad \mathrm{c} 2 * \mathrm{~S} 1 *($ gbest $(\mathrm{var})-\mathrm{x}($ particle, $\mathrm{var}))$

if (velocity(particle,var).lt.vmin(var)) then

velocity $($ particle, var $)=\operatorname{vmin}($ var $)$

end if

if (velocity(particle,var).gt.vmax(var)) then

velocity $($ particle, var $)=\operatorname{vmax}($ var $)$

end if

velocity_p $($ particle, var $)=\operatorname{velocity}($ particle, var $)$

$\mathrm{x}($ particle, $\mathrm{var})=\mathrm{x}($ particle,, $\mathrm{var})+$ velocity $($ particle, $\mathrm{var})$

$X($ particle, var $)=X($ particle, var $) * 100$

$X($ particle,, ar $)=\operatorname{NINT}(X($ particle,, ar $))$

$\mathrm{X}($ particle,, $\mathrm{var})=\mathrm{X}($ particle,, $\mathrm{var}) / 100$

$\&$

if ((x(particle,var).lt.bound_min(var)).or.(x(particle,var).

gt.bound_max(var))) then

CALL RANDOM_NUMBER(S)

$\mathrm{x}($ particle, $\mathrm{var})=$ bound_min $(\mathrm{var})+$ (bound_max $(\mathrm{var})-$

$\&$ bound_min(var) $*$ S

end if

write $(222$, ,'(f8.2)') x(particle,var)

write $(4, *) \times($ particle,var),particle, $r$

matr $($ particle, $\mathrm{var})=\mathrm{x}($ particle, $\mathrm{var})$ 
enddo

do $\operatorname{var}=3, \mathrm{~m}$

WRITE(2555,*)NO1DAY(var)

DO $\mathrm{i}=1, \mathrm{IMX}$

WRITE $(2555, *) \times($ particle,var $)$

ENDDO

end do

rewind(222)

REWIND(2555)

CALL CE_QUAL_W2

rewind(2252)

rewind $(2555)$

$\operatorname{read}\left(333,{ }^{*}\right) \operatorname{iij}($ particle $)$

write $(888, *) i i j($ particle $)$

$\mathrm{kk}=1$

jj $1=1$

rewind(555)

!kk= number of controling point in optimizer

if (particle $==p$ ) then

iiii=iij(particle)

endif

if (particle $==1)$ then

iii=iij(particle)-iiii

write $(888, *)$ iii

endif

if (particle >1) then

iii=(iij(particle $)-\mathrm{iij}(($ particle-1) $))$

write $(888, *)$ iii

endif

do $\mathrm{jk}=1$, iii

$\operatorname{read}\left(555,(\mathrm{~F} 9.2, \mathrm{f} 10.2)^{\prime}\right) \mathrm{DEPTH1}(\mathrm{jk})$, Temprature1(jk)

if $(\mathrm{jk}>1)$ then

if (Depth1 $(\mathrm{jk})<$ Depth1 $(\mathrm{jk}-1))$ then

$\mathrm{kj}(\mathrm{kk})=\mathrm{jj} 1-1$

$\mathrm{kk}=\mathrm{kk}+1$

$\mathrm{jj} 1=1$

endif

endif

depth11(kk,jj1)=depth1(jk) 


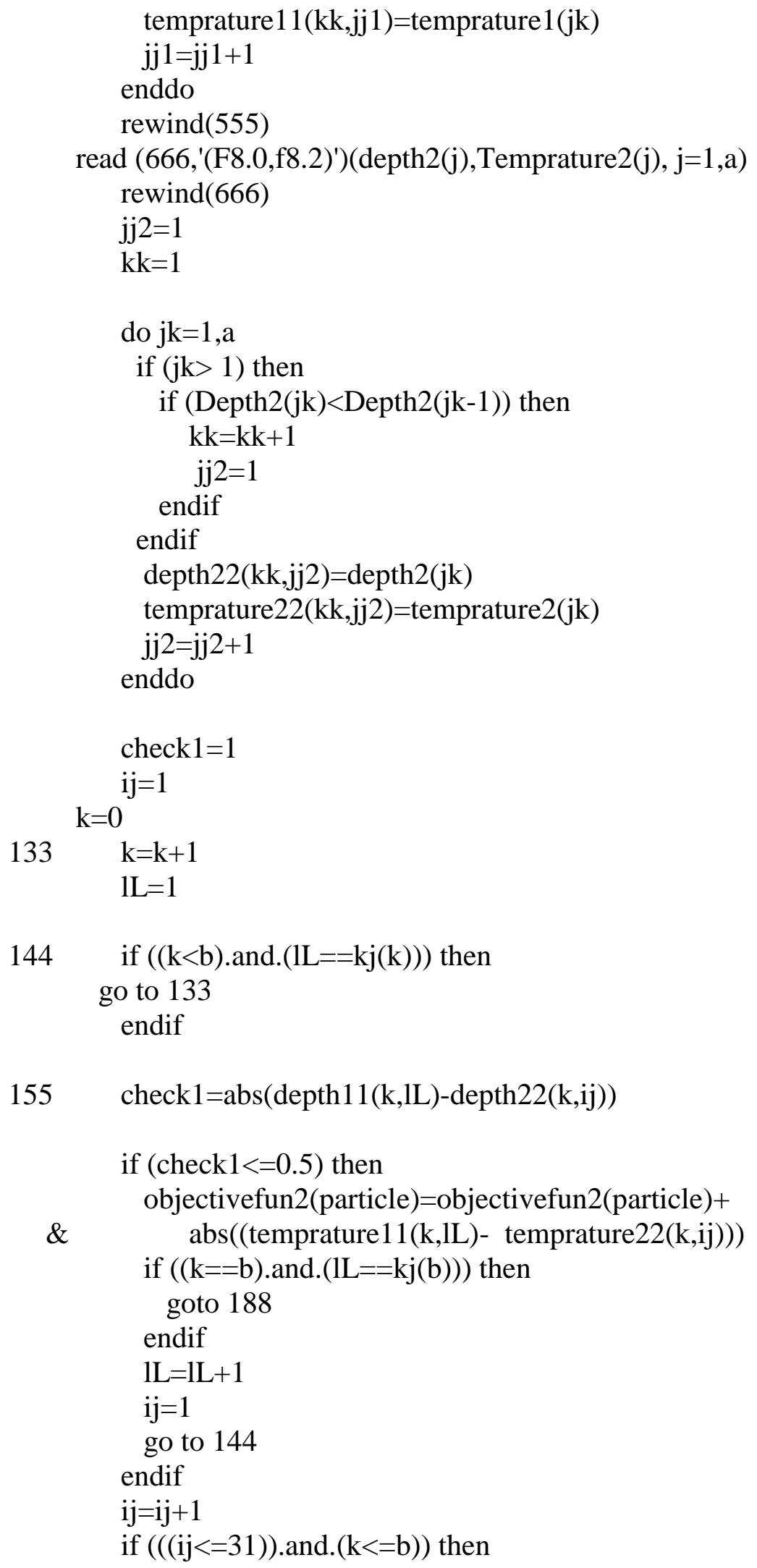

144 if $((\mathrm{k}<\mathrm{b})$.and. $(\mathrm{lL}==\mathrm{kj}(\mathrm{k})))$ then go to 133

endif

$155 \operatorname{check} 1=\operatorname{abs}(\operatorname{depth} 11(\mathrm{k}, \mathrm{IL})-\operatorname{depth} 22(\mathrm{k}, \mathrm{ij}))$

if $($ check $1<=0.5)$ then objectivefun 2 (particle $)=$ objectivefun $2($ particle $)+$

$\&$ 


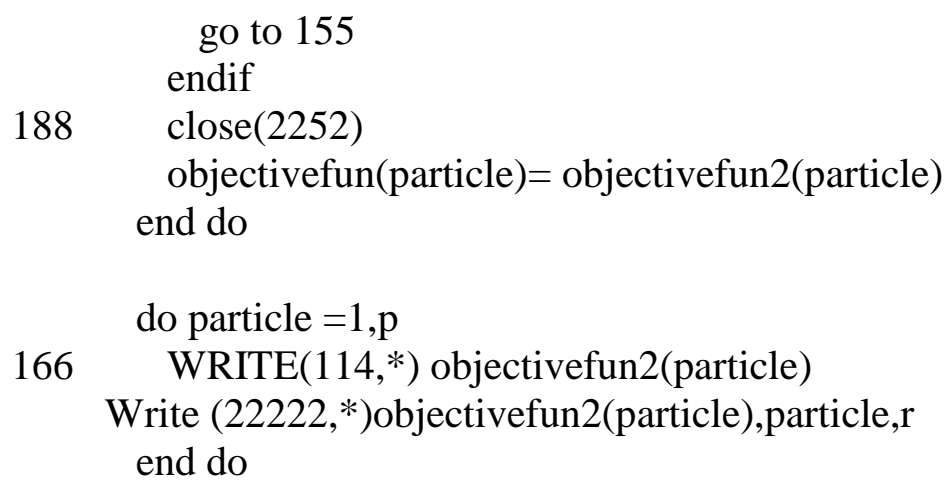

enddo

do particle $=1, \mathrm{p}$

do var $=1, \mathrm{~m}$

write $(3, *)$ 'pbests=',particle,var,pbest(particle,var),num_iter1 write $(5, *)$ velocity(particle,var),particle,var,r end do 


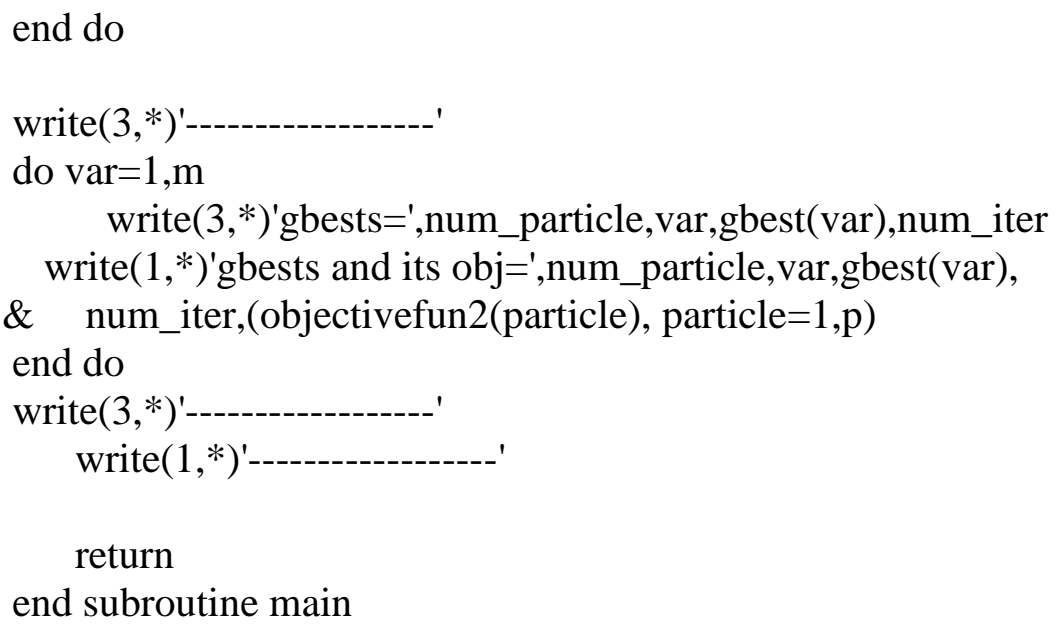

!@@@@@@@@@@@@@@@@@@@@@@@@@@@@@@@@@@@@@@ @@

!@@@@@@@@@@@@@@@@@@@@@@@@@@@@@@@@@@@@@@ @@

!@@@@@@@@@@@@@@@@@@@@@@@@@@@@@@@@@@@@@@ @@ end subroutine pso 